\title{
Sociologia della tortura
} Immagine e pratica

del supplizio postmoderno

Iside Gjergii 

Sociologia della tortura

\section{Società e trasformazioni sociali}

Serie diretta da $\mid$ A series edited by

Pietro Basso

Fabio Perocco

7

Edizioni

Ca'Foscari 


\section{Società e trasformazioni sociali}

\section{Direttori|General editors}

Pietro Basso (Università Ca' Foscari Venezia, Italia)

Fabio Perocco (Università Ca’ Foscari Venezia, Italia)

\section{Comitato scientifico |Advisory board}

Ricardo Antunes (Unicamp Universidade Estadual de Campinas, Brasil)

Alain Bihr (Université Franche-Comté, France)

Alex Callinicos (King's College, London, UK)

Giuliana Chiaretti (Università Ca' Foscari Venezia, Italia)

Steve Jefferys (London Metropolitan University, UK)

Olga Jubany (Universitat de Barcelona, Espanya)

Enzo Pace (Università degli Studi di Padova, Italia)

Enrico Pugliese (Sapienza Università di Roma, Italia)

Nouria Oauli (Université Libre de Bruxelles, Belgique)

\section{Comitato di redazione | Editorial staff}

Rossana Cillo (Università Ca' Foscari Venezia, Italia)

Francesco Della Puppa (Università Ca' Foscari Venezia, Italia)

Iside Gjergji (Università Ca' Foscari Venezia, Italia)

Lucia Pradella (Università Ca' Foscari Venezia, Italia)

Ottavia Salvador (Università degli Studi di Genova, Italia)

Tania Toffanin (Università Ca' Foscari Venezia, Italia)

\section{Direzione e redazione | Head Office}

Dipartimento di Filosofia e Beni Culturali

Palazzo Malcanton Marcorà

Dorsoduro 3484/D

30123 Venezia

sts@unive.it

\footnotetext{
e-ISSN 2610-9689

ISSN 2610-9085
}

URL https://edizionicafoscari.unive.it/it/edizioni/collane/societa-e-trasformazioni-sociali/ 


\section{Sociologia della tortura Immagine e pratica del supplizio postmoderno}

Iside Gjergji

Venezia

Edizioni Ca' Foscari - Digital Publishing 2019 
Sociologia della tortura. Immagine e pratica del supplizio postmoderno Iside Gjergji

(c) 2019 Iside Gjergji per il testo

(c) 2019 Edizioni Ca' Foscari - Digital Publishing per la presente edizione

(ㄷ)(1)

Quest'opera è distribuita con Licenza Creative Commons Attribuzione4.0 Internazionale This work is licensed under a Creative Commons Attribution 4.0 International License

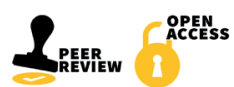

Qualunque parte di questa pubblicazione può essere riprodotta, memorizzata in un sistema di recupero dati o trasmessa in qualsiasi forma o con qualsiasi mezzo, elettronico o meccanico, senza autorizzazione, a condizione che se ne citi la fonte.

Any part of this publication may be reproduced, stored in a retrieval system, or transmitted in any form or by any means without permission provided that the source is fully credited.

Edizioni Ca' Foscari - Digital Publishing

Università Ca' Foscari Venezia

Dorsoduro 3246, 30123 Venezia

http://edizionicafoscari.unive.it |ecf@unive.it

1 a edizione dicembre 2019

ISBN 978-88-6969-391-5 [ebook]

Certificazione scientifica delle Opere pubblicate da Edizioni Ca' Foscari - Digital Publishing: tutti i saggi pubblicati hanno ottenuto il parere favorevole da parte di valutatori esperti della materia, attraverso un processo di revisione doppiamente anonima sotto la responsabilità del Comitato scientifico della collana. La valutazione è stata condotta in aderenza ai criteri scientifici ed editoriali di Edizioni Ca' Foscari.

Scientific certification of the works published by Edizioni Ca' Foscari- Digital Publishing: all essays published in this volume have received a favourable opinion by subjectmatter experts, through a double anonymous peer review process under the responsibility of the Scientific Committee of the series. The evaluations were conducted in adherence to the scientific and editorial criteria established by Edizioni Ca' Foscari.

URL http://edizionicafoscari.unive.it/it/edizioni/libri/978-88-6969-391-5/

DOI http://doi.org/10.30687/978-88-6969-391-5 


\section{Sociologia della tortura \\ Immagine e pratica del supplizio postmoderno \\ Iside Gjergji}

\section{Abstract}

This work addresses torture with the ambition to strengthen a properly sociological approach to it by bringing to the fore the social history of the tortured, also through the fundamental contribution of the political economy. This category is not utilised in an abstract way, it is brought into the picture through the social history of the bodies of those tortured. These bodies are not considered mere biological bodies subjugated by 'power', but rather bodies with a voice, bodies capable of revealing their social standing. Placing the bodies' class at the centre of the analysis allows us to fully grasp the sociological substance of torture, to understand the underlying reasons for its historical persistence and constant diffusion.

The book explores torture in a threefold way: firstly by analysing the image of torture as an effective hermeneutic tool of late modernity; secondly by adopting a historical perspective to identify structural elements and metamorphoses; thirdly by examining the concrete practices of torture to enable the establishment of a mutual relationship between history and biography.

Keywords Torture. Image. Social practice. Postmodern. State. 

Sociologia della tortura

Immagine e pratica del supplizio postmoderno

Iside Gjergji

\section{Sommario}

$\begin{array}{ll}\text { Introduzione } & 11\end{array}$

1 L'immagine dentro la tortura 15

2 Critica sociologica del supplizio postmoderno 49

Bibliografia $\quad 89$ 

A Betta,

perché saremo sempre Doni

A Ottavia,

perché insieme uccideremo

il chiaro di luna e danzeremo

in tondo nella laguna dei morti 



\section{Introduzione}

La tortura è un tema discusso in sociologia, nonostante la segretezza e l'invisibilità sociale che circondano la sua pratica rendano impossibili le analisi quantitative e, di sicuro, non agevolino l'indagine qualitativa; non è pensabile, ad esempio, l'osservazione partecipante e si rivelano assai problematiche, seppur possibili, le interviste con torturati e torturatori. Ma la sociologia è anche quella scienza che, con i suoi metodi di osservazione e analisi, riesce ad accostare le riflessioni degli altri campi scientifici in modo nuovo e diverso (Simmel 1989) e, di conseguenza, è in grado di fornire la propria originale prospettiva anche sulla tortura. Si tratta, in altre parole, di applicare all'analisi della tortura ciò che Charles Wright Mills ha definito «immaginazione sociologica» $(2018,23)$, ovvero quella qualità della mente che aiuta a servirsi delle informazioni e a sviluppare la ragione fino ad arrivare a una lucida sintesi di quel che accade e può accadere nel mondo e, contemporaneamente, anche nella biografia dei singoli.

I sociologi hanno studiato la tortura come fenomeno sociale diffuso in ampie regioni del mondo (Reemtsma 1991), oppure come casi di studio in Paesi come Argentina (Feitlowitz 1998; Lewis 2002), Cile (Ensalaco 2000), Brasile (Huggins, Haritos-Fatouros, Zimbardo 2002), Grecia (Haritos-Fatouros 2003), Cambogia (Chandler 1999) e altrove. Più di recente, a seguito dell'applicazione sistematica della tortura nella 'guerra al terrore', il dibattito scientifico si è ampliato anche negli Stati Uniti (Hajjar 2013; Koch 2008; Mayer 2008; Jaf- 
fer, Singh 2007; McCoy 2006; Cohen 2005, etc.). Allo studio comparativo della tortura si sono dedicati Cohen e Corrado (2005), mentre Greenberg e Dratel (2005), Einolf (2007) e MacMaster (2004) hanno analizzato la tortura come strumento di dominio nelle democrazie occidentali. Perocco (2019) ha esaminato il legame tra tortura e migrazioni, Barnao e Saitta (2012) hanno studiato il fenomeno a partire dalle trasformazioni avvenute nei processi di reclutamento e addestramento delle forze militari e dell'ordine. Linklater (2007), invece, ha indagato la tortura all'interno del processo di civilizzazione e, più di recente, Reemtsma (2012) l'ha collocata alla base della modernità. Le conseguenze della tortura sulle vittime sono al centro delle riflessioni di Asad (1996), Conroy (2001), Hooks e Mosher (2005), Sofsky (2005), von Trotha (2011) e di molti altri ancora. Si può dunque affermare che, al pari di altre discipline scientifiche (storia, diritto, filosofia, psicologia e scienze politiche), la letteratura sociologica sulla tortura sia ampia e ricca (Inhetveen 2011).

Il presente lavoro si nutre di questa letteratura, così come di quella di altre discipline, con l'ambizione di contribuire a consolidare un inquadramento propriamente sociologico della tortura portando in primo piano la storia sociale dei corpi-individui torturati anche attraverso l'apporto fondamentale dell'economia politica. Tale categoria, infatti, non è impiegata in maniera astratta; entra in scena attraverso i corpi torturati, che qui non si presentano come semplici corpi biologici soggiogati dal 'potere'; sono, invece, corpi che hanno voce e che sono in grado di rivelare a quali ceti o classi sociali appartengono, perché non è possibile (se non nella teoria iperuranica) separare i corpi dalla loro radice sociale e, ancora meno, dalla loro voce (o anima/mente/psiche). Porre al centro dell'analisi i corpi-ceto o corpi-classe consente di cogliere a pieno la sostanza sociologica della tortura, di comprendere le ragioni di fondo della sua storica persistenza e costante diffusione e, nel contempo, di sottrarla da speculazioni astratte incentrate su una generica concezione del potere, oppure sulla (presunta) 'naturale' tendenza degli uomini alla devianza o perversione.

Va subito chiarito che il concetto di tortura al quale si riferisce il libro non si limita alle varie formulazioni giuridiche; la tortura, intesa come fenomeno sociale, è una violenza sistematica, di tipo fisico e psicologico, esercitata dagli Stati per il raggiungimento dei loro scopi (Cohen, Corrado 2005; Rejali 2003). Questa prospettiva disvela anche lo specifico approccio adottato: nonostante in letteratura si sia affermato che la tortura serva «diversi propositi» (Skoll 2010, 83) ${ }^{1}$ e che, addirittura, ne esistano diverse sue tipologie - tortura da interrogatorio, tortura monito/deterrente, tortura disumanizzante (Tin-

Tutte le traduzioni nel libro sono dell'Autrice. 
dale 1996), altrimenti definita anche «tortura terroristica» (Hajjar 2013, s.p.) - in questo lavoro si condivide l'idea che la tortura non riguardi il bisogno degli Stati di estrarre informazioni dalle gole dei torturati - come giustamente afferma Elaine Scarry: «l'obiettivo non è mai la confessione» $(1985,29)$ - ma che, al contrario, essa abbia sempre come obiettivo finale la disumanizzazione delle vittime e dei gruppi sociali ai quali esse appartengono, così come - ed è questa la particolare prospettiva del libro - il controllo e la svalorizzazione della loro forza lavoro. Altra necessaria premessa da fare è che l'analisi effettuata si concentra maggiormente sull'immagine e sulle pratiche della tortura nel mondo occidentale, perché «nella nostra epoca, i problemi delle società occidentali sono, quasi inevitabilmente, problemi del mondo» (Wright Mills 2018, 196).

Il libro si divide in due parti, dialoganti tra di loro, ma che conservano una certa autonomia nel procedimento analitico. La prima parte prende in esame l'immagine della tortura, nella sua duplice accezione di immagine 'reale' e immagine mentale. Tale combinazione dialettica consente di conoscere le conseguenze sociali delle immagini della e nella tortura. La scelta di avviare la riflessione partendo dalle immagini si è rivelata obbligatoria per varie ragioni: in primo luogo, perché - eccezion fatta per alcune popolazioni e alcuni gruppi sociali - buona parte delle persone oggi conosce la tortura attraverso le sue immagini; in secondo luogo, perché la tortura instaura sempre un rapporto profondo e complesso con le immagini per poter raggiungere un elevato grado di efficacia, anche in considerazione del fatto che il suo bersaglio non è semplicemente, e neppure in prima istanza, il singolo torturato o la singola torturata, bensì il torturato-ceto o torturato-classe; in terzo luogo, perché nonostante le immagini fotografiche o filmiche delle torture abbiano storicamente avuto un ruolo importante nella propaganda politica, dopo l'11 settembre 2001 tali immagini si sono trasformate nella forma finale della tortura. Il crescente legame tra immagine e tortura non si può però affrontare senza preliminarmente prendere posizione nel dibattito teorico sul digital imaging. Si spiega in questo modo la decisione di aprire il libro con una riflessione teorica sull'immagine e, in generale, sulla cultura visuale oggi.

Obiettivo specifico della seconda parte, invece, è l'individuazione delle ragioni di fondo che spingono gli Stati a torturare. In questa prospettiva, è apparso indispensabile sviluppare l'analisi su un piano storico, ponendo al centro le pratiche concrete, al fine di individuare le connessioni fra una grande varietà di contesti e, naturalmente, il loro impatto sociale. Essenziale si è rivelato in questo percorso l'uso di alcune categorie concettuali della sociologia classica.

Infine, un breve chiarimento sull'aggettivo 'postmoderno' utilizzato per distinguere la tortura contemporanea da tutte le altre. La fase storica definita 'postmoderna' si è avviata negli anni Settanta del se- 
colo scorso ed è caratterizzata da ampie e profonde ristrutturazioni nel campo produttivo, accompagnate da altrettante ampie e profonde trasformazioni politiche, sociali e culturali (Harvey 1993; Crouch 2003; Jameson 2007). Ciò che maggiormente distingue la modernità dalla postmodernità è il ruolo assunto dal mercato nella vita sociale, sia collettiva che individuale:

La postmodernità è il capitalismo senza più residui e opposizioni, è il 'mondo dentro il capitale', per parafrasare Peter Sloterdijk, è un capitalismo che può essere definito 'tardo' solo nel senso di ultimo, più recente, più - paradossalmente - moderno, in quanto esito di una modernizzazione dei mezzi e dei rapporti di produzione infinitamente più estesa e pervasiva. [...] Noi non regoliamo il mercato, ma il mercato, autoregolandosi, regola noi. (Giglioli 2007, 423)

È proprio in questo periodo che si è registrata un'importante metamorfosi nella tortura, i cui tratti distintivi si sono resi visibili soltanto a partire dall'11 settembre 2001. 


\section{L'immagine dentro la tortura}

Sommario 1.1 L'immagine che cambia: alcune premesse. - 1.2 La tortura fotografica. - 1.3 Immagini reali e immagini mentali. - 1.4 Arte e violenza politica: la questione della rappresentabilità. - 1.5 Notte e nebbia. -1.6 La battaglia di Algeri. -1.7 La tortura seriale post 11/9. - 1.824 Hours Chrono. - 1.9 Note conclusive.

Ciò che distingue le immagini dalle 'essenze' della fenomenologia è il loro indice storico. [...] L'indice storico delle immagini dice, infatti, non solo che esse appartengono a un'epoca determinata, ma soprattutto che esse giungono a leggibilità solo in un'epoca determinata. È precisamente questo giungere a leggibilità è un determinato punto critico del loro intimo movimento. Ogni presente è determinato da quelle immagini che gli sono sincrone: ogni adesso è l'adesso di una determinata conoscibilità. In questo adesso la verità è carica di tempo fino a frantumarsi. (Benjamin 2002, 517)

Ogni società si forma e conserva le immagini di sé stessa: in particolare, quelle immagini e quelle formule che giustificano il suo sistema di potere e i modi del potente. (Wright Mills 2018, 112)

\subsection{L'immagine che cambia: alcune premesse}

«Tout, au monde, existe pour aboutir à un livre», scriveva Stéphane Mallarmé. Con una frase lapidaria il poeta intendeva esprimere, probabilmente, l'idea che non vi sia altro destino concepibile dell'universo se non quello di diventare letteratura. Questo suo apparente acosmismo se, da un lato, sembra negare al mondo un'esistenza autonoma per segnalare la sola esistenza della letteratura, dall'al- 
tro ha la capacità di chiarire il rapporto dialettico tra realtà e rappresentazione: nei libri non si riversa altro che il mondo, la cui rappresentazione si trasforma, attraverso i nostri pensieri e le nostre azioni, in cose del mondo, che a loro volta finiscono per essere narrate in altri libri.

Ormai tutti condividono l'idea che oggi si viva nell'era visuale (Mitchell 1994), che il modo primario di comunicazione avvenga attraverso le immagini (Elkins 2003; Kress 2003), che le relazioni siano mediate dalle immagini e che il loro uso immaginativo ed emozionale costituisca un tratto distintivo del tardo capitalismo (Jameson 1998). In termini filosofici, il medium visivo si presenta oggi come lo strumento allegorico ed ermeneutico più adatto alla descrizione dell'attuale sistema sociale-politico-economico (Jameson 2007). Si può dunque affermare, con Mallarmé, che tutto nel mondo esista oggi con lo scopo di finire in un'immagine, un video o film, in una serie televisiva oppure in un selfie. La dialettica mondo/rappresentazione è dunque essenzialmente una dialettica mondo/immagine, intesa non solo nel senso che nell'immagine vediamo il mondo, ma anche che l'immagine vede il mondo in noi. Le immagini non espongono soltanto le caratteristiche visibili degli oggetti che cadono sotto i nostri occhi, ma sono anche riflessi del mondo esterno incorporati e trasformati dal soggetto che guarda (Angel 2009).

A causa di questo visuale ipertrofico che caratterizza il presente, i modi e la portata della comprensione percettiva del mondo si sono enormemente ampliati:

Sappiamo di più e abbiamo visto di questo secolo più di quanto le generazioni di ogni secolo precedente sapessero o vedessero del loro. [...] Viviamo nell'epoca dell'informazione, e la fotografia, il cinema e la televisione ci hanno portato prove visive. (Ellis 2000,9)

John Ellis afferma che la conseguenza più grave di questa modifica nella percezione sia quella di evidenziare la passività e perfino la complicità di chi guarda l'orrore del mondo rappresentato nelle immagini. Chi guarda l'atrocità non ha scampo, non può essere assolto, perché non può negare di sapere. Le immagini, infatti, specie se drammatiche, ci rendono testimoni (Peters 2001) di eventi lontani: «Negli eventi mediatici, gli occhi e le orecchie prese in prestito dai media diventano, per quanto provvisoriamente o pericolosamente, i nostri» (Peters 2001, 717). John Durham Peters usa un termine forte - testimonianza - che si impone su tanti altri, «più incolori, come vedere, ascoltare o consumare, leggere, interpretare o decodificare» $(2001,707)$. Il merito nell'uso di questo particolare termine è quello di mettere in stretta relazione il vedere, il conoscere e l'agire, oltre che di porre l'attenzione sulle responsabilità che derivano dalla diffusa capacità di vedere/conoscere a distanza. 
Nel suo libro Regarding the Pain of Others (2003), Susan Sontag alza però la posta in gioco nell'analisi del visuale, laddove parla della stanchezza che subentra nei testimoni del dolore altrui quando vengono storditi da una crescente sequela di immagini atroci, ciascuna delle quali riduce l'effetto della successiva. La ricerca di immagini sempre più drammatiche guida oggi le produzioni dell'industria audiovisiva, afferma la Sontag (2003), trasformando la violenza o il trauma in stimoli al consumo e, contemporaneamente, in piaceri e fonti di valore: «L'immagine come shock e l'immagine come cliché sono due aspetti della stessa presenza» $(2003,20)$. Ciò dipende anche dal fatto che, come ha ben illustrato Fredric Jameson (2007), nell'era del tardo capitalismo, la produzione e le sperimentazioni estetiche sono elementi strutturali del sistema di produzione delle merci. Eppure, secondo la Sontag, nell'immagine (in particolare in quella fotografica) persiste sempre una dimensione etica e morale; riconosce che ora c'è «un ampio repertorio di immagini» e chiede che «le immagini atroci ci tormentino» $(2003,102)$ : «Anche se sono solo dei simboli, e non possono includere tutta la realtà che incontrano, esse svolgono comunque una funzione vitale» (102). Contro le narrazioni contemporanee che vorrebbero svuotare l'immagine della sua vitalità, Susan Sontag continua ad affermare la vita dell'immagine.

La sua riflessione però è messa in discussione dalle più recenti analisi sulle nuove tecnologie di digital imaging, le quali si sostiene abbiano prodotto radicali cambiamenti nella natura stessa delle immagini, ossia che abbiano creato una coupure epistemologica. Sul punto convergono diversi studi. Marita Sturken e Lisa Cartwright, per esempio, nel loro importante lavoro introduttivo sulla cultura visuale, Practices of Looking. An Introduction to Visual Culture (2001), spiegano che «negli anni Ottanta e Novanta, lo sviluppo delle immagini digitali ha iniziato a trasformare radicalmente il significato delle immagini nella cultura occidentale» $(2001,138)$. Tale radicale differenza si manifesterebbe nel confronto con le immagini analogiche. Queste ultime, secondo Sturken e Cartwright, «hanno un rapporto fisico con i loro strumenti materiali» $(2001,138)$ e, di conseguenza, hanno uno status semiotico dal quale viene generato uno specifico atteggiamento epistemologico, che essenzialmente dipende dal rapporto instaurato con la realtà. L'immagine analogica, infatti, «può essere sfocata, deformata scolorita, senza valore documentario, ma essa proviene attraverso la sua genesi dall'ontologia del modello» (Bazin 1999, 8). Il rapporto tra immagine e oggetto è tendenzialmente oggettivo, cioè non alterato dall'intervento dell'uomo.

Del resto, il gruppo di lenti che costituisce l'occhio fotografico sostituito all'occhio umano si chiama appunto 'l'obiettivo'. Per la prima volta, un'immagine del mondo esterno si forma automaticamente senza intervento creativo dell'uomo, secondo un determini- 
smo rigoroso. La personalità del fotografo non entra in gioco per la scelta, l'orientamento, la pedagogia del fenomeno; per quanto possa essere visibile nell'opera finita, essa non vi figura allo stesso titolo di quella del pittore. Tutte le arti sono fondate sulla presenza dell'uomo; solo nella fotografia ne godiamo l'assenza. $(1999,7)$

In altre parole, il significato dell'immagine analogica deriverebbe dalla certezza di avere un rapporto con il reale. Questo «transfert di realtà dalla cosa alla sua riproduzione» $(1999,8)$ si pensa sia assente nelle fotografie digitali. Le tecnologie digitali fornirebbero i mezzi per generare immagini che possono sembrare fotografie (analogiche), ma che non possono conferire a queste una validità epistemologica. Secondo le due studiose, in termini semiotici, ciò significa che l'immagine fotografica digitale è prodotta nella realtà senza che si abbia con essa un rapporto effettivo (Sturken, Cartwright 2001, 139).

Indubbiamente, l'avvento delle tecnologie digitali ha creato le condizioni per rendere estremamente facile la produzione e riproduzione delle immagini, il che oggettivamente minaccia, sotto diversi aspetti, l'integrità delle stesse, o meglio la loro unicità:

Il valore di un'immagine digitale deriva in parte dalla sua funzione informativa e dalla sua capacità di essere facilmente accessibile, manipolata, memorizzata su un computer o un sito web, scaricata, etc. L'idea che un'immagine sia unica non ha alcun senso con le immagini digitali. (Sturken, Cartwright 2001, 139)

Tuttavia, dalla vaga definizione fornita - che è diffusa nella letteratura sul digital imaging - non appare chiaro in cosa consista l'asserita frattura epistemologica tra immagini analogiche e digitali. L'unica differenza sarebbe da rintracciare nell'aggiunta della qualità di manipolabilità, la quale ha tuttavia caratterizzato, da sempre, anche le immagini analogiche. Come le stesse autrici ammettono, «è sempre stato possibile 'falsificare' il realismo nelle fotografie» $(2001,139)$. Anche la definizione di Lev Manovich, vera autorità nel settore, non giustifica la posizione del cambiamento radicale: «Un nuovo media è un media analogico convertito in forma digitale» (Manovich 2004, 72). ${ }^{1}$ L'innovazione digitale ha senza dubbio creato le condizioni per

1 Per ragioni di economia espositiva non si può qui esaustivamente rappresentare l'ampiezza e la ricchezza del dibattito scientifico sul rapporto tra immagine digitale e analogica. Appare importante, tuttavia, sottolineare che i Digital Enthusiasts non sono finora riusciti a dimostrare la radicale autonomia dell'immagine digitale dal reale. Con riferimento a fotografie o film ciò appare palese, essendo possibile riprodurre la realtà anche tramite il digitale, pur in presenza di una maggiore capacità di manipolazione e riproduzione. Né viene meno il rapporto fisico con il reale: l'assenza della 'camera oscura' nell'attuale processo di riproduzione non cancella il fatto che i dispositivi digitali (macchina 
un'espansione dialettica rispetto alla fase precedente, ma finora non appare ragionevole affermare che abbia prodotto una frattura epistemologica. La raffinata analisi di Claudio Marra del rapporto tra digitale e analogico ne fornisce una convincente valutazione:

L'avvento del digitale non ha cambiato nulla. Ha reso più facile e più articolata la via della rappresentazione ma al tempo stesso ha arricchito e confermato quella della presentazione. Si lodi dunque l'ipotetica perdita del referente, si esalti pure l'infinita gamma di manipolazioni che il nuovo sistema concede, ma certo non si dimentichi che proprio da questo scenario è anche scaturita quella nozione di simulazione che ha ulteriormente rafforzato l'identità della fotografia come esibizione diretta del reale. (Marra 2006, 128)

Tra i più importanti effetti dell'espansione dialettica vi è da sottolineare quello inflazionistico: la facilità e velocità acquisita nella produzione e riproduzione delle immagini digitali costruisce un ambiente saturo di immagini, che spinge incessantemente verso la costruzione di un «flusso totale» (Williams 2000, 98). L'iperproduzione di immagini ha come conseguenza la svalutazione del valore delle stesse.

La crisi descritta dalla Sontag, quindi, si è pienamente realizzata con l'avvento delle nuove tecnologie digitali. Baudrillard aveva anticipato questo esito nel suo Simulacres et simulations (1981), laddove descriveva il postmoderno come un mondo caratterizzato da un costante flusso di immagini, nel quale la percezione risulta frammentata in innumerevoli sequenze. Le immagini sono svalutate dalla loro assoluta ubiquità e ciò produce una crisi cognitiva e concettuale, con enormi ricadute etiche ed estetiche e, ovviamente, anche sociali e politiche.

Lo studio delle immagini ha raggiunto ormai un momento cruciale, sia con l'elaborazione di un approccio interdisciplinare sia con la costruzione di un vasto campo di 'cultura visuale'. Il rischio in questo momento, come ha sottolineato Mitchell (2002), è che il 'visuale' si autonomizzi e venga concepito in termini talmente ampi da risultare praticamente privo di significato. Oppure, peggio ancora, che l'oggetto esclusivo dell'analisi diventi 'l'immagine', in un senso va-

fotografica, macchina da presa o computer da utilizzare per l'eventuale fase di post-produzione) siano pur sempre composti da materiali plastici o metallici che adoperano, nel funzionamento complessivo, anche dei processi chimici. In quei dispositivi non c'è meno 'realtà' materiale rispetto a quella già contenuta nella 'camera oscura'. Con riferimento, invece, alle immagini automaticamente prodotte da algoritmi o Artificial Intelligence Machines, si può affermare che ci troviamo nel regno della combinazione intenzionale o casuale, cioè nel campo dell'invenzione, e il pre-digital, come è noto, non ha mai mancato di inventare immagini totalmente avulse dal reale, a partire dai fumetti, cartoni, pittura, etc. Se si tiene conto di queste osservazioni, l'individuazione del punto di rottura epistemologica tra immagine analogica e immagine digitale risulta (al momento) impossibile. 
gamente articolato, piuttosto che il rapporto di questa con la realtà. In altri termini, il rischio che ora si corre è quello di attribuire alla sola immagine ogni responsabilità. «Il compito politico della cultura visiva», insiste Mitchell, «è quello di fare critica senza il conforto dell'iconoclastia» $(2002,170)$.

Questa esortazione, insieme alle osservazioni sopra accennate, complicano il quadro analitico delle immagini delle torture, a partire dal quale si intende avviare la presente indagine. Il ruolo del visuale in questo ambito appare particolarmente rilevante e con forti ed esplicite dimensioni sociali e politiche, anche perché, se gran parte delle persone oggi, specie nel mondo occidentale, hanno un'idea della tortura, questa non deriva dall'esperienza diretta, ma dalle sue immagini, dalle rappresentazioni visive. Di conseguenza, per comprendere appieno la funzione sociale della tortura non si può che parlare della realtà concreta così come delle sue rappresentazioni visive (Amato 2014).

\subsection{La tortura fotografica}

L'archivio fotografico delle torture commesse nel carcere di Abu Ghraib (Mitchell 2011) fu reso noto al mondo il 28 aprile 2004, durante la trasmissione televisiva 60 Minutes II del network CBS. Risalgono allo stesso periodo (30 aprile; 9 maggio; 15 maggio) anche gli articoli di Seymour Hersh sul New Yorker. ${ }^{2}$ Prima di allora, la tortura era presente soprattutto nel campo linguistico dei media (Hutchings 2013), dove stava acquisendo uno spazio crescente dopo l'11 settembre 2001. Infatti, il 26 dicembre 2002, il Washington Post aveva pubblicato un articolo sui centri di detenzione segreti della CIA e il 31 marzo 2003, la Nation aveva pubblicato un articolo dal titolo «In Torture We Trust». Nel corso del 2003 altre storie riguardanti le violenze commesse sui prigionieri di guerra erano diventate note al pubblico. Eppure, poche immagini significative avevano accompagnato queste importanti pubblicazioni. Lo stesso può dirsi anche per le trasmissioni in TV. Secondo il rapporto di Human Rights First, «tra il 1995 e il 1999, ci sono state 12 scene di tortura sulle reti televisive in prima serata» $(2007,3)$. Come ha evidenziato anche Stanley Cohen, i due elementi che hanno contraddistinto il periodo tra il 2001 e il 2004 sono stati «la saturazione mediatica e il populismo etico» sul tema della tortura (Cohen 2005, 25). La satura-

2 «Torture at Abu Ghraib», New Yorker, April 30, 2004, https://www.newyorker. com/magazine/2004/०5/10/torture-at-abu-ghraib; «Chain of Command», New Yorker, May 9, 2004, https://www.newyorker.com/magazine/2004/05/17/chain-of-command-2; «The Gray Zone», New Yorker, May 15, 2004, https://www.newyorker.com/ magazine/2004/05/24/the-gray-zone (2019-09-15). 
zione mediatica si è prodotta dall'elevata quantità di spazio dedicato a notizie e dibattiti sulla tortura. L'articolo apparso il 5 novembre 2001 sul New York Times, dal titolo «Torture Seeps Into Discussion by News Media», ne è una chiara conferma. Gli eventi dell'11 settembre hanno dato a questo argomento un senso di urgenza. La saturazione dei media non si poteva però basare esclusivamente sulle parole pronunciate nei notiziari o nei talk show; essa esige delle immagini e queste, effettivamente, arrivarono numerose nel 2004, direttamente dal carcere di Abu Ghraib, modificando il rapporto linguaggio-immagine nei media, fino al punto di rovesciarlo. Dopo Abu Ghraib la tortura è diventata (quasi) muta e si presenta al mondo attraverso la sua agghiacciante silhouette.

Da un punto di vista storico, queste fotografie hanno documentato la massiccia presenza della tortura nelle forze armate americane (Danner 2004). Nonostante l'adesione formale degli Stati Uniti alla Convenzione di Ginevra contro la tortura, l'amministrazione Bush, in piena 'guerra al terrore', ha ufficialmente accolto la tortura (ora meglio nota con l'eufemismo giuridico 'interrogatorio coercitivo') come strumento necessario per garantire la sicurezza nazionale. George W. Bush lo spiega chiaramente nelle sue memorie: «Dopo l'11 settembre [...] la mia più solenne responsabilità come presidente era quella di proteggere il paese. Io ho approvato l'uso dell'interrogatorio coercitivo» (Bush 2010, 169). Le fotografie digitali realizzate nel carcere iracheno - la cui autenticità non è mai stata messa in discussione - hanno mostrato, una volta per tutte, in cosa davvero consistono le tecniche degli interrogatori coercitivi, approvate dall'amministrazione Bush e, in seguito, mai messe al bando. Va dunque riconosciuto l'alto valore testimoniale delle fotografie di Abu Ghraib, perché «sollevarono [...] il coperchio sul vaso di pandora e portarono alla luce innumerevoli altri casi di abusi, torture, omicidi perpetrati non solo ad Abu Ghraib [...], ma in tutto il sistema penitenziario militare in Iraq» (Di Cesare 2016, s.p.).

Osservando da vicino le fotografie si possono distinguere nettamente due tipologie di soggetti: i detenuti e le guardie. Dei primi si vedono: i corpi maschili, i corpi morti, i corpi nudi in fila, i corpi nudi ammucchiati in piramidi, i glutei, le schiene, i genitali, i volti coperti e quelli scoperti, i cappucci neri, la pelle violacea, le ecchimosi, i corpi coperti di elettrodi, i corpi che strisciano in pozzanghere di feci e urina, i corpi minacciati, morsi da cani o legati come animali, l'umiliazione e la sofferenza. Dei secondi si possono notare: i corpi vestiti in uniforme, la presenza di soldatesse, le pose da turisti davanti ai corpi dei torturati, il compiacimento, l'eccitazione, l'allegria, i sorrisi, la spensieratezza da gita fuori porta e, talvolta, anche una certa noia.

Le condizioni materiali e visibili registrate nelle fotografie rendono il quadro chiaro, di facile interpretazione: dei soggetti indifesi sono sottoposti a dolori estremi (fisici e psichici), discontinui o in- 
cessanti, da parte di altri soggetti che esercitano, in un determinato spazio e momento, il potere conferito dall'autorità di uno Stato. È l'atto di tortura.

Abbastanza nitido appare anche il distacco affettivo tra i due gruppi: se gli uni soffrono pene indicibili, gli altri ridono con brio. Sotto questo profilo, l'esibita letizia dei carcerieri assume un significato particolare, che punta a coprire o rovesciare l'orrore che regna nel contesto:

Le immagini dal carcere - come, più in generale, tutte le immagini di guerra che ci sono piombate addosso negli ultimi venti anni - hanno il compito di rovesciare l'evidenza: la plateale allegria dei soldati ci dovrebbe comunicare che non c'è niente di cui preoccuparsi. Dovrebbero testimoniare che non sta succedendo nulla di veramente grave e memorabile: guarda, è una situazione come un'altra; vedi, non c'è nulla da vedere. (Amato 2014, 35; corsivo nell'originale)

Il distacco affettivo descrive anche l'esigenza psicologica dei torturatori di cancellare o rinnegare qualsiasi sentimento di empatia o compassione nei confronti dei torturati. Tale esigenza è una condizione imprescindibile dell'atto di tortura. Come ha spiegato Ariel Dorfman, la tortura "presuppone, richiede, brama l'abrogazione della nostra capacità di immaginare la sofferenza degli altri, disumanizzandoli fino al punto in cui il loro dolore non è il nostro dolore» $(2004,8)$.

La tortura, intesa come pratica umiliante e degradante, raggiunge simultaneamente due obiettivi: disconosce l'umanità del torturato e, nel contempo, isola quest'ultimo dalla propria comunità di riferimento. Le fotografie possono svolgere un ruolo cruciale in questo, partecipando all'atto di tortura o diventando esse stesse tortura:

Tradizionalmente il reporter di guerra è una figura, almeno idealmente, neutrale rispetto alla dinamica dell'evento che deve registrare. La sua posizione defilata dovrebbe creare le condizioni per cogliere il senso di ciò che accade. Un'inquadratura, fissando un brandello del tempo, dovrebbe catturare la situazione generale. Dovrebbe esprimere, arrestando una scheggia del divenire, l'universo che lo circonda. Al contrario, chi riprende l'allegria dei volti di Abu Ghraib, è anch'esso artefice della tortura dei prigionieri. (Amato 2014, 51)

Questo appare evidente ovunque si costruisca e venga registrata consapevolmente una scenografia festosa della tortura. Nel caso di Abu Ghraib c'è di più: l'umiliazione dei prigionieri, i cui volti erano riconoscibili, passava anche per la minaccia di diffondere le fotografie al fine di compromettere irrimediabilmente la loro reputazione sociale e i loro legami familiari. Inoltre, le fotografie avrebbero rag- 
giunto l'obiettivo di esporre la vittima anche allo sguardo di spettatori ostili, aggiungendo così un surplus di umiliazione, fungendo da «shame multiplier» (Hajjar 2013, s.p.). Si voleva far comprendere ai prigionieri che, anche se fossero sopravvissuti al dolore fisico, non avrebbero mai avuto un futuro (Mitchell 2011).

Immortalare le torture non era un'iniziativa autonoma dei soldati o contractors in servizio, rientrava in una strategia ideata dai vertici della catena di comando. Lynndie England, una delle donne soldato che appare in posa gioiosa con i torturati, in almeno sei delle fotografie, ha più volte ribadito ciò:

Certo che era sbagliato. Ora lo so. Ma quando mostri alle persone della CIA, del FBI e del MI le foto e loro dicono: 'Hey, ottimo lavoro. Continuate così', uno pensa che sia giusto. Erano tutti lì e non hanno detto una parola. (England 2008)

I torturatori usano la vergogna sessuale per annientare non solo la virilità delle vittime, ma anche la loro cultura, religione e identità collettiva, producendo nel contempo un sentimento e un'immagine di potere di e per se stessi e, simbolicamente, di e per tutti i maschi della loro nazione (Mann 2014). L'umiliazione sessuale dei soggetti torturati ha come obiettivo anche la rappresentazione della popolazione araba come popolazione incapace e infantile; come ha ampiamente illustrato Edward Said (2006), tali obiettivi sono vecchi di secoli e non una novità introdotta dalla 'guerra al terrore'. Inoltre, la rappresentazione della sofferenza del torturato può diventare anche uno spettacolo che esalta il potere del torturatore; non solo il suo potere, ma anche il suo piacere. Un vasto filone di studi, dedicato al genere 'torture porn', ha sottolineato il carattere pornografico delle fotografie di Abu Ghraib (Kerner 2015), di come queste evocassero delle scene di film pornografici. In quel contesto visivo, infatti, il corpo torturato è anche un corpo ambito o esibito dai torturatori. Il fine ultimo è quello di trarre piacere dall'umiliazione altrui. Le parole di uno dei torturati di Abu Ghraib, riportate nel libro di Mark Danner, lo confermano:

Mi portarono nella stanza e mi dissero di mettermi per terra. Uno dei poliziotti mi infilò nel sedere una parte del bastone che portava sempre con sé e sentii che entrava dentro di due centimetri, più o meno. E iniziai a urlare, e lui lo tirò fuori...e loro mi fotografavano in tutti questi momenti. $(2004,248)$

La fotografia è parte della tortura anche nel racconto di un cittadino britannico arrestato in Pakistan nel 2001 e, in seguito, trasferito nel carcere statunitense di Kandahar (prima di essere mandato definitivamente a Guantanamo): 
Ho sentito un oggetto metallico freddo e affilato contro le mie gambe: stavano usando un coltello per tagliare tutti i miei vestiti... mi hanno rimesso in piedi e tolto il cappuccio... mi sono trovato circondato da soldati che urlavano abusi e scattavano di nuovo fotografie. (Begg, Brittain 2006, 24)

Dopo l'11 settembre 2001 si è verificato un cambiamento: dalla fotografia della tortura si è passati alla tortura fotografica. L'immagine (digitale) della tortura è diventata la sua forma finale, avvicinandola pericolosamente ai supplizi pubblici premoderni, notoriamente caratterizzati dall'esaltazione e dalla spettacolarizzazione della punizione e delle sue liturgie (Foucault 1976), dove agli astanti era assegnato un ruolo attivo. Attraverso gli sguardi, il pubblico globale delle torture fotografiche, che ne abbia o meno consapevolezza, è in qualche modo chiamato a fare da assistente al torturatore.

Inoltre, l'atto di posare o di costruire scenografie con i torturati al fine di fotografarle racconta non soltanto della presenza di un certo godimento dei torturatori nel momento dell'istantanea, ma anche della volontà di assegnare un carattere duraturo a tale godimento. Nella possibilità di rivedere e diffondere l'immagine della tortura risiede però anche la possibilità di reiterare all'infinito l'umiliazione del torturato. È come se, a causa dell'esistenza della fotografia (digitale), la tortura diventasse senza tempo, eterna. Le tecnologie digitali vengono usate dai torturatori come strumenti che fanno precipitare le vittime in un pauroso loop di tortura, più di quanto non lo siano già:

Chi ha subito la tortura non può più sentirsi a casa nel mondo. L'onta dell'annientamento non può essere cancellata. La fiducia nel mondo, crollata in parte con la prima percossa, e definitivamente con la tortura, non può essere riconquistata. Nel torturato resta stagnante l'orrore di aver vissuto il proprio prossimo come avversario: a partire da qui nessuno può sollevare lo sguardo oltre, in un mondo in cui regni il principio della speranza. (Amery 1993, 82)

Dall'analisi delle fotografie delle torture emerge anche un altro dato importante e inconfutabile: la tortura non ha a che fare con il bisogno urgente di estrarre informazioni dai torturati. Non si evince infatti in un nessun frame fotografico l'esigenza dei soldati di ottenere importanti informazioni per salvare delle vite umane (la teoria del 'ticking bomb'). Ciò che emerge dalle fotografie è il solo obiettivo della tortura: umiliare, degradare e ridurre i torturati in sotto-uomini.

Negli ambienti accademici occidentali, in particolare in quelli statunitensi, le foto di Abu Ghraib hanno avuto un effetto deflagrante, che ha portato alla nascita di un sottogenere distinto nella letteratura scientifica: l'analisi dell'immagine della tortura (Simpson 2006; Adelman 2012). Numerosi sono gli studiosi che hanno espresso la loro ra- 
dicale opposizione alla tortura attraverso le analisi delle fotografie di Abu Ghraib, Guantanamo e altri campi di detenzione. L'enfasi posta sulla corporeità umiliata e dignità dei torturati è servita ad affermare il carattere criminale delle aggressioni statunitensi in diversi contesti.

Al di fuori del mondo accademico, gli atroci eventi di Abu Ghraib - così come quelli avvenuti altrove - e il loro corredo fotografico sono rapidamente scivolati in quello che Julie Gerk Hernandez (2007) ha descritto come un «vuoto epistemologico» di dimenticanza. Questa rapida amnesia si afferma essere una reazione frequente tra gli spettatori occidentali quando posti dinanzi alle immagini delle tragedie altrui. Carrie Rentschler (2004), nella sua analisi dei rapporti tra cittadinanza e immagini che rappresentano la sofferenza di altri soggetti, ha avanzato l'ipotesi che ciò accade perché, di fronte alle atrocità, «non sappiamo come trasformare il sentimento in azione» $(2004,300)$. Essere spettatori del dolore degli altri, ha affermato la Rentschler, «ci allena a immaginare noi stessi come vittime della violenza di cui siamo testimoni, oppure a sentirci sollevati dal fatto pensando 'non sono stato io'» (300).

Occorre tuttavia tenere conto anche di un diverso utilizzo delle fotografie di Abu Ghraib, che rappresenta una risposta politica alla pratica della tortura nel mondo. Alcuni artisti, attraverso la manipolazione delle fotografie, hanno cercato di produrre immagini capaci di rovesciarne l'effetto degradante e umiliante (Apel 2005). Così, ad esempio, la fotografia che ritrae la soldatessa England mentre tira al guinzaglio un prigioniero iracheno, oppure quella dove si vede un altro prigioniero incappucciato e coperto di elettrodi, sono diventate dei murales nelle strade di Sadr City a Baghdad, Teheran, Tunisi e altrove. Le stesse fotografie sono entrate nelle gallerie di New York, Londra, Los Angeles, Parigi e Tokyo. Ė come se le immagini delle torture venissero, da un lato, scagliate contro i torturatori (attraverso l'uso rovesciato dello stigma) e, dall'altro, utilizzate come tremendo reminder per le future generazioni.

Sarebbe stato opportuno sviluppare una riflessione separata su ciascuna di esse, per valutarne l'effetto ottenuto. In queste pagine, però, ci si limiterà a segnalarne l'uso capovolto (almeno nelle intenzioni), finalizzato a trasformarle in strumenti di protesta politica. ${ }^{3}$

3 Del complesso rapporto tra arte e violenza politica si parlerà in modo più approfondito nei paragrafi seguenti. 


\subsection{Immagini reali e immagini mentali}

Ken Davis, un ex soldato in servizio ad Abu Ghraib, quando intervistato nell'ambito del documentario The Human Behavior Experiments ${ }^{4}$ dichiarò: «Ci dicevano: sono soltanto cani. Così metti in testa quell'immagine e d'un tratto cominci a guardare quella gente come se fosse meno umana, e fai cose che non ti saresti mai sognato di fare». Diversi anni prima, il generale Jacques de Bollardière, uno dei pochi francesi ad essersi opposto all'uso della tortura, intervistato nel film La Guerre d'Algerie (1984), precisò: «Noi non vedevamo gli algerini come esseri umani. Li chiamavamo topi. Oppure bougnouls. Ed è facile torturare un bougnoul, perché si immagina che non sia un essere umano» (Todorov 2007, 21). Anche altri militari hanno tentato di spiegare - in documentari, interviste 0 udienze penali - il loro comportamento violento attraverso la presenza o assenza di determinate immagini nella loro mente. Non a caso, Ariel Dorfman individua l'esigenza primaria della tortura nella cancellazione della «capacità di immaginare la sofferenza degli altri» (Dorfman 2004, 8). È come se il torturatore avesse bisogno di trasmutare la realtà in finzione per poterla sopportare (Todorov 2007, 2009, 2011), oppure di frapporre tra sé e la realtà concreta una montagna di determinate immagini mentali per non sentire e vedere la vittima. La tortura sembra costruirsi dentro un invisibile e selettivo archivio di immagini mentali. Tale archivio non solo appare agevolare la percezione del mondo al di là del qui e dell'ora, ma anche possedere la capacità di alterare la realtà presente (cambiando perfino gli stati psicologici e fisiologici dei soggetti). La presenza o l'assenza di certe immagini mentali appare come il prerequisito dell'interazione sociale disintegrata che si stabilisce con la tortura. Di conseguenza, la relazione tra tortura e immagine si rivela particolarmente intima e complessa, senza esaurirsi nel rapporto tra tortura e immagini 'reali' (digitali o analogiche).

Le domande da porsi a questo punto sono: cosa sono e come si creano/cancellano le immagini mentali? In quanto tempo? Qual è il loro formato? Come si relazionano con la coscienza e con il mondo esterno? Domande complesse alle quali il dibattito teorico, che tocca diverse discipline scientifiche - psicologia, neuroscienze, biologia, filosofia, etc. - non ha saputo finora dare risposte definitive.

L'immaginario mentale, secondo gli psicologi e i neuroscienziati, gioca un ruolo chiave nella costruzione del tessuto emotivo del soggetto (Freud 1997), così come in molte sue operazioni cognitive, come la memoria (Paivio 1986), la creatività (Finke et al. 1992), la pianifi-

4 Il documentario fu trasmesso in contemporanea il $1^{\circ}$ giugno 2006 da CourtTV e da Sundance Channel. 
cazione del futuro (Moulton, Kosslyn 2009) e l'orientamento spaziale (Piccardi et al. 2017). Tuttavia, al di là del riconoscimento dell'importanza dell'immaginario nella vita e nei comportamenti soggettivi, né l'approccio analogico (illustrativo)-propositivo (descrittivo), né quello cognitivo, intento a spiegare l'interdipendenza tra percezione, cognizione e azione, sembrano capaci di fornire una conclusione condivisa sul suo funzionamento e formato (Palmiero et al. 2019). Anche in filosofia il dibattito dura da secoli e non può dirsi concluso. Platone, Aristotele, Kant, Hume, Bergson, Sartre, Husserl e Merleau-Ponty sono soltanto alcuni dei filosofi che hanno cercato di fornire soluzioni ai problemi relativi alle immagini mentali.

Per non limitarsi a fare una rassegna dei dibattiti in corso e per costruire un discorso aperto a diverse riflessioni, è necessario chiamare in causa Jean-Paul Sartre, colui che più di chiunque altro si è interrogato sulla tortura - dedicandole drammi, racconti, saggi filosofici, impegno politico - e, contemporaneamente, sulla natura e funzione delle immagini mentali. Il filosofo non ha mai esplicitato il loro nesso, ma uno sguardo anche superficiale ai suoi scritti non può che confermare l'elevata consapevolezza che egli aveva a riguardo.

Sartre inizia a riflettere da giovanissimo sulle immagini mentali. La sua tesi di laurea si intitola: L'image dans la vie psychologique. Da questa riflessione sono nati anche due libri: L'imagination (1936) e L'imaginaire (1940). Per il giovane filosofo l'immagine mentale non può considerarsi un fatto interno alla coscienza, perché è altra cosa. Per dimostrare la validità della sua tesi - che si oppone alle categorie a priori utilizzate da altri (da Hume in particolare) - avvia l'analisi partendo da un'esperienza concreta, come ad esempio l'osservazione di un foglio bianco posato sulla sua scrivania:

Guardo questo foglio bianco sul mio tavolo; percepisco la sua forma, il suo colore, la sua posizione. Queste differenti qualità hanno caratteristiche comuni: prima di tutto si danno al mio sguardo come esistenze che posso solamente constatare e l'essere delle quali non dipende in nessun modo dal mio capriccio. Esse sono per me, non sono me. [...] Ma ecco che ora volgo la testa. Non vedo più il foglio di carta. [...] Il foglio non è più presente, non è più là. Purtuttavia so che non s'è annientato: la sua inerzia lo preserva da ciò. Il foglio ha semplicemente cessato di essere per me. E tuttavia eccolo di nuovo. [...] È sì lo stesso foglio, il foglio che è ora sulla mia scrivania, ma esiste in un altro modo [...]: non esiste di fatto, esiste in immagine. (Sartre 2004, 6-7)

Sartre distingue la percezione, alla quale corrisponde un mondo osservabile e reale, dall'immagine mentale che, invece, trascende il dato reale. L'immagine è simile alla percezione, - e da qui discen- 
de quella che Sartre chiama «l'illusione dell'immanenza» (2004, 8), che induce erroneamente a considerare l'immagine come una cosa reale -, ma non è la percezione. Si manifesta alla mente come una sintesi di impressioni accumulate nel passato e informazioni più recenti, non esiste come elemento della coscienza perché l'immagine:

Può entrare nella corrente della coscienza solo a condizione che sia essa stessa sintesi e non elemento. Non ci sono, non potrebbero esserci immagini nella coscienza. Ma l'immagine è un certo tipo di coscienza. L'immagine è un atto e non una cosa. L'immagine è coscienza di qualche cosa. $(2004,150)$

L'immagine mentale è dunque un atto della coscienza 0 , più precisamente, un rapporto che si sviluppa tra la coscienza e l'oggetto. Quest'ultimo si rende presente alla coscienza attraverso un rappresentante, l'analogon, che non ha una dimensione fisica, esteriore 0 spaziale; non è la cosa, rappresenta però la cosa (in qualche modo) e contribuisce a conferirle determinate caratteristiche fisiche. È questo il contenuto psichico dell'immagine mentale.

Per Sartre l'immaginario è la condizione essenziale del soggetto - «une détermination cardinale d'une personne» (Sartre 1976, 101) - ed egli lo situa alla base della libertà individuale. Nonostante le critiche ricevute sulla sua teoria delle immagini, il filosofo non ha cambiato idea con il passare degli anni. Semmai si è solo rammaricato per non aver saputo utilizzare nell'analisi le categorie materialiste $(1976,102)$. Del resto, è esattamente ciò che gli rimprovera Jameson (1977), ovvero l'assenza di un punto di vista sociale nella formazione dell'immaginario.

Tre anni dopo L'imagination (1936) e un anno prima di Imaginaire (1940), Sartre pubblica il racconto Le mur (1939). Il racconto è ambientato in un carcere durante gli anni della guerra civile in Spagna, dove vengono portati alcuni membri della resistenza. Le guardie non li torturano, si limitano a fare delle domande e, nel caso, a fucilarli nel cortile dopo una sommaria condanna a morte. La violenza politica estrema è presente nel racconto sotto forma di immagine. È durante l'attesa prima della fucilazione che questa si manifesta.

- Non è chiaro, - egli disse con un'aria ostinata. Voglio avere coraggio, ma bisognerebbe almeno che sapessi.... Senti, ci condurranno nel cortile. Bene. Quelli si schiereranno davanti a noi. Quanti saranno?

- Non lo so. Cinque o otto. Non di più.

- Va bene, saranno otto. Gli ordineranno: 'Puntate!' e io vedrò gli otto fucili spianati su di me. Penso che vorrò rientrare nel muro, spingerò il muro con la schiena con tutte le mie forze ed il 
muro resisterà, come negli incubi. Tutto questo posso immaginarlo. Ah! Tu sapessi come posso immaginarlo!

- Va bene! - gli dissi, - lo immagino anch'io.

- Deve fare un male cane. Sai che mirano gli occhi e la bocca per sfigurarci, - aggiunse con cattiveria. - Sento già le ferite; da un'ora ho delle fitte in testa e nel collo. Non dei veri dolori; è peggio: sono le fitte che sentirò domattina. (Sartre 2015, 13)

L'immagine/coscienza del dolore estremo altera lo stato psicologico e fisiologico dei prigionieri: «Sono materialista, te lo giuro; non sto diventando pazzo. Ma c'è qualcosa che non va. Vedo il mio cadavere: non è difficile ma sono io che lo vedo, con i miei occhi» $(2015,14)$; «Noi altri non sentivamo più i nostri corpi: non più allo stesso modo, in ogni caso» (15).

Dopo la pubblicazione di Imaginaire (1940), Sartre fu reso prigioniero dall'esercito tedesco e trasferito, prima in Francia e poi in Germania, in un campo di detenzione. Dopo nove mesi, riuscì a fuggire rocambolescamente. In seguito, inizierà a riflettere intensamente sulla tortura, argomento che lo ossessionerà per lungo tempo. Molte di queste riflessioni confluiranno nel dramma Morti senza tomba (1946), interamente dedicato alla tortura:

Per quattro anni aveva pensato molto alla tortura. Dentro di noi e fra di noi ci domandavamo: ce la farei a non parlare? Come fare a resistere? Inoltre aveva pensato a lungo sul rapporto tra torturatore e vittima. Mise in quest'opera tutti i suoi fantasmi. (de Beauvoir 1966, 113)

Il dramma è ambientato negli anni della Resistenza francese e narra i comportamenti di un gruppo di partigiani reso prigioniero e poi torturato da alcuni miliziani. La tortura domina ogni scena, specie quando è immaginata. L'immagine della tortura è già tortura. Questo emerge sin dalle prime battute, quando Sorbier, uno dei prigionieri, mentre attende di essere portato nella stanza delle torture, dice: «Non è troppo divertente aspettare quando s'immaginano tante cose». Le cose immaginate sono gli atti di tortura.

Tutti i dialoghi dei prigionieri - e anche le loro azioni - si costruiscono in presenza di un solo elemento dominante: l'immagine della tortura, che Sartre, fedele alla sua teoria, rappresenta come una sintesi tra memorie/impressioni del passato e informazioni recenti. Ciascuno dei prigionieri racconta agli altri le proprie impressioni sulla tortura, a partire dalle osservazioni ed esperienze del passato. È l'immagine della tortura a condizionare le vittime nelle decisioni da prendere e non la tortura reale. Infatti, quando ciascuno di loro si troverà faccia a faccia con questa ne resteranno quasi delusi. Nella stanza delle torture il dolore passa in secondo piano e le deci- 
sioni dei prigionieri, a quel punto, sono condizionate da altre immagini: quelle della resistenza. La necessità di vincere il duello con i torturatori si impone in quei momenti perché consente ai prigionieri di sopravvivere al dolore fisico e di dare un senso alla loro eventuale sopravvivenza fisica. Henri Alleg, sopravvissuto alla tortura dei soldati francesi in Algeria, ha scritto qualcosa di simile nel suo celebre libro di memorie, La question (1958): «Ero esaltato dalla battaglia che avevo impegnato senza cedere, dal pensiero che andavo alla morte come mi ero sempre augurato, fedele al mio ideale, ai miei compagni di lotta» $(1958,73)$. Anche i torturatori sono condizionati nelle loro decisioni dalle immagini mentali sui torturati, immagini che si presentano sempre come una sintesi di elementi del passato e del presente: 'il più giovane dei prigionieri parlerà'; 'alla fine tutti parlano'; 'sono dei vigliacchi', etc.

$\grave{E}$ in questo dramma che Sartre illustra alcuni elementi strutturali della tortura: (a) le immagini (mentali) della tortura (intese come prerequisito della tortura); (b) l'obiettivo della tortura (ovvero la degradazione dell'uomo in sotto-uomo) e (c) il complesso rapporto tra torturato e torturatore («Sorbier: 'Io t'attiro vero? Non è me che torturi, ma te stesso'»).

Da questo momento in poi, il filosofo ribadirà in ogni scritto successivo la compresenza di questi elementi in ogni contesto di tortura. Userà questa sua analisi strutturale della tortura anche nella lotta politica contro il colonialismo, in particolare contro quello francese in Algeria (Gjergji 2019). È proprio in questa lotta che Sartre aggiungerà un punto di vista sociale e materialista sulla tortura e, di conseguenza, anche sulle sue immagini mentali. È nel contesto coloniale che egli individuerà la funzione sociale della tortura. Sartre, infatti, ravvisa un legame indissolubile tra tortura, colonialismo e razzismo. Pensando il colonialismo come un sistema di oppressione e ipersfruttamento sorretto dal razzismo e dalla violenza (Sartre 2019a), egli giunge a definire la tortura - praticata a grandi dosi nelle colonie - come la forma più violenta e perversa dell'odio razziale eretto in sistema; non ha nulla a che fare con il bisogno di estrarre informazioni dai torturati, serve soltanto a ridurre in bestie loro e le popolazioni di appartenenza. La tortura, dunque, «serve affinché la vittima definisca sé stessa, con le sue grida e la sua sottomissione, come una bestia umana. Davanti agli occhi di tutti e anche ai suoi» (Sartre 2019b, 99-100).

Se il torturatore vuole imporre al torturato lo status di bestia umana, di sotto-uomo, lo fa anche per assegnare a sé stesso quello di uomo. Se questa è la radicale posta in gioco, allora il rapporto tra il torturatore e la sua vittima assume inevitabilmente le sembianze di una 'lotta' per lo status di uomo. Si spiega così, secondo Sartre, la tenacia dei torturatori, «la loro volontà di ridurre all'abiezione le loro vittime» $(2019 b, 99)$ e, infine, l'odio che s'impossessa di loro, modellandoli. La prospettiva psicoanalitica di Michel de Certeau offre 
forse una visuale più specifica del «sotto-uomo», ricorrendo al concetto di 'immondo': ${ }^{5}$

ciò che il carnefice vuole in definitiva dalla sua vittima, è ridurla a non essere altro che [...] un essere immondo, vale a dire quello che il carnefice stesso è e sa di essere, ma non confessa. (de Certeau 2006, 199)

In questa prospettiva, il bisogno di immaginare la vittima come un cane, di cui parlava Ken Davis, per arrivare a sottoporre a tortura i prigionieri iracheni, nasce dalla volontà di stabilire per sé lo status di uomo (o di super-uomo), dal bisogno di assicurarsi per sé tutti i diritti dell'uomo, i quali, per definizione, spettano ai soli uomini.

Stando alla teoria di Sartre, le immagini mentali di cui parlava Davis non potevano generarsi dalle osservazioni concrete o dal semplice ordine impartito dai superiori, né tanto meno dalle sole informazioni recenti. Esse comprendevano necessariamente anche un misto di impressioni, memorie, e immagini accumulate nel passato. Appare chiaro che l'immagine (o la coscienza) che Davis aveva della popolazione irachena fosse pregna di razzismo. L'intimazione di immaginare i prigionieri come dei cani ha solo ravvivato i colori di alcune immagini già presenti nella sua mente.

Le parole di Lynndie England aiutano a comprendere meglio questo processo, laddove spiega che la sua decisione di combattere contro altre popolazioni l'ha ricavata da diversi film di guerra hollywoodiani:

Ho sempre voluto essere nell'esercito. Tutta la mia vita. Non sapevo in quale ramo - Marina, Esercito, Guardia Costiera, Marines, Aeronautica. Volevo solo servire il mio paese ed essere una patriota, credo. Da bambina sono cresciuta soprattutto con i film di guerra, ed è qui che ho avuto l'idea. I vecchi film di Chuck Norris, 'Delta Force', 'Rambo', 'Missing in Action', 'Platoon'. (England 2008)

La consapevolezza di England circa l'origine del proprio immaginario, e la relativa influenza di questo sulla propria esistenza, non cancella la presenza di altri condizionamenti, di tipo materiale, relazionale e simbolico. Se si considerano anche le sole condizioni materiali, non è difficile comprendere che alla giovane England - figlia di proletari, povera e disoccupata - non restassero molte altre occasioni per migliorare il proprio status socio-economico. Arruolarsi nell'esercito rappresenta (l'illusione di) una via d'uscita dalla povertà per molti giovani negli Stati Uniti, molti dei quali sono immigrati o figli di immigrati. Allo 
stesso tempo, però, se si vuole cogliere appieno la sostanza sociologica delle sue scelte di vita, non avrebbe senso trascurare le sue parole (così come quelle di molti altri) circa l'importanza dell'immaginario acquisito nel corso degli anni. Del resto, come ha spiegato Georg Simmel, «nessuna esperienza psicologica è un calco del suo oggetto» $(1992,17)$. Nel caso specifico, dunque, occorre prendere atto di come la soldatessa England si sia nutrita di un immaginario pregno di razzismo, nel quale il posto assegnato a certe popolazioni (specie se musulmane) è sempre quello riservato ai nemici, ai sotto-uomini, alle bestie e, di conseguenza, ciò ha avuto un impatto nei suoi comportamenti.

Il razzismo e l'odio verso altre popolazioni, che poi diventano vittime delle torture, fa parte dell'addestramento militare. Per attecchire nelle coscienze dei soldati, si attinge a piene mani dalle immagini del passato e dagli stereotipi. La testimonianza di Tony Lagouranis, uno dei soldati in servizio ad Abu Ghraib, apre una finestra su questi processi quando descrive gli insegnamenti ricevuti dagli istruttori dell'esercito:

questo gruppo di istruttori ha diffuso il loro odio in modo uniforme su tutto il mondo arabo. Avevano un'opinione su ogni tipo di arabo. Gli iracheni, per esempio, erano chiassosi, sfacciati, machi e molto stupidi. La cosa più positiva che abbia mai sentito dire su un arabo era che gli yemeniti parlavano un arabo molto bello, nonostante la loro scarsa intelligenza. (Lagouranis, Mikaelian 2007, s.p.)

L'ideologia razzista svolge un ruolo cruciale nella costruzione dell'immaginario diffuso, in Occidente così come nel resto del mondo. Il razzismo della modernità non deve però essere confuso con la xenofobia (ossia la 'semplice' paura dello straniero), esso va considerato come elemento strutturale dell'attuale sistema socio-economico, un sistema che necessita - ai fini della propria riproduzione - della costruzione di una forte gerarchizzazione della forza-lavoro mondiale (Wallerstein 1985; Basso 2010). Tale gerarchizzazione passa anche dalle immagini di tortura, sia 'reali' che mentali.

\subsection{Arte e violenza politica: la questione della rappresentabilità}

Il dibattito teorico sulla possibilità (o meno) di rappresentare artisticamente la violenza politica estrema è ricco e articolato su molti livelli. Sul piano epistemologico, si possono rintracciare due posizioni: da un lato si colloca quella corrente di pensiero che affronta il tema della rappresentazione della violenza politica e dei suoi effetti attraverso l'elaborazione del concetto di irrappresentabile e, dall'altro, si trova il pensiero di coloro che ritengono insensato il concetto di irrappresentabile nell'arte. 
Per i primi l'irrappresentabile è un surplus di esperienza che supera la rappresentazione artistica. L'esempio che spesso si fa in questi casi è l'impossibilità di rappresentare la violenza e i traumi causati dall'Olocausto (Caruth 1996; Felman, Laub 1992):

Dico sempre che se ci fosse stato, per pura oscenità o miracolo, un film girato in passato su tremila persone che muoiono insieme in una camera a gas, prima di tutto, penso che nessun essere umano sarebbe stato in grado di guardarlo. In ogni caso, non avrei mai incluso questo nel film. Avrei preferito distruggerlo. Non è visibile. Non si può guardare questo. (Lanzmann 1991, 83)

L'elemento di irrappresentabilità è visto come una prospettiva sul trauma, irrecuperabile attraverso il discorso storico.

La nozione di irrappresentabile va collocata nel campo teorico dell'impensabile di Jean François Lyotard (1991), il quale lo descrive come la distanza esistente tra ciò che ci tocca e ciò che la razionalità è capace di gestire. Per Lyotard, il sublime moderno nell'arte risiede proprio nella registrazione di un atto impensabile. Questa concezione nasce dalla convinzione di Lyotard circa l'esistenza di uno scarto tra sentimento e pensiero: vale a dire che si può essere toccati da qualcosa senza che ne vengano colte appieno le implicazioni intellettuali. L'impensabile si situerebbe nello spazio tra il sensibile e l'intelligibile. Secondo Lyotard, dunque, le forme dovrebbero essere all'altezza dell'oggetto rappresentato, al fine di produrre un effetto 'corretto' sullo spettatore. Il che significa, inevitabilmente, che vi sono oggetti o esperienze che si spingono oltre la capacità dell'arte di rappresentarli, perché per questi non esiste alcuna forma adeguata.

In direzione contraria a quello di Lyotard va il pensiero di Jacques Rancière (2003). Egli non crede nel concetto di irrappresentabilità nell'arte. Non contesta il fatto che certe esperienze, certi sentimenti, luoghi ed eventi possano travalicare le capacità estetico-rappresentative dell'arte, dati i limiti intrinseci dell'arte stessa. Gli eccessi e le insufficienze intrinseche dell'arte hanno portato, secondo Rancière, all'emergere di quella che è stata definita una witness narrative, che egli considera una nuova modalità di fare arte. Si tratta di una forma d'arte che non si propone di rappresentare l'esperienza nella sua totalità sensoriale e fattuale, ma piuttosto di registrarne una traccia e, nel contempo, di sottolineare la difficoltà di inscriverla nella rappresentazione (integrale). In questo modo, piuttosto che tentare di rappresentare l'oggetto o l'esperienza, l'arte 'semplicemente' registra la presenza dell'oggetto o il verificarsi dell'esperienza. Inoltre, secondo Rancière, forma e significato possono essere armonizzati in infinite possibilità. Di conseguenza, egli giunge alla conclusione che non vi è nulla di non rappresentabile nell'arte: si tratta soltanto di trovare la giusta combinazione tra forma e significato. Si tratta, in breve, di fare delle scelte. 
In relazione alla violenza estrema - come nel caso della tortura che è stata spesso evocata all'interno del discorso teorico sulla 'non rappresentabilità' - Rancière sostiene che la rappresentazione di essa è sempre possibile, senza necessitare di nuove forme. Ciò che va fatto, anche in questo caso, è la scelta sulla combinazione di forme (già esistenti) e significati.

In Images malgré tout (2003), Didi-Huberman sostiene l'importanza delle immagini di e da Auschwitz per trasmettere l'idea dell'inferno dei campi nazisti. Prendendo in esame quattro fotografie contenute nel film documentario Notte e nebbia nelle quali si vedono dei corpi gasati e delle donne spinte verso la camera a gas, Didi-Huberman scrive: «Strappare un'immagine da questo, nonostante questo? Sì. Era necessario a tutti i costi dare forma a questo inimmaginabile [orrore]» $(2003,21)$. L'arte è considerata qui come uno strumento che consente di fornire tracce del reale, prove, ma anche come dispositivo che agevola la presa di coscienza su un evento traumatico, che può rendere immaginabile l'inimmaginabile.

Notte e nebbia (1956), di Alain Resnais, e La Battaglia di Algeri (1966), di Gillo Pontecorvo, sono due esempi emblematici di come sia difficile rappresentare la violenza inimmaginabile, mostrando nel contempo le vie dell'arte per riuscire a renderla comunque immaginabile.

\subsection{Notte e nebbia}

Il film fu commissionato al regista dal Comité d'Histoire de la Deuxième Guerre Mondiale, all'epoca diretto dagli storici Henri Michel e Olga Wormser, per ricordare la tragedia dell'Olocausto e dei campi nazisti a distanza di dieci anni dalla fine della Guerra. Resnais accettò di farlo a patto che lavorassero con lui lo scrittore Jean Cayrol, che aveva personalmente vissuto l'esperienza dei campi nazisti, e il musicista Hanns Eisler. Il film è il risultato del montaggio di immagini raccolte in alcuni archivi ${ }^{6}$ - rese poco accessibili dai governi e dagli eserciti (Resnais 2002, 162) - e di riprese del regista. Un ruolo fondamentale è assegnato alla musica di Eisler e alla voce fuori campo dell'attore Michel Bouquet che legge il testo di Cayrol, ma la caratteristica estetica più evidente del film è il contrasto tra le immagini a colori e quelle in bianco e nero, così come tra le immagini del passato e quelle del presente. Interrogato su questa scelta stilistica, Resnais ha detto:

6 L'esistenza di queste immagini negli archivi dimostra come l'uso delle immagini delle torture e delle violenze estreme come strumento di propaganda non sia affatto nuovo nella storia. 
I colori e le parti mute servono a mostrare la differenza. Del resto nei ricordi si pensa un po' in grigio, in ogni caso in un colore un po' meno netto. Il contrasto fra il movimento e l'immobilità per certi aspetti drammatici sembrava molto ricercato, ne ho un po' avuto vergogna al momento del montaggio. $(2002,163$, nota 7$)$

Il lavoro per contrasti crea "costantemente ostacoli alla visione indisturbata» (Bersani, Dutoit 1993, 183) e allo stesso tempo mette in una posizione scomoda lo spettatore: «Ci sono discrepanze tra ciò che vediamo e ciò che sentiamo, [...] che tuttavia hanno l'effetto cumulativo di irritare i nostri sensi» (183). L'effetto irritativo è moltiplicato dalla colonna sonora del film. Qui i contrasti creano un effetto quasi straniante: nelle prime sequenze, quando la videocamera cattura immagini di campi fioriti ed erba alta, quando cioè nulla lascia immaginare il loro passato di campi di concentramento, la musica di Eisler ci annuncia la tragedia con note elegiache, suonate da un'orchestra d'archi (Dümling 1998). Quando le immagini si riempiono di fili spinati, corpi morenti o torturati, sguardi immersi nell'orrore, Eisler allenta la presa e le accompagna con note quasi ottimistiche, suonate da un'orchestra da camera, composta di solo flauto e clarinetto. In letteratura si è affermato che «Eisler voleva mostrare che l'ottimismo e la speranza umana possono esistere perfino in un campo di concentramento» (Armes 1968, 50).

L'estetica dei contrasti spiazza continuamente lo spettatore mettendolo in una posizione disagevole, che lo spinge a non adagiarsi su facili sentimenti pietistici, ma a comprendere la condizione storica ed esistenziale delle vittime dell'Olocausto.

Il film è esteticamente riuscito, ma ciò che importa di più, in questa riflessione, è che la combinazione di tutti gli elementi che lo compongono (forme e significati) lo rendono una dichiarata sfida al dibattito teorico sull'irrappresentabilità della violenza politica nell'arte. Il film è autoconsapevole dell'impossibilità del progetto e non la nasconde. Anzi, la esclama a gran voce, attraverso il testo di Cayrol, il quale volontariamente si distanzia dalle immagini, rivelando l'irrappresentabilità dei campi nazisti e della violenza che li ha prodotti. Quando appare un'inquadratura a colori degli interni dei blocchi di Birkenau, si sente la voce di Bouquet dire:

Questi blocchi di legno, queste cuccette a più piani in cui dormono in tre, dove il sonno era una minaccia, queste tane in cui rifugiarsi, per strappare un morso furtivo di cibo. Nessuna immagine, nessuna descrizione può catturare la loro vera dimensione di paura costante.

In una scena successiva del film, mentre Bouquet prova a descrivere come sono stati usati i capelli, le ossa e i corpi dei prigionieri nei 
campi, il commento vacilla e piomba il silenzio: «con i corpi... ma le parole falliscono». Nei successivi dieci secondi del film si sente solo il silenzio a commento. Sylvie Lindeperg, analizzando Notte e nebbia, ha scritto: «Questo film mostrava le terribili immagini d'archivio integrandole in una riflessione implicita sui limiti dell'immagine» (Lindeperg 2000, 183).

Consapevole dei limiti intrinseci dell'immagine, Resnais non ha cercato di costruire un «monumento ai morti» $(2002,161)$, motivando la sua scelta così:

L'idea alla quale mi ero attaccato e che mi pare la più importante, era che non volevo fare un film 'monumento ai morti'. Era questo ciò di cui avevo paura, di fare un film che fosse: 'Mai più tutto ciò' [...]. Allora ho tentato di spingere molto il film verso il punto interrogativo che rappresenta: il fatto che una cosa come questa sia esistita a quell'epoca, ma che in fondo nel passato avesse altre forme. $(2002,161)$

Resnais voleva far riflettere lo spettatore sulle condizioni che rendono possibili in ogni momento eventi come l'Olocausto: «Volevo un film che non dicesse alle persone: 'Non dimenticate' - il che non mi interessava - ma: 'Cercate di capire perché questo accade. Soprattutto non attendete che sia accaduto per occuparvene'» $(2002,164)$. La scelta dell'estetica dei contrasti e dell'oggettività della distanza si è in qualche modo imposta al regista francese. Inoltre, quando egli montava il film, la Guerra d'Algeria giungeva al secondo anno e le immagini algerine lo inquietavano più di quelle dei campi nazisti, proprio perché erano immagini del presente e non del passato: «La Guerra d'Algeria cominciava e già c'erano delle zone nel centro del paese in cui vi erano dei campi di raggruppamento» (161).

Resnais è riuscito a costruire una relazione tra l'inimmaginabile e le tracce materiali della storia (fili spinati, ossa, capelli, tombe, reliquie, fotografie). Lavorando in questo intreccio ha saputo rendere consapevole lo spettatore delle difficoltà di rappresentazione di certi oggetti o eventi storici e, nel contempo, spingerlo a immaginare ciò che non aveva visto.

\subsection{La battaglia di Algeri}

Per realizzare La battaglia di Algeri, Gillo Pontecorvo fu contattato nel 1964 da Yacef Saadi, ex capo militare del Fronte di Liberazione Nazionale (FLN) della capitale algerina, ex giocatore di calcio e, in seguito, direttore di Casbah Film. Prima di Pontecorvo, Saadi aveva provato a coinvolgere Francesco Rosi e Luchino Visconti, i quali però avevano declinato l'offerta. Il compito assegnato al regista era quello di ricostruire la memoria della resistenza collettiva attraver- 
so la rappresentazione degli anni della Guerra d'Algeria (1954-62). Pontecorvo accettò con entusiasmo perché conosceva l'Algeria e perché aveva già scritto, insieme a Franco Solinas, una sceneggiatura dal titolo Parà - film che non sarà mai realizzato - dove si narrava la vicenda di un ex paracadutista francese, il quale dopo aver partecipato alla guerra coloniale ritornava in Algeria come fotoreporter di Paris-Match, con l'obiettivo di fotografare l'attimo in cui un colono avrebbe ucciso un uomo arabo (Floris 2010, 22).

Pontecorvo seleziona un periodo particolare della Guerra d'Algeria per il film: quello che va dall'estate del 1956 all'autunno del 1957. E il momento in cui ad Algeri arrivano i reparti speciali dell'esercito francese (i paracadutisti) con l'obiettivo di annientare, a qualsiasi costo, la rivolta popolare. L'uso della tortura divenne la regola. Proprio alla tortura Pontecorvo dedica la scena d'apertura del film. Si vede un uomo semi-nudo, tremante, che a malapena si regge in piedi. Intorno a lui dei soldati che, muovendosi con disinvoltura tra lettini e strumenti di tortura, cercano di confortarlo. La scena appare più nuda della vittima. Dal dialogo tra i soldati si comprende che l'uomo, Sadek, era stato torturato fino a un attimo prima e aveva fornito ai torturatori le informazioni richieste, cioè il nascondiglio di Alì, uno dei capi della resistenza:

- Ma non potevi deciderti prima, senza fare tante storie, no?

- E così, ha parlato? Ma sa davvero dov'è Alì?

- Sembra proprio di sì. Adesso andremo a vedere. ...Dagli un po' di caffè.

Pontecorvo sceglie di non sconcertare da subito lo spettatore con la tortura, con le unghie strappate, il sangue, il waterboarding, le grida e la confessione estorta dalla gola di Sadek. L'orrore si fa strada negli occhi di chi guarda attraverso i marcati contrasti della scena: il volto di un uomo povero e visibilmente innocente circondato da strumenti di tortura; il corpo sofferente e barcollante di Sadek in mezzo ai corpi atletici dei militari; le carezze e attenzioni dei torturatori nei confronti del torturato; l'entusiasmo dei militari per il 'successo' della tortura e il tentativo di Sadek di buttarsi dalla finestra, per superare la vergogna. Lo spettatore è spinto così a ricostruire da sé le immagini della tortura appena conclusa; il film si limita a porgli davanti tutti gli elementi necessari per completare il puzzle.

Come Resnais, anche Pontecorvo utilizza l'estetica dei contrasti per rappresentare la violenza politica. La costante alternanza tra luci e ombre è un elemento che accompagna ogni scena. L'effetto è potenziato dall'utilizzo del bianco e nero. I contrasti si estendono anche ad altri livelli: agli spazi verticali del quartiere francese si contrappongono quelli orizzontali della Casbah; al cinico e calcolatore potere coloniale si contrappone il nuovo potere popolare nascente, quello del 
FLN; alle scene accompagnate da rumori, voci o musica assordante si contrappongono dei lunghi momenti di silenzio. L'estetica dei contrasti rafforza il tono cronachistico del film, sottolineato anche dalla voce fuori campo che utilizza un linguaggio chirurgicamente preciso.

La denuncia politica contro l'uso sistematico della tortura in Algeria (Stora 1991) viene affidata anche al linguaggio (Prochaska 2003). È il colonnello Philippe Mathieu - l'unico vero personaggio del film, essendo questo fortemente caratterizzato da una dimensione corale - a dire la verità della tortura durante una conferenza stampa. La descrive come parte strutturale del sistema coloniale, come il volto perverso dello sfruttamento europeo e non come un mero capriccio di soldati sadici. Sfidato dai giornalisti che provocatoriamente gli chiedevano di precisare meglio i metodi dell'esercito francese in Algeria, il colonnello risponde scandendo le parole e alzando di una tonalità la voce. Non lo fa per imporsi ai giornalisti presenti, ma per rivolgersi direttamente agli spettatori occidentali: è il j'accuse di un servitore dello Stato, di medio livello, che non ne può più di assumersi tutta la colpa della ferocia statale nelle colonie. La sua accusa smaschera l'ipocrisia dei democratici spettatori europei, i quali accettano ben volentieri il colonialismo, senza però voler conoscere le atrocità che esso produce:

No, signori, credetemi, è un circolo vizioso. E possiamo discutere ore senza arrivare a una conclusione, perché non è questo il problema. Il problema è: l'FLN vuole mandarci via dall'Algeria e noi vogliamo restarci. Ora, a me sembra che qui, anche se con sfumature diverse, siete tutti d'accordo che dobbiamo rimanere. E quando è cominciata la ribellione non c'erano neanche le sfumature. Tutti i giornali, anche quelli di sinistra, hanno chiesto che fosse soffocata. Noi siamo stati mandati qui per questo. E noi, signori, non siamo né pazzi né sadici. Quelli che oggi ci dicono fascisti dimenticano il contributo che molti di noi hanno dato alla resistenza. Quelli che ci dicono nazisti non sanno che tra noi ci sono dei sopravvissuti di Dachau e Buchenwald. Noi siamo soldati e abbiamo il dovere di vincere. Quindi, per essere precisi, adesso pongo io a voi una domanda: la Francia deve rimanere in Algeria? Se risponderete ancora sì dovete accettarne tutte le necessarie conseguenze.

Il discorso del colonnello Mathieu è un trattato politico sulla tortura che descrive con persuasione la sua vera funzione sociale: uno strumento di oppressione, sfruttamento e umiliazione di massa.

Attraverso un'attenta combinazione tra forme estetiche e significati, il film riesce a raggiungere l'obiettivo che Pontecorvo si era posto, ossia quello di «dare allo spettatore la sensazione di essere presente, di vivere la storia in quel momento» (Faldini, Fofi 1981, 402).

Il 7 settembre 2003, Michael T. Kaufman scriveva su New York Times della proiezione di un film organizzata dalla Direzione opera- 
zioni speciali e conflitti a bassa intensità del Pentagono. La visione del film era considerata un'occasione di apprendimento e discussione sulle tattiche di guerriglia negli scenari di guerra. Il film in questione era La battaglia di Algeri e, come riferisce Kaufman, nel volantino del Pentagono si poteva leggere quanto segue:

Come vincere una battaglia contro il terrorismo e perdere la guerra delle idee. I bambini sparano ai soldati a bruciapelo. Le donne piazzano bombe nei caffè. Presto l'intera popolazione araba sarà animata da un folle fervore. Vi suona familiare? I francesi hanno un piano. Funziona tatticamente, ma fallisce strategicamente. Per comprendere la ragione, venite a una rara proiezione di questo film. ${ }^{7}$

Non è la prima volta che il film di Pontecorvo viene incluso nel programma di addestramento del Pentagono, così come in quelli di altri eserciti e forze speciali sudamericane (Argentina, Brasile, Panama, etc.). Allo stesso tempo, il film è stato utilizzato anche per la formazione politica e militare delle Black Panthers, così come per quella di gruppi politici della resistenza anticoloniale in ogni angolo del mondo. Le cronache raccontano persino della proiezione de La battaglia ai mondiali di calcio del 2010 per sollevare il morale della nazionale algerina.

Questo utilizzo del film ha portato alcuni ad accusarlo di ambiguità ideologica. Il ragionamento è pressappoco questo: un film politico non può servire sia la causa dei reazionari che quella dei rivoluzionari. Forse è vero, ma con La battaglia è accaduto quello che accade con ogni opera in cui si instaura «la dittatura della verità» (Faldini, Fofi 1981, 402). La struttura narrativa del film è solida, attinge informazioni da documenti storici (Branche 2001; Erickson 2013), prove e testimonianze dirette (Alleg 1958), dalle cronache dei quotidiani, dai testi di Frantz Fanon, Jean-Paul Sartre, Pierre Vidal-Naquet (1963). Del resto, non era difficile reperire il materiale storico a distanza di soli due anni dalla fine della guerra. Se la verità è dunque ben rappresentata nel film, allora non deve stupire perché siano in tanti a volerla conoscere, pur partendo da prospettive diverse per raggiungere diversi obiettivi. La battaglia ideologica, in fondo, è una lotta corpo a corpo con la verità.

7 Michael T. Kaufman, «The World: Film Studies; What the Pentagon See in 'The Battle of Algiers'», New York Times, Sept. 7, 2003, https://www. nytimes.com/2003/09/07/ weekinreview/the-world-film-studies-what-does-the-pentagon-see-in-battleof-algiers.html (2019-09-09). 


\subsection{La tortura seriale post $11 / 9$}

Si afferma che «ogni epoca è dominata da una forma o da un genere privilegiati, i quali paiono più adatti a esprimere le verità segrete 0 , forse, se si preferisce un modo di pensare più contemporaneo, che sembrano manifestare il sintomo più intenso di quella che Sartre avrebbe chiamato la 'nevrosi oggettiva' di quel particolare tempo e luogo» (Jameson 2007, 82). Se ciò è vero, allora le serie televisive rappresentano oggi la forma visuale che meglio esprime il modo di pensare contemporaneo. A partire dalla fine del secolo scorso e, soprattutto, dall'inizio del nuovo, gli investimenti dei grandi network occidentali nella produzione di serie televisive sono stati cospicui. Scelta dettata anche dalla estensione della 'cultura on-demand' (Tryon 2013), a seguito della diffusione della tecnologia digitale, che ha agevolato la costruzione di nuove e potenti piattaforme per la produzione delle serie televisive.

Il pubblico delle serie cresce in modo esponenziale di anno in anno, e non soltanto in Occidente. Si è affermato che il successo nasca anche dalla difficoltà dei soggetti di vivere in un'epoca fortemente caratterizzata dall'impossibilità di agire. Impossibilità che non scaturisce dai divieti formali, ma dalla sensazione/convinzione che oggi l'agire sia «ineffettuale, senza esito» (Giglioli 2015, s.p.), privo di concretezza. Chi nella realtà vive questa paralisi dell'agency tende a cercarla nelle serie televisive, in quanto in queste

c'è una rappresentazione del soggetto umano [...] come qualcuno che non sente e patisce, ma agisce e decide [...] Non si sceglie una volta per sempre: si sceglie sempre, ogni giorno è teatro di una decisione impegnativa, urgente e radicale. La vita è una continua E.R. [...] Le serie combinano l'interruzione tragica e il continuum dell'epopea - non del romanzo, e sbaglia chi sostiene che la narrativa seriale è l'equivalente del realismo ottocentesco: il romanzo vive di un'alternanza di stati roventi e stati tiepidi; non c'è guerra senza pace. (Giglioli 2015, s.p.)

In altre parole, lo spettatore delle serie televisive trasferisce su un piano immaginario il proprio desiderio di agire, il quale nella realtà appare costantemente frustrato. A prescindere dall'argomento, infatti, le serie mettono in scena un mondo incentrato sull'azione. Questo è particolarmente evidente nelle serie dedicate ai temi del terrorismo e controterrorismo, le quali dopo l'11 settembre 2001 sono diventate numerose. Dopo questa data, le serie criminali e drammatiche (in particolare quelle statunitensi che dominano attualmente il mercato mondiale) hanno iniziato a dare sempre più spazio ai temi della violenza politica e della sicurezza nazionale, sviluppando trame legate agli atti terroristici reali o minacciati, dando vita a quella 
che è stata definita la 'Terror Tv' (Tasker 2012), nella quale risultano sovraesposti, come personaggi pericolosi e spregevoli, gli arabi o i musulmani. Avvalendosi di strategie narrative già consolidate, per quanto concerne la comprensione e la drammatizzazione della devianza e della criminalità, le serie già esistenti si sono 'limitate' ad accogliere la dimensione militare della 'guerra al terrore' e quelle nuove a fare di tale dimensione la linea narrativa centrale. Particolarmente rilevante risulta lo spazio dedicato alla tortura in queste serie.

Molti sono gli esempi che si possono segnalare: 24 Hours Chrono, Third Watch, The Agency, Alias, MI-5, Threat Matrix, The Ring, NCIS, Sleeper Cell, The Unit, The Border, The Kill Point, Generation Kill, Damages, Homeland, Nikita, Person of Interest, etc. Quasi tutte queste serie sono state trasmesse dai network europei e italiani. Il loro successo è stato notevole e ha senza dubbio contribuito a creare una «cultura della paura» (Tasker 2012), ma la serie che più di altre ha contribuito a promuovere la tortura come utile e legittimo strumento di lotta al terrorismo, è stata 24 Hours Chrono: «Molto più degli argomenti dei filosofi o degli articoli dei giornalisti ha influito sull'opinione pubblica americana la serie televisiva, prodotta dall'emittente FOX, 24 hours chrono» (Di Cesare 2016, s.p.).

Lo strepitoso successo di pubblico e critica, - venti Emmy Awards e due Golden Globes (per il miglior attore nel 2002 e la migliore sceneggiatura nel 2004), oltre che innumerevoli nomination in una miriade di competizioni -, l'indubbia qualità estetica, l'innovativa struttura narrativa e l'ampio focus sulla tortura fanno di questa serie l'urtext della rappresentazione visiva della tortura nell'era post 11 settembre.

\subsection{Hours Chrono}

Per otto stagioni, tra il novembre 2001 e il maggio 2010, 24 è stato uno dei programmi televisivi più popolari, e non soltanto negli Stati Uniti dove ciascun episodio aveva una media di dieci milioni di telespettatori (Neroni 2015). La sua estetica e i suoi contenuti hanno esercitato, rispettivamente, un forte impatto sull'industria della televisione e sulla cultura popolare in generale. Sotto il profilo estetico, l'elemento più distintivo è rappresentato dal suo stile visuale, sotto il profilo contenutistico, invece, dall'avvincente racconto della 'guerra al terrore'. Ma il più importante contributo innovativo è la sua struttura narrativa, per la prima volta costruita sul principio del Real-TimeTv. Ogni episodio dura sessanta minuti che corrispondono ad altrettanti minuti della storia narrata. Così, i ventiquattro episodi di ogni stagione raccontano soltanto una giornata nella vita dei personaggi.

La simulazione di un reality che stilisticamente evoca i notiziari, intensifica la velocità della narrazione e, allo stesso tempo, il coinvolgimento dei telespettatori, i quali hanno così la sensazione di se- 
guire le operazioni militari in diretta tv; l'appartamento di ciascun telespettatore si trasforma in una situation room. Eppure, come accade in ogni reality che si rispetti, la realtà è l'unico elemento a essere completamente assente: 24 non ha infatti mai menzionato la guerra in Afghanistan, che pure era iniziata il 7 ottobre 2001 e che è proseguita per tutta la durata della serie, così come mai ha fatto riferimento alla guerra in Iraq, iniziata il 20 marzo 2003. Ci sono alcuni riferimenti alle armi di distruzione di massa, agli attacchi biochimici e alle 'bombe sporche' che evocavano lo spettro di Saddam Hussein, ma nulla più.

Il primo episodio fu mandato in onda pochi giorni dopo l'approvazione del Patriot Act, il cui nome completo - The Uniting (and) Strengthening of America (by) Providing Appropriate Tools Required (to) Intercept (and) Obstruct Terrorism Act - aiuta a spiegare anche la filosofia di fondo della serie, perché come ha evidenziato Hilary Neroni: «Nessuna fiction è sui generis. Risponde $a$ e scaturisce da un momento culturale» $(2015,17)$. Il momento era quello della securitizzazione di ogni ambito sociale, nel nome della lotta al terrorismo.

Il personaggio principale, Jack Bauer, interpretato dall'attore canadese Kiefer Sutherland, è un eroe che opera al di fuori della legge (proprio come prescrive il Patriot Act), la cui notorietà aumenta con l'aumentare del suo impegno nella tortura, ritenuta essenziale per ottenere le informazioni necessarie a garantire la sicurezza nazionale. Nonostante Bauer agisca da sovrano, al di sopra della legge, le trame narrative lo fanno sempre apparire come una pedina o un eroe strumentalizzato per combattere il terrorismo. Sotto questo profilo, tuttavia, non ci sono innovazioni di rilievo, perché il personaggio si colloca in una lunga tradizione di detective e agenti segreti che combattono il crimine e il terrore dai margini della legge. In generale, va detto che la serie è costellata di storie convenzionali e personaggi stereotipati, sia in termini razziali che di genere. Infatti, nella maggioranza degli episodi, non si fa altro che riproporre in nuove combinazioni scene di serie e film del passato, dando vita a quello che Jameson ha definito «pastiche postmoderno» (Jameson 2007).

Come accennato, in 24 la tortura non è casualmente presente nella struttura narrativa; al contrario, rappresenta il suo pilastro principale. Ciò risulta evidente anche dal solo conteggio delle scene di tortura presenti in ogni episodio e stagione: il Parents Television Council ha calcolato che nelle prime sei stagioni - ovvero in sei giorni, se si applica la logica del real-time-tv della serie - ci sono state ottantanove scene di tortura (Neroni 2015). Bauer ha usato quasi tutte le tecniche di tortura: ha minacciato, ricattato, picchiato, soffocato, accoltellato, sparato, folgorato, drogato, etc. (Danzig 2012 , 21). Si può affermare, senza tema di smentita, che la serie è una campagna promozionale della tortura lunga otto anni. La tortura è rappresentata come uno strumento necessario per strappare 
ai nemici informazioni vitali, indispensabili a garantire la sicurezza e il benessere dei cittadini americani e occidentali, posti costantemente in pericolo da terribili minacce di morte.

L'inserimento di un orologio sullo schermo, in modalità countdown che, di frequente, scocca il suo pesante ticchettio, ha una doppia funzione: servire da costante giustificazione della tortura (il tempo passa, una bomba sta per esplodere e molte persone possono morire) e accrescere il livello di fidelizzazione degli spettatori attraverso l'aumento della loro ansia (chissà se riuscirà Jack a fare in tempo?). L'orologio di 24 evoca l'Orologio dell'Apocalisse, ideato nel 1945 da un gruppo di scienziati atomici per scandire il tempo rimasto all'umanità prima della catastrofe nucleare, simbolicamente rappresentata dalla Mezzanotte. L'ultima regolazione dell'orologio risale al 24 gennaio 2019: il consiglio degli scienziati ha deliberato che all'umanità restano appena due minuti (metaforici) da Mezzanotte. Dal momento della sua ideazione, l'Orologio dell'Apocalisse ha simbolicamente rappresentato lo scorrere del tempo della nostra epoca, un tempo in perenne countdown, in scadenza, senza futuro, il tempo del capitalismo globalizzato (Mazzocco 2019; Leccardi 2015; Jameson 2002). Nel campo delle serie televisive è The Walking Dead (tuttora in produzione dal 2003) a segnare:

un punto di non-ritorno nell'immaginario catastrofico [...]. Essa anzitutto chiude un cerchio: quello iniziato oltre un quarantennio prima, quando nel 1968 il tema della catastrofe del mondo dei viventi sulla Terra acquista, ne Il pianeta delle scimmie, la valenza di un discorso apertamente critico sulla civiltà tecno-scientifica. (Frezza 2015, 279) ${ }^{8}$

Ernesto De Martino (2002) ha ampiamente illustrato nei suoi studi antropologici come la civiltà occidentale contemporanea sia costantemente esposta alla minaccia della tentazione apocalittica, evidenziando anche come l'apocalittica occidentale moderna sia senza escaton, ${ }^{9}$ senza riscatto, o «torturante», come la definì il filosofo cattolico Emmanuel Mounier (1949), in quanto non contempla la possibilità di invertire o modificare il corso della storia.

24 offre, in modo paradossale, una soluzione all'incombente fine del mondo; in essa è, in qualche maniera, riesumato il rapporto dia-

8 Colgo l'occasione per ringraziare Gino Frezza per i preziosi consigli e stimoli, oltre che per gli innumerevoli suggerimenti di film, serie televisive e fumetti che trattano in vario modo l'argomento della tortura. Anche se in questo capitolo non sono stati espressamente citati, essi hanno contribuito a costruire il mio punto di vista sulle immagini della tortura.

9 Sul punto, si legga il saggio di Adriano Vinale (2015), dove si illustra con profondità analitica e brillante sintesi l'impatto dell'apocalittica cristiana nella teoria e pratica della politica moderna occidentale e, in particolare, di quella statunitense. 
lettico tra crollo e recupero, si è in presenza di un intervento umano teso a modificare il corso della storia, ma il suo agire presente aperto verso il futuro si traduce nel solo atto di tortura. È questa, infatti, a svolgere il ruolo di medium nel nesso dialettico crisi-riscatto: per fermare il countdown e aprire il tempo al futuro bisogna torturare (certe categorie di persone, ça va sans dire): «la tortura in qualche modo proviene direttamente dal conto alla rovescia cronologico» (Neroni 2015, 98). Riprendendo la riflessione di Giglioli (2015) sulle serie televisive e utilizzando il linguaggio di De Martino sulla fine del mondo, si può affermare come 24 costruisca una «patria culturale dell'agire» (De Martino 2002, 282) dentro l'universo della tortura. Il paradosso narrativo consiste nel fatto che l'atto in grado di fermare la fine del mondo, tradizionalmente raffigurato con l'immagine della discesa agli inferi (De Martino 2002), sia, a sua volta, una discesa agli inferi, la quale, come ha spiegato Amery (1993), non prevede ritorno, né per le vittime né per i carnefici. Con un abile gioco di prestigio, la serie spaccia come soluzione all'apocalisse incombente un'altra apocalisse. Non si esce mai, allora, dall'orizzonte apocalittico, il quale, secondo De Martino (2002), riflette la profonda crisi della società borghese contemporanea.

A proposito di tempo, vi è un'altra piccola annotazione da riportare: la serie lancia un vero e proprio assalto al tempo del sonno. In tutte le stagioni, che corrispondono ciascuna a una giornata di ventiquattro ore, Jack Bauer, «il torturatore gentiluomo» (Di Cesare 2016), non dorme mai. Ė «il sogno perverso del capitalismo» avere «un mondo di insonni, un pianeta in costante stato di veglia, popolato da individui pronti per lavorare o per consumare» (Mazzocco 2019). Analogamente, si può affermare che, essendo la pratica della tortura inserita in un sistema di produzione di tipo capitalistico, il sogno perverso dei governi impegnati nella 'guerra al terrore' è quello di avere dei torturatori insonni, in costante stato di veglia, pronti a torturare chiunque sia marchiato come nemico. La tortura postmoderna non contempla sacche di tempo non utilizzate, deve essere sempre produttiva, ovvero just-in-time.

L'impatto di 24 su militari e contractor che hanno praticato la tortura negli scenari di guerra e nei campi di detenzione statunitensi è stato ampiamente documentato in letteratura (Neroni 2015; Danzig 2012; Lagouranis, Mikaelian 2007; McCoy 2006). In molti casi, infatti, i torturatori di Guantanamo (Russo 2016; Bonini 2004), Abu Ghraib, Falluja, Bagram e altrove, per sopperire alla scarsa preparazione tecnica e rispondere alle pressanti richieste dei loro superiori che li spingevano alla 'creatività', sono ricorsi alla visione di film e serie televisive. Tra questi un ruolo di prestigio è riservato a 24 , il quale si è imposto anche nel discorso politico diventando lo strumento migliore di qualsiasi altro in grado di spiegare le ragioni a sostegno della tortura. Così, Jack Bauer è diventato in poco tempo il pro- 
totipo del patriota, colui che incarna i valori giusti, sempre pronto a torturare e sacrificarsi per la sicurezza della nazione. Innumerevoli sono le citazioni di Bauer nei discorsi di politici, magistrati e militari che si riconoscono nei valori neo- o teo-con. Ma Bauer è apprezzato come modello valoriale - seppur con qualche trascurabile riserva - anche nel campo progressista degli Stati Uniti; Bill Clinton, in un'intervista rilasciata il 30 settembre 2007 sull'emittente NBC, durante la campagna elettorale per le presidenziali del 2008, pur affermando la propria contrarietà alla tortura, non mancò di riconoscere pubblicamente il valore dei personaggi come Bauer:

se uno fosse la persona di Jack Bauer e mancassero solo sei ore dallo scoppio della bomba o altro, non potrebbe sapere quello che sarebbe capace di fare, e dovrebbe - ma penso che la nostra politica deve essere intransigente contro il terrore - intendo dire torturare, e se fosse Jack Bauer, farebbe ogni cosa necessaria e dovrebbe essere pronto ad assumersene le conseguenze. ${ }^{10}$

Da 24 in poi, la presenza delle immagini di tortura nelle serie televisive è esponenzialmente aumentata, confezionando, nella maggior parte dei casi, una sua implicita o esplicita giustificazione e, nel contempo, testimoniando la crescente influenza della tortura nella società contemporanea:

La proliferazione di scene di tortura nel cinema e nella televisione contemporanea è indice della continua influenza della tortura. Infatti, le scene di tortura dopo gli attacchi dell'11 settembre 2001, iniziarono a fungere da strumenti di narrazione naturale della vicenda a tutti i livelli dei media - dagli spot pubblicitari agli spettacoli televisivi ai film d'animazione per bambini. (Neroni 2015,4$)$

Accurate ricerche e numerosi sondaggi post 11 settembre (Blauwkamp, Rowlin 2018; Wallace 2013; Lobe 2011; Gronke et al. 2010; Kull et al. 2008) sono riusciti a stabilire, pur partendo da differenti punti di vista e utilizzando differenti strumenti di ricerca, una stretta relazione tra la diffusione delle immagini di tortura (in serie televisive, film, giornali, social media) e il crescente grado di accettazione della tortura nell'opinione pubblica occidentale, a dimostrazione del fatto che - al di là dello sviluppo della cultura 'on demand' - la funzione della propaganda nella società contemporanea è ancora potente.

10 La trascrizione dell'intervista rilasciata dal presidente statunitense si può rintracciare nel seguente indirizzo: http://www.nbcnews.com/id/21065954/ns/meet_the_ press/t/meet-press-transcript-sept/\#.XeTx0y-h3e॰ (2019-12-02). 


\subsection{Note conclusive}

Questo capitolo si è aperto con una veloce panoramica sullo stato dell'arte nella letteratura sull'immagine. Volendo adottare un andamento circolare che consente di spaziare in altre direzioni e, allo stesso tempo, di ritornare al punto d'avvio della riflessione, appare necessario in conclusione risalire brevemente all'accesa disputa teorica circa il rapporto tra immagine digitale e immagine analogica. Se si tiene conto delle immagini di tortura analizzate, si può affermare che la tecnologia digitale non ha alterato la dialettica tra realtà e immagine, semmai l'ha resa più complessa, veloce e intensa. Le violenze catturate nelle fotografie digitali di Abu Ghraib non sono meno vere e reali di quelle registrate nelle fotografie analogiche dei campi di concentramento di Birkenau o Auschwitz; la rappresentazione degli eventi realmente accaduti non è inficiata dal metodo di produzione e riproduzione dell'immagine (Marra 2006, 36). Da questa specifica prospettiva, ciò che davvero conta nella riproduzione fotografica (o filmica) della realtà - sia essa digitale o analogica - è il ruolo che l'autore di tali immagini decide di assumere nel rapporto tra immagine e realtà $(2006,79)$. Il digitale offre maggiori possibilità di falsificazione rispetto all'analogico, ma questo non rende automaticamente falsa ogni immagine fotografica, o filmica.

Non può dirsi radicalmente modificato neanche l'uso propagandistico delle immagini di tortura. L'elemento di differenza - e non si tratta di una differenza di poco conto - è da rintracciare nelle maggiori possibilità di produzione, riproduzione e circolazione delle immagini digitali. La trasformazione della fotografia della tortura in tortura fotografica si impernia esattamente in questa importante differenza.

La maggiore diffusione delle immagini di tortura, nonché la (ri)produzione più facile e veloce di esse, generano conseguenze nella formazione delle immagini mentali, ossia contribuiscono, secondo la teoria sartriana dell'immagine, alla costruzione del rapporto tra coscienza e tortura. Le innumerevoli immagini di tortura contenute nelle più recenti serie televisive finiscono per condizionare proprio questo rapporto, essendo anche parte di un sistema di produzione fondato sulla competizione e mercificazione, trasformano l'immagine della tortura in mero entertainment, utile a creare una fidelizzazione crescente del pubblico e, non di meno, a promuovere la vendita di merci. David Danzig (2012) ha evidenziato come gli sceneggiatori e i produttori delle serie televisive di maggiore successo guardino alla tortura dal punto di vista dell'intrattenimento. Le parole di Jeff Pinkner, produttore esecutivo di Lost (2004-10), sintetizzano efficacemente l'approccio di tutti i suoi colleghi sull'argomento: 
Onestamente, quando si guarda una scena di interrogatorio o di tortura e si cerca di decidere se includerla o meno, si riduce tutto al valore dell'intrattenimento. Secondo noi, cosa catturerà l'attenzione del pubblico? (Danzig 2012, 27)

La tortura rappresentata nelle immagini delle serie televisive post $11 / 9$ si nutre, a sua volta, di memorie che, per parafrasare ancora De Martino (2002), sorreggono 'la rocca dell'ovvietà', una rocca che risulta affollata di stereotipi razzisti. La tortura, infatti, nella quasi totalità dei casi, è (quasi) sempre usata nei confronti di personaggi di colore, origine araba o religione musulmana, contribuendo in tal modo a rinvigorire gli stereotipi razzisti già circolanti nel quotidiano. I soggetti che appartengono a queste categorie sono rappresentati come membri della razza dei torturabili e la tortura è considerata il suo più efficace demarcatore.

Le immagini, come si è cercato di dimostrare, sono lo strumento ermeneutico più adatto alla descrizione della tortura contemporanea, la quale però nasce e si sviluppa in un determinato contesto sociale, economico e politico; un contesto che implicitamente o esplicitamente le assegna un ruolo importante per la propria riproduzione. Nel capitolo successivo si cercherà di analizzare proprio questo ruolo. 



\section{Critica sociologica del supplizio postmoderno}

Sommario 2.1 I corpi-classe sotto tortura. - 2.2 La classe dei torturati, in passato. 2.3 La classe sociale dei torturati, nella tarda modernità. -2.4 Guerra e tortura dopo l'11 settembre. -2.5 La divisione del lavoro nella tortura. -2.6 La stanza delle torture. -2.7 II segreto del torturatore. -2.8 Note conclusive.

La tortura si è stabilita lì da sé: è stata prodotta dalle circostanze e richiesta dall'odio razzista; in un certo modo [...] è al centro del conflitto e forse è ciò che esprime la sua verità più profonda. (Sartre 2019b, 103)

Il danno che stavamo facendo a questi ragazzi, sia fisico che psicologico, era molto più grave e duraturo di un colpo alla testa. [...] Ho messo il prigioniero in una posizione di stress, ma è stato il suo stesso peso a causare il dolore. L'ho lasciato fuori tutta la notte, ma è stato il freddo che gli ha causato disagio. Gli ho impedito di dormire, ma è stata la stanchezza a sconvolgergli la psiche. Ero separato dal suo dolore da almeno un nesso causale. [...] Questa è la torturata logica della tortura. Il punto fondamentale è che tutti noi abbiamo seguito questo percorso mentale contorto perché volevamo farlo. (Lagouranis, Mikaelian 2007, s.p.)

\subsection{I corpi-classe sotto tortura}

Henri Alleg, autore de La question (1958), durante un'intervista realizzata nel 2014, spiegò così il suo approccio alla tortura: «Occorre disfarsi della domanda morale se la tortura debba essere usata o meno. La vera domanda è: perché spingono delle persone a tortura- 
re delle altre?» (Célérier 2014, 157). Questa domanda ha il merito di sottrarre la tortura dall'analisi astratta o moralistica. Alleg, infatti, non la considera un accidente della storia, espressione della malvagità innata degli esseri umani, oppure estrema manifestazione di comportamenti devianti dei singoli; al contrario, le attribuisce il carattere di un fenomeno storico-sociale. Affermare l'esistenza di una spinta che induce «delle persone a torturare delle altre», significa presupporre che nella società contemporanea vi siano delle dinamiche (oggettive e soggettive) o forze capaci di creare le condizioni per la realizzazione della tortura e che questa, di conseguenza, svolga una qualche funzione nella riproduzione di tale modello di società. Se queste dinamiche o forze sono reali, lo sforzo per individuarle non può che partire dall'analisi dell'oggetto della tortura, vale a dire dai torturati, da coloro sui quali si scarica tutta la sua violenza.

Bisogna irrompere allora nelle stanze delle torture per conoscere le vittime. Le lacrime, la stanchezza, le ecchimosi, gli arti fratturati, la pelle bruciata, il sangue grondante, i denti rotti e tutti gli altri segni della violenza scagliata su di loro non devono distrarre; conoscere i torturati significa, prima di tutto, conoscere la loro storia sociale, chi erano prima di finire sotto tortura. Per riuscirci non è sufficiente la visione dei verbali della tortura (quando esistono), dove al massimo si segnano la nazionalità, il genere e l'età.

Si potrebbe obiettare rilevando che la storia sociale delle vittime non conta quando queste entrano nella torture room. Lì dentro, le vittime sono spogliate di tutto, di ogni identità, poiché il bersaglio principale è il loro corpo e, si sa, i corpi si somigliano nella loro sostanza biologica. Lì dentro il potere penetra direttamente nei corpi, diventando ciò che Michel Foucault (2005) ha definito biopolitica. Questa è intesa come una pratica di esercizio del potere (sviluppatasi in Occidente a partire dal XVII secolo) nei confronti degli esseri umani intesi come popolazione, che disciplina e regola sia il corpo-organismo dei singoli sia il corpo-specie della popolazione. La storia sociale dei corpi è un omissis nella biopolitica foucaultiana; non a caso, infatti, non vi sono cenni sul corpo-ceto o corpo-classe. Il corpo di un bracciante non è ritenuto dissimile da quello di un proprietario terriero. In Sorvegliare e punire, ${ }^{1}$ ad esempio, dove si analizza la metamorfosi dei sistemi punitivi, Foucault apre la propria riflessione descrivendo dettagliatamente il supplizio di Damien, condannato a «fare confessione pubblica davanti alla porta principale della Chiesa di Parigi»

1 Questo libro di Michel Foucault è ormai considerato uno dei testi più influenti in sociologia e contiene uno dei resoconti più letti sulla tortura premoderna (Simon 1998). Foucault, diversamente da altri autori, non separa la 'tortura giudiziaria' dalla 'tortura penale', perché è maggiormente interessato ad analizzare le modalità con le quali si esercita il potere, piuttosto che a tipizzare le torture premoderne. Non a caso, infatti, egli le unisce tutte nell'espressione «la lugubre festa punitiva» (Foucault 1976, 10). 
(Foucault 1976, 5). Egli si dilunga in ben tre pagine a illustrare come un condannato del 1757 fosse torturato pubblicamente e poi squartato, pezzo dopo pezzo, con gli strumenti dell'epoca, fino alla morte. Ci informa del ruolo e delle attività dei tecnici attorno al condannato, i quali vengono socialmente qualificati: si può conoscere il boia Samson, il cancelliere Le Breton, i confessori, gli aiutanti, e altre figure tecniche. Damien-il torturato, invece, non è socialmente qualificato, nulla si sa del suo mestiere o del suo status sociale; l'unica cosa nota è che fosse un parricida. Il corpo lentamente squartato di Damien potrebbe appartenere a chiunque, a un individuo povero così come a uno ricco, a un carpentiere così come a un banchiere. Foucault non manca, però, qualche pagina dopo, di informare i lettori del fatto che, nella modernità:

È in gran parte come forza di produzione che il corpo viene investito da rapporti di potere e di dominio, ma, in cambio, il suo costituirsi come forza di lavoro è possibile solo se esso viene preso in un sistema di assoggettamento (in cui il bisogno è anche uno strumento politico accuratamente preordinato, calcolato e utilizzato): il corpo diviene forza utile solo quando è contemporaneamente corpo produttivo e corpo assoggettato. (Foucault 1976, 29)

L'affermazione è importante perché mette in relazione diretta la sfera della produzione con quella del sistema repressivo/punitivo, ma appare più un'annotazione di superficie che uno strumento centrale dell'analisi foucaultiana, nella quale la dimensione dell'economia politica è pressoché inesistente. Non cambia il giudizio neanche con riferimento alle lezioni tenute al corso del Collège de France tra il 1978-79 e in seguito pubblicate in Nascita della biopolitica (Foucault 2005), dove egli mette in campo il liberalismo per spiegare la biopolitica. Il liberalismo di cui narra Foucault si riferisce essenzialmente alle tecniche di «governamentalità» e al «regime di verità». Non vi sono riferimenti specifici al sistema di produzione, alle sue leggi del profitto e alle modalità con le quali tale sistema interviene nella gestione della vita (e dei corpi) dei soggetti, cioè di coloro che per vivere devono vendere al mercato la loro forza lavoro, ${ }^{2}$ salvo pochi, veloci e superficiali cenni a un (metafisico) mercato:

Mi sembra che l'analisi della biopolitica non si possa fare senza aver compreso il regime generale di questa ragione governamentale di cui vi sto parlando, regime generale che si può chiamare questione di verità, in primo luogo della verità all'interno della ra-

2 Foucault menziona, al massimo, i 'consumatori', riducendo così il liberalismo alla sfera della circolazione, eliminando dall'orizzonte analitico la produzione. 
gione governamentale, e di conseguenza se non si comprende bene di che cosa si tratta in questo regime che è il liberalismo, [...] e una volta che avremo saputo che cos'è questo regime governamentale chiamato liberalismo potremo sapere cos'è la biopolitica. (Foucault 2005, 23)

Può dirsi altrettanto del concetto di biopolitica di Agamben (2003), il quale, correggendo Foucault, pensa che la sovranità sia tout court biopolitica, avendo il sovrano il potere di imporre lo stato di eccezione e di decidere sulla vita e sulla morte di individui e popolazioni: «Lo stato di eccezione, in cui la nuda vita era, insieme, esclusa e catturata dall'ordinamento, costituiva, in verità, nella sua separatezza, il fondamento nascosto su cui riposava l'intero sistema politico» (Agamben 2003, 12). Per Agamben il potere è sempre biopotere perché è capace di inscrivere la propria azione direttamente nel corpo, ovvero nella «nuda vita». Menzionare nella vigna dei testi il liberalismo, il capitale o il mercato - come fa Agamben in diversi suoi libri - non equivale all'adozione di tali categorie come strumenti di analisi e neanche a inquadrare i corpi, la «nuda vita», dentro una storia sociale. A dominare la sua analisi è l'elemento politico.

Entrambi questi concetti (di biopolitica), pur nella loro relativa diversità, pensano la politica senza la polis in carne ed ossa (perché la polis alla quale si riferiscono è essenzialmente priva di radici o articolazioni sociali) e, di conseguenza, non consentono un'adeguata conoscenza dei torturati, impedendo così l'individuazione di una risposta alla domanda di Alleg (1958): «perché spingono delle persone a torturare delle altre?». Più utile, a questo scopo, appare la biopolitica elaborata da Karl Marx, soprattutto nella sua opera più importante, Il capitale. Marx considera i corpi dentro la loro storia sociale, perché ogni corpo ha una storia sociale. Per capire il corpo (e la biopolitica) - spiega - bisogna partire dal concetto di lavoro:

In primo luogo il lavoro è un processo che si svolge fra l'uomo e la natura, nel quale l'uomo, per mezzo della propria azione, media, regola e controlla il ricambio organico fra se stesso e la natura: contrappone se stesso, quale una fra le potenze della natura, alla materialità della natura. Egli mette in moto le forze naturali appartenenti alla sua corporeità, braccia e gambe, mani e testa, per appropriarsi i materiali della natura in forma usabile per la propria vita. Operando mediante tale moto sulla natura fuori di sé e cambiandola, egli cambia allo stesso tempo la natura sua propria. (Marx 1989, 211-12)

Nel sistema di produzione capitalistico, il lavoro è sempre «uso di forza-lavoro» e il lavoratore è «forza-lavoro in azione» $(1989,211)$. La differenza con i sistemi del passato è individuabile, secondo Marx, nel 
processo di vendita, per un tempo determinato, delle energie psicofisiche da parte del lavoratore e del loro acquisto da parte del capitalista (possessore dei mezzi di produzione):

L'antico possessore del denaro va avanti come capitalista, il possessore della forza-lavoro lo segue come suo lavoratore; l'uno sorridente con aria d'importanza e tutto affaccendato, l'altro timido, restio, come qualcuno che abbia portato al mercato la propria pelle e non abbia ormai da aspettarsi altro che la... conciatura. (Marx 1989, 209)

Coloro che per vivere sono costretti a vendere la propria forza-lavoro, che non possiedono null'altro da scambiare al mercato se non le proprie energie psico-fisiche, che sperimentano la povertà assoluta, sono consegnati alla sola dimensione della «corporeità immediata» (Marx 1976, 244): diventano «pelle» che non aspetta altro che la «conciatura». Si tratta di una corporeità che è manipolata dal capitale, che diventa, in ogni aspetto, subalterna ai suoi andamenti e processi (Finelli, Toto 2012). Partendo da questa idea di corporeità, Marx «mette in scena un'altra biopolitica» (Bidet 2012, 58), che non esclude il ruolo dello Stato, dei tecnici, del potere e del diritto dall'analisi, ma che completa il quadro collocando al suo interno altri elementi, in grado di rendere visibili i segni e le gerarchie imposte dal capitale.

Mettendo in campo la biopolitica marxiana - all'interno della quale i corpi non sono semplici corpi ma corpi-al-lavoro (Bidet 2012) - si può costruire anche un punto di vista particolare sulla tortura: questa può essere ora osservata come un fenomeno sociale collocato all'interno delle dinamiche del mercato, perché i corpi dei torturati - sia prima che dopo l'atto di tortura - sono oggettivamente immersi in tali dinamiche.

\subsection{La classe dei torturati, in passato}

Michel de Certeau, parafrasando l'antropologo Pierre Clastres (1977), afferma che: «La tortura costituisce l'iniziazione per eccellenza alla realtà delle pratiche sociali» (de Certeau 2006, 200). Invero, molteplici studi storici, antropologici e sociologici hanno dimostrato che la tortura non è un fenomeno recente. Esecuzioni, torture e mutilazioni sono fenomeni che hanno caratterizzato le società umane sin dall'età del ferro; si trattava di società fortemente stratificate attorno a forme di governo patrimoniale. Questa stratificazione si traduceva in relazioni di dominio, trasformando i confini morali estesi lungo le linee etnico/religiose in confini della stratificazione patrimoniale. Così, l'estrema punizione dei gruppi collocati negli strati 
più bassi da parte di quelli collocati in alto non solo era ritenuta moralmente neutrale, ma spesso era rappresentata come un'autodifesa del gruppo dominante, assumendo di conseguenza un valore morale positivo (Collins 1974, 421). Da qui il carattere pubblico delle mutilazioni, delle torture e delle esecuzioni: assistendo alle violenze, i gruppi dominati apprendevano che lo status di quelli dominanti non poteva essere minacciato o violato in alcun modo, non senza subire le punizioni più atroci.

In seguito, la tortura si è progressivamente stabilizzata, fino a diventare parte strutturale dei sistemi giuridici:

Per secoli diritto, sistema giuridico e tortura hanno rappresentato una coppia certo male assortita e tuttavia fedele e affettuosa. La tortura è stata a lungo parte del diritto processuale penale e le biblioteche giuridiche sono colme di dotte trattazioni nelle quali si insegna come e quando bisogna torturare nell'ambito del processo giudiziale. La tortura per vari secoli è stata materia di insegnamento e, sì pure, di studio e ricerca nelle facoltà di Giurisprudenza. Vari grandi giuristi sono stati teorici della tortura e in qualche caso persino torturatori essi stessi. (La Torre, Lalatta Costerbosa 2013, s.p.)

Nell'antica Grecia la tortura era il mezzo attraverso il quale ottenere le prove durante il processo, una specie di test della verità, che poteva essere usato soltanto nei confronti di alcune categorie sociali: gli schiavi e gli stranieri. La tortura, infatti, non era ammessa nei confronti dei cittadini liberi. Lisa Hajjar, nel suo libro Torture: A Sociology of Violence and Human Rights (2013), elenca le motivazioni alla base di questo particolare trattamento riservato agli schiavi (e agli stranieri):

Le motivazioni alla base della tortura degli schiavi erano fondate sull'idea che (a) lo stato servile di questi rendesse impossibili delle dichiarazioni veritiere spontanee, perché (b) la paura di essere puniti dal padrone li avrebbe indotti spontaneamente a mentire, e quindi (c) solo attraverso il dolore gli schiavi avrebbero potuto affermare la verità. Le dichiarazioni estorte con la tortura erano considerate delle prove. (Hajjar 2013, s.p.)

Assai simile si presentava la situazione nell'antica Roma. Il diritto romano, sin dagli inizi, riteneva lecita la tortura degli schiavi. Con il consolidamento dell'impero e la divisione complessiva della società in honestiores (il ceto dirigente) e humiliores (tutti gli altri), si ampliò anche la base della popolazione torturabile: gli humiliores potevano essere sottoposti a torture processuali e i condannati potevano subire punizioni che un tempo erano riservate ai soli schiavi (Hajjar 2013). Edward Peters $(1996,18)$ segnala che, con il passare del tempo, divenne ammis- 
sibile anche la tortura degli honestiores, ma soltanto con riferimento a particolari tipologie di delitti gravi, come ad esempio il tradimento. ${ }^{3}$

Nella Grecia antica e nell'Impero Romano, la popolazione torturabile rappresentava la maggioranza dell'intera popolazione, perché questa era composta essenzialmente «da schiavi provenienti dalla Grecia, da Roma, dai Balcani, e dal Mediterraneo settentrionale» (Jaffe 2010, s.p.). La struttura sociale e il modo di produzione schiavistico - caratteristica tipicamente europea - poggiava sull'ipersfruttamento e «l'abuso spesso tirannico degli schiavi» (Jaffe 2010). In un siffatto sistema, la tortura assumeva una triplice funzione: (1) marcare ufficialmente lo status inferiore di schiavi e humiliores, cioè di coloro sui quali poggiava l'intero sistema di produzione; (2) sfruttare la potenza pedagogica della tortura per insegnare a tutti la sottomissione all'autorità; (3) dividere la società in due gruppi sociali distinti: i 'torturabili' e i 'non torturabili'. Nel saggio storico di Piero Fiorelli, La tortura giudiziaria nel diritto comune (1953), è stato evidenziato in modo efficace lo stretto legame tra tortura e classe sociale:

le gravi disuguaglianze sociali che in quell'età si conservarono, determinarono la sostituzione alle ordalie di mezzi di prova diversi da classe a classe. La testimonianza era la prova fondamentale. Ma l'uomo libero la doveva convalidare con proprio giuramento e coll'altrui mallevadoria; lo schiavo non era creduto se non l'avesse confermata tra gli spasimi della tortura. Gli schiavi erano cose. Come cose, non si poteva logicamente ammettere che riconoscessero la forza innata del vero e la santità del giuramento. Come cose, non se ne potevano saggiare la veridicità se non colla prova di sofferenze materiali. (Fiorelli 1953, 13)

Si può affermare, pertanto, che i torturati dell'antichità appartenevano - nella stragrande maggioranza dei casi - alle classi sociali più povere e sfruttate, ai membri delle quali non venivano riconosciute le qualità umane, in quanto considerati degli oggetti, esseri cosificati. La tortura svolgeva in questo contesto la funzione di demarcatore sociale:

Le economie schiavistiche hanno sempre richiesto il supplizio fisico intenzionale, ed è difficile immaginare di poter organizzare la schiavitù in un modo in cui tale dolore costituisca una caratteristica accessoria. (Rejali 2009, 38)

3 Il dibattito storico su questo specifico punto è ricco e controverso. Per una sua ricognizione si rinvia al testo di Carmela Russo Ruggeri, Quaestiones ex libero homine. La tortura degli uomini liberi nella repressione criminale romana dell'età repubblicana e del I secolo dell'Impero (2002). 
Nell'alto Medioevo gli schiavi e gli humiliores - compresi quelli presenti nei regni barbarici (Levack 2008) - continuarono a conservare la qualifica di 'classe torturabile', ma la concezione privatistica dei delitti e del processo penale, la contaminazione del diritto con quello di altre popolazioni del nord nonché la segmentazione del potere e delle proprietà portarono a «un parziale silenzio della tortura» (La Torre, Lalatta Costerbosa 2013). Fu nel basso Medioevo, infatti, che la tortura giudiziale tornò prepotentemente in scena per continuare a colpire con maggiore intensità le stesse classi sociali, selezionando però all'interno di queste dei soggetti specifici: le donne. È in questo momento che la storia della tortura si intreccia con quella della stregoneria. Dal XV al XVIII secolo, le donne divennero il bersaglio privilegiato della tortura, attraverso la quale si condusse nei loro confronti una vera e propria guerra (Sallmann 1991; Ginzburg 1973; Vivan 1972). Fu la tortura, infatti, a trasformare la 'caccia alle streghe' in un fenomeno sociale di massa:

Le confessioni relative ad atti di satanismo [...] venivano frequentemente estorte con la tortura o con la minaccia della tortura. Le ammissioni di colpa ottenute in questo modo erano manifestamente inficiate: era probabile che un accusato confessasse ciò che il torturatore voleva sentirsi dire e non ciò che aveva realmente commesso. In Europa, nel Sei e Settecento, quasi tutti i giudici, sia ecclesiastici che secolari, avevano un'idea molto rigida e preconcetta delle pratiche sataniche delle streghe [...] Con il ricorso a strumenti di tortura estremamente efficaci le costringevano spesso a confessare di avere stretto un patto col diavolo e di essersi riunite ad adorarlo. Poi, nel tentativo di spazzare via l'intera setta delle streghe, le torturavano di nuovo per ottenere i nomi dei loro presunti complici. La prova più evidente dell'esistenza di una stretta relazione tra la tortura e la confessione di pratiche sataniche è che in genere [...] le accuse di satanismo venivano formulate durante la tortura. [...] La tortura, in un certo senso 'creò' la stregoneria. (Levack 2008, 22-3)

Le torturate, come si è già accennato, erano donne appartenenti alle classi sociali più povere e, non di rado, erano anziane:

È di norma la classe più debole, quella delle donne anziane, strane, vedove, nubili e povere, il capro espiatorio del panico sociale, alimentato dall'autorità politica per la propria sicurezza, per spiegare e neutralizzare le sciagure naturali e le epidemie, ma anche la crisi delle classi più povere a fronte della nascita del capitalismo agrario. (La Torre, Lalatta Costerbosa 2013, s.p.) 
La 'caccia alle streghe' ebbe luogo in un contesto particolare, colmo di cambiamenti sociali epocali. La diffusione senza precedenti della povertà fu alla base della radicale trasformazione sia della vita rurale che di quella urbana. I tre tipi di capitalismo nascente - agrario, commerciale e industriale - esigevano la creazione di un mercato di manodopera a basso costo, il quale richiedeva, a sua volta, la costruzione di un sistema sociale fortemente gerarchico (Geremek 1986). La 'caccia alle streghe' era una delle risposte ai bisogni crescenti del nuovo sistema di produzione: mirava a svalorizzare la forza lavoro femminile, la più richiesta dal 'libero' mercato insieme a quella dei bambini, e allo stesso tempo a imporre una gerarchizzazione di genere all'interno della nascente classe dei lavoratori 'liberi'. Il legame tra tortura e stregoneria nasconde, nelle sue pieghe, il legame tra tortura e capitale.

Non va dimenticato che il forte ritorno della tortura come strumento di controllo delle classi povere e sfruttate in Europa si verifica contemporaneamente alla colonizzazione delle Americhe - e, in seguito, di altri territori sparsi in ogni angolo del mondo - da parte di diversi Stati europei. Luciano Parinetto, profondo conoscitore del fenomeno della stregoneria in Occidente, ha saputo gettare luce sullo stretto rapporto tra la 'caccia alle streghe', l'ipersfruttamento delle popolazioni colonizzate e il sistema di produzione capitalistico:

Le grandi persecuzioni delle streghe in occidente non sarebbero affatto un orroroso lascito d'un affabulato 'buio' Medioevo, che inquina la luce del Rinascimento e gli albori dell'età moderna, ma, invece, una consapevole applicazione di metodi politici dello sterminio, in vista della dominazione, sperimentati con successo dal potere durante le cruenti vicende di assoggettamento dei popoli amerindi, da parte dei primi colonizzatori dell'America, ed esportati nella vecchia Europa, sempre in vista dell'imposizione del dominio. L'originario capitale, cioè, streghizza il Vecchio e il Nuovo mondo, non solo per dominare/annientare ogni tentativo di opposizione o di ribellione, ma rinvenendo nel lavoro mal pagato (o addirittura forzato) degli indios (superstiti di un'immane carneficina) lo schema stesso mediante il quale avvierà le masse dei miserabili, dei mendicanti, dei diversi del Vecchio mondo sulla via del cosiddetto 'libero mercato del libero lavoro', che sono il basamento stesso della valorizzazione. Sicché la strega [...] diventa inaspettatamente una delle figure originarie del cosiddetto 'libero lavoro del capitale'! (Parinetto 1997, 8)

Nella vasta letteratura storica (Churchill 1997; Jaffe 2010; Stannard 2001; Todorov 2014) sul colonialismo e i suoi crimini, è stato ampiamente dimostrato come il ricorso massiccio alla tortura (accanto ad altre misure di oppressione, sfruttamento e terrore, s'intende) abbia con- 
sentito l'instaurazione e il consolidamento del sistema coloniale europeo, sia nelle Americhe che altrove. È stato nelle colonie che si è realizzato l'incontro tra tortura e razzismo moderno - incontro dal quale si è generata una solida coalescenza che tuttora persiste e che costituisce il suo fondamento logico e ontologico - perché quest’ultimo, così come oggi lo conosciamo, ha un luogo e una data di nascita: è nato nelle colonie durante il colonialismo (Basso 2000, 2010). Il razzismo moderno, come ha efficacemente spiegato Immanuel Wallerstein, «non ha niente a che fare con gli 'stranieri'» (1985, s.p.) o con la xenofobia, perché a produrlo non è un pregiudizio culturale o ideologico, ma la necessità (strutturale) del capitalismo di creare ovunque gerarchie:

Ciò che intendiamo per razzismo ha poco a che fare con la xenofobia che esisteva in vari sistemi storici precedenti. La xenofobia era, letteralmente, paura dello 'straniero'. Il razzismo interno al capitalismo storico non ha niente a che fare con gli 'stranieri'. Tutto al contrario. Il razzismo è stato il modo con cui vari segmenti di forza-lavoro interni alla stessa struttura economica sono stati costretti a porsi in relazione gli uni agli altri. (Wallerstein 1985, s.p.)

Per rapinare le terre e le risorse delle colonie nonché per sfruttare al massimo la manodopera locale occorreva creare un sistema che fosse capace di ridurre i colonizzati in sotto-uomini, cose, lavoratori sottomessi e ubbidienti. La risposta a tale bisogno strutturale del colonialismo fu il razzismo; si ribadisce, non un razzismo inteso come semplice paura dell'altro, ideologia o credenza, ma un razzismo-operazione che poggiasse interamente sulla violenza, che fosse esso stessa violenza, una violenza complessa con giustificazione incorporata:

Il razzismo deve farsi pratica: non è un risveglio contemplativo dei significati incisi nelle cose; è in sé una violenza che si dà la propria giustificazione: una violenza che si presenta come violenza indotta, contro-violenza e legittima difesa. (Sartre 1960, 677)

Se il razzismo contemporaneo è inteso come violenza, diventa inevitabile individuare la sua fonte primaria nello Stato: «Il monopolio dell'uso legittimo della forza fisica» (Weber 1998, 178) e della «violenza simbolica» (Bourdieu 2013) appartiene allo Stato. Del resto, nelle colonie (dal XV secolo in poi), l'occupazione, l'espropriazione delle terre, la cacciata dei braccianti, il reclutamento, il lavoro forzato, le istituzioni politico-amministrative, le politiche sanitarie, l'istruzione, etc., fino alla repressione e alla tortura, sono state tutte operazioni sostenute finanziariamente e realizzate concretamente dagli Stati colonizzatori.

La tortura è servita per marchiare e atrofizzare i corpi (e le anime) dei colonizzati, per renderli servili, sottomessi, piegati, il che si 
traduceva in conferma della loro inferiorità. La tortura è stata uno dei più importanti strumenti utilizzati dalle potenze coloniali per segnare un confine invalicabile tra le 'razze' nei territori coloniali, dagli inizi fino alla fine del colonialismo storico. L'esperienza coloniale europea si presenta, in questo senso, come un lungo catalogo di orrori.

La funzione primaria del razzismo-violenza è quella di spezzare e umiliare i colonizzati/sfruttati, distruggere il loro coraggio, la loro volontà e intelligenza. Nella sua essenza è una violenza disumanizzante che mira a mantenere la propria vittima tra la vita e la morte, la vuole annullare ma mai del tutto, perché la vittima deve pur sempre continuare a servire e lavorare, a obbedire agli ordini, ma come una bestia, come uno zombie (Sartre 1960, 678). Se il razzismo è concepito come violenza, diventa facile comprendere come la tortura possa rappresentare la sua verità estrema, essendo la tortura la forma più estrema della violenza. Non è di certo per caso, infatti, che tortura e razzismo condividono lo stesso obiettivo: entrambi vogliono distruggere l'uomo, senza però farlo morire, perché ciò che davvero vogliono è cancellare le sue qualità umane.

Se la tortura aveva - de jure et de facto - imposto, sin dall'inizio, il proprio dominio nelle colonie, a partire dalla seconda metà del diciottesimo secolo che essa veniva ufficialmente messa al bando nei Paesi occidentali. Dalle rivoluzioni borghesi dell'epoca, nate per abbattere le tirannie monarchiche e anche il vecchio sistema di produzione (di tipo feudale), si generò una nuova concezione del diritto, che non contemplava più la presenza stabile della tortura negli ordinamenti, perché questa era considerata una «tirannia in un microcosmo» (Luban 2005, 438). «La modernità giuridica» si fondava sostanzialmente sull'«abolizione della tortura come pena, come strumento di prova nel processo e come pratica di polizia» (La Torre, Lalatta Costerbosa 2013, s.p.).

Paradossalmente, proprio nel momento in cui maggiore era stato il suo utilizzo e cruciale si era rivelato il suo ruolo nella produzione/ riproduzione del sistema socio-economico della modernità, la tortura scompariva dal palcoscenico della storia occidentale, ma per continuare a operare intensamente nell'ombra, da dietro le quinte. Va da sé che queste conquiste formali in materia di diritti umani non potevano riguardare le popolazioni colonizzate, i diritti dell'uomo erano appunto per gli uomini, non per i sotto-uomini:

Il colonialismo nega i diritti dell'uomo agli uomini che ha sottomesso con la violenza, che mantiene con la forza nella miseria e ignoranza, cioè, come direbbe Marx, in uno stato di 'sotto-umanità'. [...] poiché l'indigeno è un sotto-uomo, la Dichiarazione dei Diritti dell'Uomo non lo riguarda; al contrario, poiché non ha dei diritti, egli è abbandonato senza protezione alle forze inumane della natura, alle 'leggi ferree' dell'economia. (Sartre 1964, 51) 


\subsection{La classe sociale dei torturati, nella tarda modernità}

La tortura iniziò a essere abolita formalmente a partire dalla Costituzione degli Stati Uniti nel 1787 (emendamenti V e VIII del 1791), seguita dalla Dichiarazione dei Diritti dell'Uomo e del Cittadino nel 1789 e anche dalla Costituzione spagnola di Cadice nel 1812. Tre degli Stati che avevano fatto maggiore uso della tortura - per scopi di dominio e sfruttamento - decisero di cancellare ogni legame formale con essa a cavallo tra il diciottesimo e il diciannovesimo secolo. Da questo momento in poi, l'opposizione sociale e politica alla tortura continuerà a crescere progressivamente in Occidente. Ė nella seconda metà del ventesimo secolo, però, subito dopo la Seconda guerra mondiale, che la tortura subirà un attacco generalizzato; in alcuni casi perfino con norme di rango costituzionale (art. 1, co. 1 della Costituzione tedesca del 1949). Altrettanto significativo risulta l'impegno internazionale per l'abolizione della tortura: Dichiarazione universale dei diritti dell'uomo (1948); Convenzione di Ginevra per il trattamento dei prigionieri di guerra (1949); Convezione europea per la salvaguardia dei diritti dell'uomo (1950); Patto internazionale per i diritti civili e politici (1966); Convenzione delle Nazioni Unite contro la tortura (1984); Convenzione europea per la prevenzione della tortura (1984).

Nonostante il moltiplicarsi dei divieti a livello internazionale e la progressiva criminalizzazione nell'ambito degli ordinamenti nazionali, la tortura non ha mai smesso di essere usata. «Più di due terzi dei governi del mondo fa ancora uso della tortura», afferma Lisa Hajjar (2013, s.p.) e i periodici report delle organizzazioni internazionali ne danno piena conferma. Sul sito web di Amnesty International campeggiano oggi le seguenti frasi: «Stiamo assistendo a una crisi globale sulla tortura. Negli ultimi cinque anni, Amnesty International ha riferito sulla tortura in 141 paesi - tre quarti del mondo» (Amnesty International 2019). Tra questi, numerosi sono gli Stati occidentali. Diventa inevitabile a questo punto una domanda: com'è possibile che la tortura sopravviva in Occidente, nonostante i numerosi divieti legali e i cambiamenti intervenuti nella forma degli Stati e dei governi (ora democratici)? In letteratura si è cercato di fornire una risposta a questa domanda: Darius Rejali, autore di Torture and Democracy (2009), non ritiene che la tortura dipenda da una specifica forma istituzionale e politica degli Stati, in quanto la democrazia può serenamente convivere con la tortura a causa della propria ipocrisia e dei propri bisogni di sicurezza; secondo lui, si tratta piuttosto di comprendere le forme di tale convivenza (Rejali 2009). Secondo Agamben (2009), la mancata rescissione del legame tra tortura e democrazia non farebbe altro che rivelare il vuoto al centro di ogni sistema democratico, o meglio, come ha esplicitato Di Cesare, che il «mistero della politica» non sia «la legge, ma la polizia» (2016, s.p.). Queste spiegazioni, assai suggestive, mancano di evidenziare il legame strutturale tra for- 
ma di Stato e di governo e contesto socio-economico. La loro analisi sul nesso tra potere e tortura, interamente fondata sulla dimensione politica, non consente di vedere quel diffuso e invisibile filo che lega storicamente e geograficamente tutte le esperienze di tortura (e che ne fornisce alla fine la spiegazione di fondo), ovvero la condizione sociale dei torturati e il loro specifico ruolo nel sistema di produzione, che è alla base del (bio)potere e del sistema politico.

Geoffrey Skoll (2010) afferma che, nel Secondo dopoguerra, la tortura nei Paesi occidentali si è sviluppata essenzialmente in tre ambiti importanti: (1) nell'ambito della 'guerra fredda', che abbraccia un periodo che va dal 1945 al 1989; (2) nell'ambito della risposta repressiva degli Stati ai movimenti sociali degli anni Cinquanta e Sessanta; (3) nell'ambito delle misure anti-terrorismo degli anni Settanta (del ventesimo secolo). A fare da guida in questo condiviso percorso sono gli Stati Uniti, il cui governo già pochi mesi dopo la caduta del regime hitleriano - prima con Operation Overcast (luglio 1945) e poi con Operation Paperclip (settembre 1946) - iniziò a reclutare membri delle SS, scienziati e medici nazisti che avevano accumulato una vasta esperienza nelle torture di massa realizzate nei campi di lavoro e concentramento in Europa (Shirer 1962): ${ }^{4}$ tra il 1945 e il 1955, gli Sta-

4 Appare doverosa qui una nota sul ruolo della tortura nel regime nazista e nei suoi campi di concentramento. L'ipersfruttamento lavorativo delle popolazioni occupate dall'esercito hitleriano, così come delle categorie sociali considerate razzialmente inferiori (ebrei, rom, omosessuali, etc.), non era un obiettivo secondario rispetto alla loro umiliazione, detenzione ed eliminazione. I campi di sterminio, infatti, prima di diventare tali nell'ultima fase del regime, furono costruiti principalmente come campi di lavoro (forzato). William Shirer (1962) ne fornisce numerose prove. Vale la pena riportare qui, per brevità, soltanto quanto annotato da Martin Bormann, fedele segretario del Führer, a proposito di quanto da questi dettato al governatore nazista della Polonia occupata: «In Polonia bisogna tener basso il tenore di vita. [...] Il governatorato generale deve servirci solo come una riserva di operai non qualificati. Di là, ogni anno, potremo procurarci gli operai di cui il Reich abbisogna» (in Shirer 1962, 1016). Così come accaduto nei sistemi coloniali, le uccisioni e le torture sono servite a svalorizzare, in senso radicale, la forza lavoro. Tale svalorizzazione costituiva la base sociale ed economica per la costruzione del potere nazista; senza una forza lavoro a basso costo (o a costo zero) non sarebbe stato possibile costruire un'industria potente, ciò che avrebbe poi fornito gli strumenti e la tecnologia necessaria all'esercizio concreto del dominio da parte del potere nazista in ogni angolo dell'Europa. A dirla tutta, senza una forza lavoro ipersfruttata e sottomessa, neanche i campi di concentramento, cioè l'emblema dello "stato d'eccezione», si sarebbero potuti materialmente realizzare e riprodurre. Shirer calcola che nel 1944, oltre ai milioni di ebrei, rom e oppositori politici detenuti nei campi, vi erano altri 7,5 milioni di lavoratori stranieri a lavorare in Germania per il Terzo Reich (Shirer 1962, 1024). Molti dei quali catturati con la forza per strada, nelle campagne, nelle chiese, nei luoghi di lavoro, in casa, etc. Un memorandum ritrovato nell'archivio di Rosemberg, intitolato «Operazione Fieno», con riferimento ai territori della Russia occupata, chiarisce bene il quadro: «Il gruppo delle armate di centro intende catturare da quaranta a cinquanta mila giovani di età tra i 10 e 14 anni per trasportarli in Germania. Lo scopo è di assegnare questi giovani, come apprendisti, a imprese tedesche. Questa misura sarà assai ben accolta dagli industriali tedeschi, perché rappresenta una misura decisiva per ovviare alla scarsità di apprendisti» (1962, 
ti Uniti accolsero settecentosessantacinque specialisti tedeschi, dei quali circa l'ottanta percento risultava essere stato membro del partito nazista o delle SS (Lasby 1975). In questo periodo, precisamente nell'aprile 1950, la CIA lancia l'Operation Bluebird per individuare e sviluppare nuove «tecniche di interrogatorio» (definizione eufemistica della tortura in democrazia). In questa operazione segreta, grazie anche alla collaborazione di diversi scienziati, la CIA riuscì a completare, nell'arco di un anno, un articolato manuale sulle «tecniche di interrogatorio»: il Kubark Counterintelligence Manual (Skoll 2010, 81). Il suddetto manuale ha guidato e ispirato le torture in molti Paesi, per molti anni, introducendo importanti modifiche rispetto al passato. Si può affermare che sia proprio con questo manuale che avvenga un cambio di paradigma nella tortura contemporanea: il corpo non è più l'unico bersaglio della sua violenza, perché a essere attentamente valorizzata nel processo è ora anche la mente del torturato. Non si punta più a procurare 'soltanto' dolore fisico, si cerca la progressiva privazione sensoriale del soggetto torturato, con il vantaggio di ottenere più velocemente il suo crollo psico-fisico, riuscendo anche, in molti casi, a non lasciare segni visibili sul corpo - elemento di non poco conto - rendendoli anche negabili, dunque. Le cinque tecniche principali, messe a punto nel manuale, consistevano in: (1) stare in piedi a ridosso del muro: costringendo gli interrogati a rimanere in posizione di stress; (2) incappucciamento: coprire le teste degli interrogati con una sacca o un cappuccio; (3) esposizione al rumore forte e continuo; (4) privazione del sonno; (5) riduzione e controllo della dieta.

Il manuale Kubark fu esportato in molti Paesi del mondo - alleati degli Stati Uniti nella 'guerra fredda' - dove fu arricchito di nuove, sofisticate e brutali tecniche. Dal 1960, per esempio, nei 18 Paesi latinoamericani nei quali furono instaurati regimi militari e autoritari, il manuale della CIA conobbe probabilmente il suo più vasto e sistematico uso. Il supporto degli Stati Uniti fu cruciale in questo processo. Non si trattava di una novità assoluta nelle sue politiche: il contributo della CIA, nel 1954, per il sovvertimento del governo democratico del Guatemala (Chomsky, Herman 1979) in favore di un regime di tortura e oppressione succede di un solo anno quanto similmente accaduto in Iran (Chomsky, Herman 1979), oppure di alcuni decenni quanto realizzato nelle Filippine (Chomsky, Herman 1979) all'inizio del ventesimo secolo. Robert McNamara, Segretario alla Difesa in due amministrazioni statunitensi, dal 1961 al 1968, lo ha esplicitato bene:

1025). Va da sé che, pur non mancando una rappresentanza della piccola o media borghesia, i grandi numeri della popolazione catturata, detenuta, umiliata, ipersfruttata e, perciò, torturata, proveniva dal proletariato, dai braccianti e dalle classi popolari. Parlare dei loro corpi assoggettati alla biopolitica dei campi, senza considerare lo scopo per il quale venivano catturati, detenuti e, in seguito, torturati - cioè per sgobbare nelle imprese tedesche - equivale a cancellare la loro storia sociale, o la storia tout court. 
Il nostro obiettivo primario in America Latina è di aiutare, ovunque sia necessario, la continua crescita delle forze militari e paramilitari, affinché insieme a quelle di polizia e altre forze di sicurezza, possano fornire la necessaria sicurezza nazionale. (Feitlowitz 1998, 10)

Il supporto degli Stati Uniti nella diffusione della tortura in America Latina e in altri Paesi si concretizzò anche attraverso l'addestramento dei torturatori locali: «Molti dei torturatori impararono il mestiere alla School of the Americas, gestita dall'esercito statunitense in Panama» (Skoll 2010, 83). La questione è stata ben sintetizzata nelle parole di Alan Dershowitz - noto docente di diritto a Harvard, neocon e sostenitore entusiasta della tortura - durante la trasmissione 60 Minutes della emittente CBS: ${ }^{5}$

Se qualcuno ha ancora dubbi sul fatto che la nostra CIA, nel corso del tempo, abbia insegnato alla gente a torturare, incoraggiato la tortura, probabilmente essa stessa torturato, allora io avrei un ponte da vendervi a Brooklyn.

Gli Stati Uniti - come hanno dettagliatamente spiegato Noam Chomsky ed Edward Herman nel loro libro The Washington Connection and Third World Fascism (1979) - hanno organizzato, subito dopo la Seconda guerra mondiale, «un sistema neocoloniale» (Chomsky, Herman 1979, s.p.), di tipo clientelare, composto da Stati «governati principalmente col terrore» (1979, s.p.), i quali facevano gli interessi di gruppi di imprese locali e internazionali:

Le brutte abitudini dei clienti statunitensi, compreso l'uso sistematico della tortura, sono funzionalmente collegate ai bisogni degli interessi commerciali statunitensi (e di altri), in quanto contribuiscono a soffocare i sindacati e a contenere le minacce che potrebbero interferire con la libertà d'azione delle imprese. (Chomsky, Herman 1979, s.p.)

Quanto accaduto in Cile, nel 1973, ne è una chiara conferma. In un Paese in cui si calcola (per difetto) che il numero dei torturati sia stato superiore a duecentomila persone (Stanley 2004), il legame tra tortura e capitale non richiede interpretazioni sofisticate, perché si rivela spontaneamente in tutta la sua articolata potenza:

5 La trasmissione 60 Minutes, intitolata «Legal Torture. Civil Libertarian Believes Torture Will Be Used in War on Terrorism», fu trasmessa dal CBS il 17 gennaio 2002. La trascrizione e la registrazione video dell'intervista sono disponibili all'indirizzo: https://www.cbsnews.com/news/legal-torture (2019-10-24). 
Il primo esperimento di creazione di uno stato neoliberista, vale la pena ricordarlo, si verificò in Cile, dopo il golpe di Pinochet, avvenuto l'11 settembre 1973 [...]. Il colpo di stato contro il governo democraticamente eletto di Salvador Allende fu organizzato dalle élite economico nazionali - che si sentivano minacciate dalla politica socialista promossa dal presidente - con l'appoggio delle grandi società americane, della Cia e del segretario di stato Henry Kissinger. Il golpe represse con la violenza tutti i movimenti sociali e le organizzazioni politiche della sinistra e smantellò qualsiasi forma di organizzazione popolare [...], mentre il mercato del lavoro veniva 'liberato' da restrizioni derivanti da regolamenti e istituzioni (come i sindacati). (Harvey 2007, s.p.)

Elisabeth Stanley, ponendo l'accento sul fatto che la tortura usata in Cile non riguardasse la necessità di raccogliere informazioni dai torturati, aggiunge ulteriore sostanza a tale legame:

i torturatori cileni spesso sapevano tutto sulla vita delle loro vittime e usavano la tortura come mezzo per dimostrare il loro potere e il potere dello Stato. I funzionari erano impegnati nella tortura per dimostrare alla vittima e ai suoi compagni che controllavano tutto, che erano al comando e potevano agire a piacimento. (Stanley 2004, 13)

L'instaurazione dello Stato neoliberista in Cile, così come la presa del potere da parte dei militari in altri Paesi, attraverso l'uso diffuso e sistematico della tortura, sono state le risposte del capitale globale ai segni «evidenti e diffusi di una grave crisi di accumulazione di capitale» (Harvey 2007, s.p.), avvertiti sin dagli anni Sessanta e poi esplosi negli anni Settanta: «Il colpo di stato in Cile e la presa del potere da parte dell'esercito in Argentina, promossi da settori dei ceti dominanti con l'appoggio degli Stati Uniti, rappresentarono un tipo di soluzione» (2007, s.p.).

Le vittime delle torture, nella maggioranza dei casi, provenivano dalle fila delle classi lavoratrici e popolari, oppure dalle loro organizzazioni sindacali e politiche. ${ }^{6}$ Questa considerazione, come si è già accennato, è valida anche con riferimento al fronte interno dei Paesi occidentali, compresi gli Stati Uniti: la risposta repressiva dei governi democratici dell'Occidente ai movimenti sociali e alle lotte sindacali di braccianti e operai degli anni Cinquanta, Sessanta e Settanta

6 Appare utile specificare, seppur velocemente, che, in molte aree del mondo, a essere inclusi nella 'classe dei torturati' vi sono stati anche dei rappresentanti della piccola e media borghesia. Questa constatazione non inficia la tesi del libro, ovvero che torturati appartengano (nella loro stragrande maggioranza) alle classi lavoratrici, semmai rivela le contraddizioni di classe nelle società contemporanee. 
si è spesso avvalsa della tortura. La letteratura scientifica sul punto è sterminata, ma un semplice sguardo alla composizione sociale della popolazione carceraria (Cassese 1994; Christie 2000; Wacquant 2009a, 2009b) - essendo le prigioni e le caserme i luoghi in cui maggiormente si usa la tortura, poiché questa ha bisogno di routinizzazione per diventare sistema (Kelman 1993) - è già un chiaro indice del fatto che i bersagli preferiti restano pur sempre le classi povere.

L'Italia, ovviamente, non ha rappresentato un'eccezione in questo quadro (Basso 1953). Il ricorso massiccio alla tortura da parte delle forze dell'ordine divenne un problema talmente grave negli anni del Dopoguerra, al punto da spingere diversi deputati e partiti politici a presentare numerose interrogazioni parlamentari. Il discorso di Piero Calamandrei alla Camera dei Deputati il 28 ottobre 1948 - riportato nel libro Hooligans di Stato (di Luzio 2019) - fornisce informazioni importanti sull'uso e sulla diffusione della tortura in Italia:

Ho voluto fare una specie di inchiesta privata e discreta fra gli avvocati e i magistrati... ho raccolto materiali impressionanti... Gli avvocati interpellati mi hanno risposto in via confidenziale, ma mi hanno fatto promettere di non dire pubblicamente i loro nomi perché essi sanno che se, nel rilevare quei metodi, precisassero dati e circostanze, verrebbero danneggiati i loro patrocinati: li esporrebbero a rappresaglie e persecuzioni, forse a imputazioni di calunnia, perché di fronte alle loro affermazioni non si troverebbe il testimone disposto a confermare che quanto dice l'imputato è vero. Accade così che il difensore, anche quando sa che il suo patrocinato è stato oggetto di vera e propria tortura per farlo confessare, lo esorta a sopportare, a tacere, a non rilevare in udienza quei tormenti ai quali, in mancanza di prove, i giudici non credono. Si chiede infine come potrebbe il Governo prendere seriamente posizione contro l'impiego di metodi, che costituiscono uno specifico mezzo di lotta contro i suoi avversari politici e sul cui impiego esso non ha mai avuto da ridire? (2019, s.p.)

Ogni possibile dubbio circa la classe sociale alla quale appartenevano gli «avversari politici» - come giustamente Calamandrei definiva i torturati - dei governi italiani è tolto dalle parole pronunciate alla Camera dei Deputati dall'Onorevole Bellavista, in data 20 febbraio 1952:

Dovete credere a quello che vi dico, perché io non ho debolezze classiste (chi parla è un liberale). La cosa più ignobile è che questo sistema delle cassette e delle torture non lo si applica ai civili, ma soltanto ai cenci, agli stracci, destinati ad andare sempre per aria, soltanto con i poveri inermi e indifesi. Se si è contesse o altolocati, si possono trovare dei riguardi. (2019, s.p.) 
Con la crisi economica, i movimenti di massa, l'avvio della strategia della tensione e la fase della lotta al terrorismo interno negli anni Settanta, in Italia così come in altri Paesi occidentali (Stati Uniti, Francia, Germania, Inghilterra e Irlanda, in primis), si è ulteriormente intensificato il ricorso alla tortura (Gonnella 2013). In Occidente, l'era neoliberista - avviata a partire dagli anni Ottanta - è stata caratterizzata da massicce privatizzazioni nel settore pubblico, dall'attacco al mondo del lavoro e dal passaggio dallo stato sociale a quello penale; questa fase è stata accompagnata da un'ondata di carcerazioni di massa e dall'avvio di politiche penali estremamente punitive verso gli strati più poveri della società (Wacquant 2009a). La tortura non ha mancato di dare il proprio contributo in questa grande trasformazione sociale ed economica.

Gli eventi dell'11 settembre 2001 hanno prodotto ulteriori cambiamenti politici e sociali in molte parti del mondo. I Paesi occidentali, guidati dagli Stati Uniti, hanno dato vita a una nuova fase di espansione imperialista. In nome della lotta al terrorismo internazionale - denominata 'guerra al terrore', che si è concretamente tradotta nell'invasione di Afghanistan e Iraq, oltre che in numerose incursioni militari in altri angoli del mondo - si è sviluppata anche una convulsa legislazione antiterrorismo che ha introdotto una serie di definizioni giuridiche e misure controverse che hanno reso socialmente e politicamente accettabile la tortura. Gli importanti cambiamenti realizzati dopo l'11 settembre hanno dunque comportato delle significative variazioni nel modo stesso di concepire e applicare la tortura nei Paesi democratici. Come ha sottolineato Ronald Crelinsten:

Il regime di tortura deve cercare di garantire che si rifletta in tutti gli aspetti della vita sociale e politica. Le tecniche utilizzate per addestrare i torturatori non sono che il riflesso di un processo molto più ampio: la trasformazione della società. (Crelisten 2003, 295)

\subsection{Guerra e tortura dopo l'11 settembre}

Una precisa definizione della riforma realizzata nell'ambito della tortura dopo l'11 settembre è stata fornita da Donatella Di Cesare:

Emersa dalla semiclandestinità, dove aveva continuato a essere affinata, la tortura è stata dichiarata una necessità dall'amministrazione americana, è stata accolta nel dibattito pubblico, ammessa per la prima volta ufficialmente in una democrazia. Questa è stata la novità dopo l'11 settembre: la condanna della tortura non è più parsa ovvia. (Di Cesare 2016, s.p.) 
Già pochi giorni dopo gli attentati terroristici dell'11 settembre, si pensava alla tortura in un modo nuovo. Le parole dell'allora vicepresidente degli Stati Uniti, Dick Cheney, pronunciate durante la trasmissione Meet the Press, il 16 settembre 2001, e riportate nel libro di Hajjar, chiariscono ulteriormente il quadro:

Dovremo lavorare nel lato oscuro, se preferite. Il mondo dell'intelligence dovrà passare del tempo nell'ombra. Molto di ciò che deve essere fatto sarà fatto in silenzio, senza discussioni, utilizzando fonti e metodi che sono a disposizione delle nostre agenzie di intelligence se vogliamo avere successo. Sarà vitale per noi utilizzare ogni mezzo a nostra disposizione per raggiungere i nostri obiettivi. (2013, s.p.)

Il discorso di Cheney ha il merito di essere chiaro e annunciare, in primo luogo, un importante cambio di paradigma nella gestione di ciò che è pubblico. Il riferimento a decisioni e azioni adottate in «silenzio» e «senza discussioni», già contiene la descrizione delle caratteristiche essenziali della governance del ventunesimo secolo nel mondo occidentale, contraddistinta dall'opacità delle procedure, da forme para-normative nell'esercizio del potere e dalla logica del just in time (Gjergji 2016). Con l'espressione «ogni mezzo a nostra disposizione», invece, il vicepresidente americano, da un lato, spalancava le porte alla tortura nella prassi quotidiana degli apparati dello Stato, dall'altro la legittimava davanti all'opinione pubblica mondiale. Come già menzionato nel primo capitolo, poche settimane dopo l'11 settembre (26 ottobre 2001), le parole di Cheney sono diventate legge con l'approvazione del Patriot Act, il che ha ulteriormente rafforzato la legittimazione della tortura, la quale viene riconosciuta come mezzo utile «per combattere gli atti di terrorismo». Il riconoscimento diretto, in realtà, si rivolge all'«interrogatorio coercitivo» - che tanto evoca la versione spagnola della tortura medievale, definita 'interrogatorio doloroso' - le cui tecniche sono a tutti gli effetti delle torture, come le fotografie di Abu Ghraib hanno testimoniato davanti al mondo intero. Inoltre, da alcuni rapporti attendibili pubblicati negli ultimi anni è emerso che, tra le tecniche dell'interrogatorio coercitivo autorizzate dalla CIA (nel marzo 2002), rientrano anche: il waterboarding (finto annegamento), l'esposizione al freddo estremo (compresa l'ipotermia indotta), le posizioni sotto stress, l'estrema privazione sensoriale, le scosse, i colpi, la privazione prolungata del sonno, l'isolamento etc. ${ }^{7}$ La semantica si è rivelata essenziale per la legittimazione della tortura in questa fase storica: attribuire

7 Dana Priest, «CIA Puts Harsh Tactics on Hold: Memo on Methods of Interrogation had Wide Review», Washington Post, June 27, 2004. 
agli stessi atti una differente terminologia - come si avrà modo di approfondire nei paragrafi successivi - ha consentito di non qualificare come tortura numerose condotte che invece rientrerebbero pienamente nella categoria.

Come è stato rilevato in numerosi studi, il dibattito pubblico e scientifico s'impaludò immediatamente nel dilemma scaturito dal «ticking bomb scenario» (Allhoff 2012); al centro di tale dilemma si trova la scelta tra l'approccio moralistico e quello utilitaristico, sintetizzabile nella seguente domanda: è giusto torturare per ottenere informazioni che servono a salvare delle vite (come, ad esempio, nel caso di una bomba in procinto di esplodere)? L'approccio sociologico si è rivelato il più idoneo a evidenziare il totale livello di astrazione di questo dibattito. Kim Scheppele, ad esempio, ha evidenziato con intelligenza quanto l'ipotetico «ticking bomb scenario» fosse avulso dalla realtà dei soggetti concretamente coinvolti nella tortura:

In primo luogo, lo scenario ipotetico presuppone che tu (come agente morale a cui tale ipotetico scenario si rivolge) e il terrorista siate soli al mondo [...]. Il contesto istituzionale non esiste [...], ma naturalmente, nel mondo reale, la scelta di coloro che devono combattere il terrorismo si farebbe in un contesto istituzionale. La questione, quindi, non è se 'tu' come individuo dovresti torturare, ma piuttosto se una nazione dovrebbe avere una politica che approvi l'uso della tortura - una questione morale molto diversa [...]. In secondo luogo, l'ipotetico scenario presume uno straordinario livello di chiarezza della situazione (l'esistenza di una bomba destinata ad esplodere) in cui tu (ora un 'tu' istituzionale) ti trovi davanti alla domanda se torturare o meno [...]. Tale certezza può essere possibile in astratto, ma nella realtà non è credibile la sua esistenza. Invece, è molto più probabile che, in primo luogo, vi domandiate se esiste una bomba e, se sì, quanto questa possa essere pericolosa. In terzo luogo, lo scenario ipotetico presuppone che la persona da torturare sia esattamente quella (forse anche l'unica) che sa dove è ubicata la bomba. È altamente improbabile che chiunque si trovi a decidere di torturare sappia se l'indagato possiede o meno le informazioni necessarie. Invece, la domanda più probabile sarà se la persona da torturare sappia veramente qualcosa di utile per tutti. Infine, l'ipotetico scenario presuppone che le informazioni fornite dalla persona torturata siano di fatto vere e utili per disinnescare la bomba. In realtà, la tortura produce risultati altamente inaffidabili. (Scheppele 2005, 292-3)

Da un lato la saturazione mediatica sul tema della tortura e la legittimazione istituzionale attraverso il Patriot Act, dall'altro il diffuso contesto bellico dove ai nemici non era riconosciuta neanche tale qualifica - definirli «combattenti illegali» invece che nemici è servito a 
rendere inapplicabili le convenzioni internazionali contro la tortura e, di conseguenza, a legittimare quest'ultima (Di Cesare 2016), - hanno creato le condizioni per rendere la tortura accettabile, socialmente e politicamente. Come aveva spiegato Cheney, il nuovo contesto mondiale imponeva una governance 'senza guanti' (take the gloves off), capace però di sfuggire alle responsabilità, ai lacci e lacciuoli del diritto formale, al fine di rendersi efficace e just in time.

A distanza di tanti anni, si può affermare, senza tema di smentita, che gli obiettivi dichiarati, in primis la sconfitta del terrorismo internazionale, ma anche la liberazione delle donne ${ }^{8}$ e l'importazione della democrazia, sono stati ampiamente mancati da parte degli Stati facenti parte della coalizione impegnata nella 'guerra al terrorismo'. Ciò che di sicuro si è realizzata è stata la loro nuova politica di espansione imperialistica. Il caso dell'Iraq rappresenta in questo senso un sequel di quanto accaduto in Cile, nel 1973. Harvey ha evidenziato, infatti, come le misure adottate dall'Autorità provvisoria della coalizione NATO in Iraq, capeggiata dallo statunitense Paul Bremer, fossero identiche a quelle imposte in Cile, essendo state caratterizzate, da un lato, dalla deregolamentazione del mercato produttivo e finanziario - «totale privatizzazione delle imprese pubbliche, pieno diritto alla proprietà privata delle attività economiche irachene da parte di aziende straniere, il rimpatrio totale dei profitti di questi, apertura delle banche dell'Iraq al controllo straniero [...], l'eliminazione di quasi tutte le barriere agli scambi commerciali» (Harvey 2007, s.p.) - e, dall'altro, dal rigido controllo dei lavoratori - «il mercato del lavoro sarebbe stato rigidamente regolamentato: gli scioperi erano di fatto proibiti nei settori chiave e il diritto a costituirsi in sindacato veniva limitato» (2007, s.p.) - al fine di tenere basso il valore della loro forza lavoro. Non a caso, l'Economist definì il nuovo Stato iracheno occupato come lo Stato «sogno di ogni capitalista»: «If it all works out, Iraq would be a capitalist's dream». ${ }^{9}$

La tortura di massa ${ }^{10}$ applicata in Iraq (così come in Afghanistan e altrove) direttamente dagli Stati Uniti, tramite soldati e contractors, rappresenta un elemento di differenza con quanto accaduto in Cile (Argentina, Brasile, etc.) negli anni Settanta (del secolo scorso), dove la tortura era realizzata da torturatori locali (soldati e paramilitari agli ordini delle autorità locali), e allo stesso tempo segnala an-

8 Ora la cronaca ci segnala che gli Stati Uniti e i loro alleati, dopo 18 anni di guerra, morte, tortura e devastazione in Afghanistan, invocano accordi con i talebani, esattamente con coloro dai quali si volevano difendere le donne afghane.

9 «Let's all go to the yard sale», The Economist, Sept. 27, 2003.

10 Nonostante non si dispongano dei numeri precisi, le fotografie di Abu Ghraib e le centinaia di testimonianze raccolte in questi anni da ricercatori e giornalisti consentono di poter affermare che si sia trattato di tortura di massa, proprio come in $\mathrm{Ci}$ le, Argentina, Brasile, etc. 
che un importante cambiamento nella politica statunitense, ovvero segna la fine del «sistema neocoloniale» senza colonie ${ }^{11}$ (Chomsky, Herman 1979). Le intrinseche contraddizioni del sistema di produzione (contrassegnate dal susseguirsi di crisi sempre più vaste e profonde), ormai pienamente globalizzato, nonché la crescente instabilità nelle relazioni tra le potenze mondiali, non garantivano più come prima il dominio degli Stati Uniti all'interno del proprio sistema di influenza. Il nuovo ordine mondiale, caratterizzato dal crescente caos politico, dalla forsennata accelerazione dei processi economici e da numerose sollevazioni popolari in molte parti del mondo, esigeva i boots on the ground, vale a dire un impegno diretto degli Stati Uniti nel controllo globale della classe-che-vive-di-lavoro.

Più che una «forma di terrore retributivo» (Di Cesare 2016, s.p.), dunque, la tortura applicata in Iraq (Afghanistan e altrove), negli anni successivi all'11 settembre, sembra aver contribuito a realizzare gli obiettivi delle imprese (straniere e nazionali) e del nuovo Stato neoliberista instaurato dalla coalizione militare.

Con riferimento, invece, allo spazio interno ai Paesi occidentali, ${ }^{12}$ si segnala la parallela e diffusa tendenza a ricorrere alla tortura come mezzo di controllo sociale. ${ }^{13}$ Solo con riferimento al caso italiano, per esempio, si possono citare in particolare - oltre ai casi singoli e noti alla cronaca - le torture di massa dell'estate 2001, poche settimane prima dell'11 settembre, nei confronti di coloro che protestarono a Genova contro lo sfruttamento e le disuguaglianze crescenti, sia a livello locale che globale. Roberto Settembre, nel suo incisivo libro, Gridavano e piangevano. La tortura in Italia: ciò che ci insegna Bolzaneto (2014), fornisce un quadro particolareggiato sullo stato e

11 Qui non si vuole sostenere che gli Stati Uniti abbiano sostituito, in questa fase o in seguito, ogni autorità locale esercitante la tortura; si vuole soltanto segnalare che all'inizio del nuovo millennio si è registrato un suo coinvolgimento militare, ampio e diretto, in diverse parti del mondo. Il che si è tradotto, inevitabilmente, anche in una maggiore e più diretta gestione della tortura.

12 È appena il caso di sottolineare che l'effetto pedagogico della tortura applicata in corpore vili in Iraq, Afghanistan e altri luoghi non conosce confini geografici e, di conseguenza, è in grado di produrre il suo impatto generale (intimidatorio) anche sulle classi lavoratrici occidentali.

13 L'espressione «controllo sociale», sin dal momento in cui Edward A. Ross (1901) la introdusse in sociologia, è stata usata in due sensi distinti: in senso ampio e in senso stretto. Il primo corrisponde, sostanzialmente, alle azioni e politiche delle istituzioni statali, mentre il secondo ha più a che fare con l'interazione a livello culturale tra individui e gruppi (Horwitz 1990). Per molti versi, questi diversi significati riflettono due distinti indirizzi della sociologia classica, che fanno capo a Émile Durkheim (nel primo caso) e Georg Simmel (nel secondo caso). In questo lavoro, per gli scopi che si prefigge, l'espressione si riferisce prevalentemente alle strategie (operative e ideologiche) messe in campo dalle classi dominanti per far sì che le altre classi eseguano i suoi ordini, poiché «nella società moderna, sono la classe e lo status a definire coloro che sono potenti e coloro che non lo sono» (Skoll 2010, 41). 
sulle tecniche della tortura oggi in Italia. Ecco alcune brevi testimonianze dirette delle torture di Bolzaneto riportate nel libro:

un sacco di ragazzi fuori ad aspettare e si sentiva gridare dalla caserma, i poliziotti ci insultavano e noi in piedi contro una rete nel piazzale, sotto il sole per una mezz'ora, tre quarti d'ora e questi in divisa nera, non so dei carabinieri e blu della polizia, che dicevano: «Sono arrivati quei bastardi del G8» e che eravamo degli ebrei [...] e a noi donne troie. (Settembre 2014, s.p.)

i colpi sulla schiena, poi la testa costretta contro il muro, e i colpi alla nuca, con la fronte che, a ogni colpo, batte contro il muro, [finché] sono svenuto per poco, ero in uno stato di svenimento e ho continuato a ricevere dei colpi anche quando ero per terra, ricordo gli ultimi calci alle costole [...] e dopo fui portato in infermeria. (s.p.)

non appena l'auto si fermò sul piazzale, non appena venni mosso per farmi scendere, si materializzò un agente in borghese, con una maglia nera a maniche corte, e quel braccio, quella mano, $\mathrm{mi}$ puntarono contro una bomboletta e mi venne spruzzata negli occhi una sostanza irritante, e allora gli altri agenti, tutti quanti ridevano. Io rimasi alcuni secondi paralizzato sul sedile, mi contrassi [...] e me la spruzzarono di nuovo, finché venni fatto scendere e condotto a testa bassa nella struttura. (s.p.)

Ciò che emerge dagli anfratti della storia getta luce sulle ragioni sociali ed economiche della tortura, alla quale gli Stati ricorrono in modo massiccio in determinate circostanze storiche: maggiore è il bisogno di controllo sulla forza lavoro, maggiore è l'uso della tortura da parte degli Stati, a prescindere dalla forma politica e istituzionale che questi possono assumere. La tortura di massa ha segnato i momenti di passaggio o di grave crisi dei sistemi di produzione mentre, nelle fasi di relativa stabilità, essa è servita a puntellarli. L'elemento stabile nel suo orizzonte storico e geografico, ovvero la provenienza sociale delle sue vittime, rappresenta una chiara conferma.

Quando David Harvey individua le due questioni chiave «che devono essere affrontate con successo» $(1993,152)$, perché l'attuale sistema di produzione «rimanga vitale» $(1993,152)$, vale a dire il carattere anarchico dei mercati e il controllo della forza lavoro, egli non fa che evidenziare le spinte oggettive del sistema nell'usare ogni possibile mezzo per riprodursi. La tortura si rivela essere uno di questi mezzi, senza dubbio il più cruento.

Il legame tra la tortura e il sistema economico si sviluppa anche su altri piani, celato dalla retorica, dalle manipolazioni (giuridiche e politiche) e dalle infinite mediazioni istituzionali e simboliche. Ed è 
proprio su questi piani che tale legame si mostra nudo: la logica del profitto - ossia il principio fondamentale della vita economica moderna - si è imposta con successo anche sulla tortura. Il processo di privatizzazione ed esternalizzazione di molteplici attività militari e di polizia, attività un tempo svolte dalle istituzioni statali, coinvolge ormai il globo intero (Dunigan, Peterson 2015). Le politiche realizzate dagli Stati Uniti nel corso degli ultimi decenni rappresentano la spinta più (antica e) potente all'interno di questo processo (Schwartz, Swain 2011). In ambito militare, queste politiche furono avviate sin dai tempi della guerra in Vietnam e in seguito consolidate con le guerre in Afghanistan, Iraq e nei Balcani (Dickinson 2011; Percy 2007; Avant 2005; Singer 2003). Il ricorso agli eserciti privati è stato massiccio, al punto da superare in termini numerici quelli ufficiali in molti scenari di guerra. È quanto avviene oggi in Africa, nello Yemen e altrove (Ballardini 2013). La privatizzazione e l'outsourcing sono diventati processi inarrestabili anche nell'ambito della sicurezza interna agli Stati occidentali (Christie 2000): la costruzione e la manutenzione delle strutture detentive (comprese quelle per immigrati), nonché molte attività di vigilanza e repressione, rientrano ora nelle competenze delle imprese private di sicurezza. Obbedendo alle logiche del mercato e alle sue 'naturali' tendenze verso la creazione di monopoli, molte imprese militari e di sicurezza si fondono, occupando così posizioni di monopolio nel mercato globale della sicurezza. La liberalizzazione del mercato della guerra, che Laura Dickinson (2011) afferma aver ricevuto uno slancio significativo con la presidenza Clinton, ha prodotto una potente spinta in questa direzione. La corporation G4S è, in questo senso, un caso emblematico. Con un fatturato di circa 6,8 miliardi all'anno e 620 mila dipendenti globali, la grande corporation inglese - che sul proprio sito web si descrive come il «principale gruppo di sicurezza integrata, specializzato nella fornitura di prodotti per la sicurezza, servizi e soluzioni» - fornisce servizi e prodotti di sicurezza a tutto campo per molti Stati e imprese ed è coinvolta in diversi scenari di guerra. Studi internazionali parlano di un business globale molto redditizio, che si ritiene raggiungerà la cifra di 210 miliardi di dollari nel 2023 (Dunigan, Peterson 2015). Si tratta ovviamente di una cifra per difetto, considerato che i bilanci ufficiali in materia sono opachi. Questo potente e gigantesco processo, che corrisponde pienamente alle esigenze della governance contemporanea, ha avuto come principale effetto la deresponsabilizzazione degli Stati rispetto alle condotte effettive degli attori coinvolti negli scenari di guerra e nel campo della sicurezza interna (Pattison 2014; Harel 2011). ${ }^{14}$ Ancor più impor-

14 Le ricerche effettuate e la cronaca giornalistica rivelano che quasi mai i dipendenti delle imprese militari private rispondono per la violazione dei diritti o per i crimini 
tante, però, è il fatto di aver posto nelle mani delle imprese private il controllo sociale.

Tutto ciò non poteva non avere un effetto dirompente nell'utilizzo della tortura, trattandosi di una oggettiva e incontenibile spinta per la sua diffusione. Per esplicitare meglio il quadro, sarebbe sufficiente proporre qui un semplice ma efficace esempio: il ruolo svolto dalla Blackwater, una delle più grandi imprese private di sicurezza negli Stati Uniti, durante la seconda guerra in Iraq. Diversi tra i suoi dipendenti sono stati tra coloro che, insieme ai soldati ufficiali, hanno partecipato e promosso le terribili torture nel carcere di Abu Ghraib (Scahill 2007). Contemporaneamente, la stessa compagnia forniva servizi di sicurezza e logistica anche a imprese straniere del settore petrolifero (e altro). I suoi guadagni, dunque, dipendevano anche dai profitti di queste imprese, la cui sicurezza erano chiamati a garantire. L'eventuale sciopero dei lavoratori iracheni, oppure le varie forme di rivendicazione salariale adottate dalle loro organizzazioni sindacali, avrebbero avuto una diretta ricaduta sui profitti della Blackwater. Torturare individui appartenenti alle classi lavoratrici irachene - ovvero coloro che-vivono-di-lavoro (Antunes 2006) - non era affatto indifferente per le casse della Blackwater. La sovrapposizione di interessi e profitti tra imprese è ancor più tangibile nelle corporation giganti, le quali, per diversificare gli investimenti e difendersi dalle crisi cicliche dei mercati, tendono ad acquistare azioni di diverse imprese, sia produttive che finanziarie.

\subsection{La divisione del lavoro nella tortura}

Le tecniche della tortura sono cambiate nel corso dei decenni. Quelle più recenti includono ora torture come: (a) lo stordimento elettrico (Wright 1996); (b) la privazione sensoriale; ${ }^{15}$ (c) l'uso delle droghe (Auerhahn, Dermody 2000); (d) il quasi-soffocamento (Amnesty International 1993): (e) la pressione con il ghiaccio (Amnesty International 2000); (f) la pressione con l'acqua (Amnesty International 1993); (g) i sistemi di contenimento come lo shabeh (Gin Bar 1998), e altri ancora. Rejali definisce queste nuove tecniche «tecnologie di tortura invisibile» $(2003,153)$, poiché il loro uso è particolarmente difficile da dimostrare:

commessi (Serralvo 2012; McKelvey 2006). Nessuno dei dipendenti della Blackwater coinvolti nello scandalo delle torture commesse ad Abu Ghraib, per esempio, è mai finito sotto processo. Il dibattito nell'ambito delle scienze giuridiche è accesso e la discussione verte sulla necessità o meno di una regolamentazione nuova delle attività di sicurezza e militari delle imprese private.

15 Michael Evans, «The White Noise Torture Room», The Times, June 19, 1999. 
La ricerca e lo sviluppo di tecniche e tecnologie nella tortura moderna si è focalizzata sui metodi che causano sofferenza e intimidazione senza lasciare tracce imbarazzanti e visibili della loro brutalità. (Wright 1996, 140)

Il carattere invisibile (o nascosto) che le nuove tecnologie attribuiscono ora alla tortura segnano anche un'ulteriore distanza tra la tortura moderna e quella classica, la quale, secondo Rejali, si articola essenzialmente in tre punti:

Le torture classiche erano eseguite in pubblico, quelle moderne non sono quasi mai visibili in pubblico. La tortura classica produceva effetti scrivendo direttamente sul corpo, come ad esempio le marcature e le cicatrici. La tortura moderna lascia sicuramente delle cicatrici, ma non mira al corpo perché va al di là del corpo [...]. Infine, le torture moderne attingono alle competenze cliniche, mentre a guidare i torturatori classici, quando sfregiavano i corpi, erano la tradizione e la religione. (Rejali 2003, 153)

Alle recenti tecniche di tortura è stato attribuito un valore differenziato nella realtà quotidiana. Alcune sono diventate polivalenti e altre no e, pertanto, non sono riuscite a diffondersi in modo significativo. A svolgere un ruolo importante nella tortura moderna è l'elettricità (Stockholm International Peace Research Institute 1978), mentre le tecniche di privazione sensoriale (SD/PD) hanno una circolazione più limitata, in quanto richiedono maggiori competenze:

SD/PD ebbe un inizio promettente, incoraggiato da esigenze militari e di intelligence per recuperare il ritardo con i russi e i cinesi. L'elettricità invece non aveva grandi finanziamenti o sostegno e ciò poteva esserle fatale. I sostenitori di SD/PD, tuttavia, non sono stati in grado di inventare nuovi obiettivi, cioè obiettivi che potevano essere soddisfatti dalla tecnologia. I torturatori elettrici sono risultati più creativi. Hanno trovato il modo di rendere la tecnologia piccola e poco costosa. Anche i principianti negli interrogatori potevano usarla senza causare vittime. L'adozione delle tecniche SD/PD, tuttavia, richiede una notevole manutenzione ad alta tecnologia e un coordinamento sociale. Inoltre, la tecnologia dello stordimento elettrico è stata in grado di creare nuovi gruppi con nuovi interessi nella tecnologia, non solo produttori di carne, ma anche società di sicurezza private che vendono sicurezza non letale. (Rejali 2003, 162)

Le nuove tecniche di tortura, al di là della specifica e variabile diffusione di ciascuna di esse, raccontano, in primis, di importanti cambiamenti nell'organizzazione complessiva della tortura. Cambiamenti che hanno richiesto investimenti importanti sia nell'innovazione tec- 
nologica sia nel coinvolgimento di esperti in diversi campi scientifici (medici, psicologi, fisici, fonici, elettricisti, etc.). Il nuovo setting (postmoderno) della tortura appare più affollato che mai, il che paradossalmente lo avvicina alle forme del supplizio premoderno, dove la presenza del pubblico rappresentava uno dei suoi elementi strutturali. Allo stesso tempo, però, si presenta come un luogo di lavoro con un preciso protocollo e regolamento, dove a ciascuno dei soggetti coinvolti - ad eccezione dei torturati, ovviamente - spetta un solo piccolo segmento del lavoro complessivo. Così, l'elettricista si deve limitare a controllare il funzionamento elettrico e lo scarico corretto del voltaggio, il medico si deve accertare della capacità di resistenza fisica del torturato, lo psicologo si deve impegnare a individuare il 'punto di crollo psicologico' della vittima, il fonico a valutare il funzionamento corretto dell'audio e della regolazione del volume, l'interrogante a fare le domande, l'interprete a tradurle, e così via.

I progressivi cambiamenti intervenuti nella tortura (post)moderna hanno creato tre maxi-categorie di attori presenti nella stanza delle torture, quello che Michael Welch (2016) definisce «il triangolo delle atrocità». Vi si trovano: (1) i torturati; (2) gli astanti (professionisti o apprendisti) e (3) gli esecutori. La maggiore centralità assunta dalle recenti tecniche di tortura - ispirate essenzialmente al modello «no-touch torture», introdotto con il manuale Kubark (McCoy 2006) - e lo spostamento progressivo del focus di queste sulla psiche dei torturati, ha modificato anche il ruolo degli astanti/professionisti, rendendoli sempre più sovrapponibili a quello degli esecutori. Questi sviluppi riflettono anche una forte dipendenza della tortura moderna dalla ricerca psicologica comportamentista (Welch 2008), particolarmente sviluppata negli ambienti scientifici statunitensi. ${ }^{16} \mathrm{I}$ ricercatori hanno infatti teorizzato che le vittime capitolano più facilmente sotto tortura quando si sentono responsabili della propria sofferenza, poiché la sinergia tra traumi fisici e psicologici accelera il crollo (Watson 1978). L'immagine iconica del prigioniero di Abu Ghraib incappucciato e posto in piedi su una scatola con le braccia distese e legate a dei fili elettrici suggerisce un metodo di interrogatorio (tortura) tipico della CIA, che combina sia la privazione senso-

16 Appare utile ricordare qui quanto scritto da Frantz Fanon sulla psicologia comportamentista statunitense: «È noto che si è sviluppata negli Stati Uniti d'America una corrente psico-sociologica. Esponenti di questa scuola pensano che il dramma dell'individuo contemporaneo risieda nel fatto che egli non ha più un ruolo, che il meccanismo sociale l'obbliga ad essere soltanto una molla. Da ciò la terapeutica proposta per permettere all'uomo di occupare dei ruoli in una vera attività ludica. Si interpreta qualsiasi ruolo, si cambia anche ruolo nella stessa giornata, si è capaci di mettersi al posto di chiunque simbolicamente. Gli psichiatri di fabbrica negli Stati Uniti compiono, pare, prodigi nella psicoterapia di gruppo degli operai. Si permette loro difatti d'identificarsi a degli eroi. La tensione nei rapporti padroni-operai si trova così considerevolmente diminuita» (Fanon 2007, 206). 
riale (attraverso l'uso del cappuccio) che il dolore autoinflitto (con le braccia distese). Il maggiore coinvolgimento della psiche nella tortura racconta anche del crescente peso simbolico della tortura nella società, perché questa tende ora a colpire il corpo delle vittime tanto quanto la percezione della loro immagine sociale.

L'introduzione dei tecnici, dei medici e degli psicologi nella stanza delle torture, è stata accompagnata dalla ridefinizione semantica di alcune procedure o atti di tortura, tesa a negarli o minimizzarli. Cohen (2001) ha spiegato che il gergo e le etichette eufemistiche tendono a mascherare e sanitarizzare il dolore inflitto ai torturati: infatti, l'utilizzo abbondante di molti termini medici finisce per qualificare la tortura come un'attività neutra o scientifica, facendola apparire persino rispettabile. Emblematiche appaiono, in questo senso, le definizioni adottate dai medici coinvolti nei programmi di interrogatori (tortura) della CIA; questi hanno definito con i termini «idratazione rettale» e «alimentazione rettale» l'introduzione di sostanze e oggetti di vario tipo nel corpo delle vittime attraverso il retto perineale (Welch 2016). Uno degli autori che ha fornito prove inconfutabili sulla (ri)progettazione in termini clinici della tortura è James Risen, il quale nel suo libro Pay Any Price: Greed, Power, and The Endless War (2014), ha riportato e analizzato centinaia di email segrete intercorse tra l'American Psychological Association (APA) e la CIA. Da questo intenso scambio epistolare emerge come entrambi i soggetti coinvolti si fossero concordati per introdurre delle modifiche mirate al codice etico e deontologico degli psicologi americani, al fine di consentire ad alcuni di loro di lavorare 'nel campo' della tortura senza rischi legali.

Il processo di razionalizzazione fonda buona parte della sua forza nella ridefinizione semantica della tortura. Questa è spesso qualificata come 'lotta al crimine', 'lotta al terrorismo', 'interrogatorio intensivo', 'interrogatorio coercitivo'. Lo stesso processo di risemantizzazione coinvolge anche i torturati e torturatori: per i primi si usano espressioni come 'terroristi', 'sovversivi', 'fuorilegge', o ancora peggio 'scarafaggi', 'vermi', 'topi', mentre i secondi vengono qualificati come 'agenti di sicurezza', 'combattenti del crimine', etc. (Huggins 2000; Conroy 2001; Haritos-Fatouros 2003).

Gli studi accurati e incisivi di Charlie Barnao e Pietro Saitta (2012) sulle tecniche e modalità di addestramento delle forze militari e di polizia, in Italia e altrove, aggiungono ulteriori elementi nell'analisi del processo di iper-professionalizzazione degli esecutori della tortura. Questi evidenziano come ormai la tortura sia anche uno strumento di addestramento di soldati e poliziotti:

l'addestramento militare fornisce in aggiunta un elemento che è particolarmente significativo per l'eventuale realizzazione di azioni violente e sadiche: la competenza tecnica e metodologica in fatto 
di tortura. Essendo stati già torturati, e venendo ripetutamente torturati (ricordiamo che l'addestramento di un militare di professione è di fatto permanente), si sono anche apprese le differenti tecniche per torturare e si è, probabilmente, anche in grado di replicarle con precisione. Questa interpretazione forse ci aiuterebbe anche a spiegare l'accuratezza metodologica con cui talvolta vengono messe in atto, in contemporanea, azioni violente e sadiche di tortura, da parte di diversi individui che - ancorché 'mele marce' - non sono dei 'torturatori professionisti' (si pensi ad es. ai casi, seppur molto diversi tra loro, di Abu Ghraib e di Bolzaneto). (Barnao 2018, 122)

Tutti questi cambiamenti, che puntano nella direzione di una crescente razionalizzazione del lavoro nella tortura, al fine di raggiungere un più alto livello di efficienza, parlano di una oggettiva tendenza di stabilizzazione della tortura nel sistema di controllo sociale. Se la tortura fosse considerata un dispositivo remoto, eccezionale, al quale si ricorre soltanto in momenti e contesti di emergenza, allora non vi sarebbe motivo alcuno di investire somme ingenti in termini di innovazione, professionalizzazione, razionalizzazione, burocratizzazione e clinicalizzazione del lavoro nella tortura. Tutto induce a pensare che il processo sia fortemente imperniato a una ragione calcolante, a un modo di porsi utilitaristico dello Stato di fronte alla tortura. L'azione dello Stato non può però considerarsi in senso 'soggettivistico', cioè utile soltanto a garantire la propria riproduzione, perché il suo agire è pur sempre subordinato all'andamento del sistema di produzione. La categoria weberiana dell'agire razionale rispetto allo scopo, infatti, all'interno del sistema capitalistico deve necessariamente essere subordinata a una categoria più ampia e comprensiva, a quella dell'agire strumentale finalizzato e dominato dall'accumulazione di capitale. In tale prospettiva, tutte le azioni statuali che spingono verso una stabilizzazione e burocratizzazione della tortura vanno poste in diretta relazione con il sistema di produzione e le sue leggi. Il processo di esternalizzazione della tortura alle imprese private di sicurezza ne è una prova tangibile.

I processi di iper-razionalizzazione, in atto da decenni, non consentono però di affermare che il lavoro della tortura sia svolto attualmente soltanto dagli iper-professionisti. Ciò che emerge da un considerevole numero di studi e di ricerche sul campo va nella direzione opposta: le torture, specie quando hanno un carattere di massa, sono non di rado commesse da torturatori improvvisati, da 'principianti' o da persone che hanno ricevuto scarso addestramento. A Guantanamo, per esempio, a torturare era una squadra che aveva ricevuto un addestramento di appena 25 giorni (Welch 2016); i torturatori di Abu Ghraib erano nella stragrande maggioranza dei casi delle reclute, degli interpreti o dei contractors senza alcun addestramento specifico, al punto che hanno dovuto fare ricorso a film e serie televisive 
per stimolare la creatività (sul punto si veda il primo capitolo). A tutti loro, infatti, sono bastati pochi elementi per costruire un adeguato setting di tortura: il razzismo e la stanza delle torture.

\subsection{La stanza delle torture}

Per realizzarsi concretamente la tortura necessita di un ambiente che possieda alcune specifiche caratteristiche. Tale ambiente deve, innanzitutto, disorientare e trasmettere disagio alla vittima (Farci, Pezzano 2009), deve toglierle ogni contatto con il mondo esterno, minare alla base ogni sua certezza, «distruggere la vita e il suo attaccamento al mondo» (Scarry 1985, 28). Elaine Scarry costruisce un parallelo tra corpo e stanza (ambiente): laddove la stanza è confortevole - afferma - il corpo si sente protetto e rilassato, nella torture room, invece, il corpo si sente profondamente minacciato, ancor prima dell'inizio della tortura.

L'ambiente della tortura deve anche essere all'altezza degli atti di tortura, deve poter mettere il torturatore a proprio agio, contribuire a rendere 'naturali' ed efficaci i suoi gesti, metterlo in una posizione di potere assoluto. Il torturatore deve avere il controllo dell'ambiente che lo circonda; senza il dominio materiale e simbolico del contesto nel quale opera, il torturatore non può neanche iniziare a definirsi tale. Allo stesso tempo, tale contesto deve garantire un certo livello di 'intimità' tra torturatore e torturato, poiché, nonostante le innovazioni tecnologiche consentano la tortura a distanza, la relazione tra torturatore e torturato esige la condivisione dello spazio e dell'esperienza. È stata anche definita come la più intima relazione tra estranei: «occhio contro occhio, mano contro mano, respiro contro respiro, torturatore e vittima sono vicini quanto lo sono gli amanti» (Ignatieff 1985, 24). Anche Elisabeth Stanley sottolinea questa ambiguità relazionale nella tortura quando riporta le parole di una torturata in Cile, la quale voleva esprimere l'insopportabile vicinanza con il proprio torturatore: «Nessuno mi ha mai guardata come lui» (Stanley 2004, 15).

L'ambiguità è oggettiva ed è data dal fatto che l'estrema contiguità fisica è accompagnata da un radicale disconoscimento reciproco; allo stesso tempo questa può anche essere appositamente costruita o intensificata. Non di rado i torturatori usano la tecnica dell'«ordine binario» (Sironi, Branche 2002, 541), per disorientare le vittime e accelerare il loro crollo psico-fisico. L'ordine binario consiste nell'alternanza di momenti di estrema violenza e altri di incredibile gentilezza, come ad esempio: offrire ai torturati da bere, da mangiare, oppure dare loro abiti per vestirsi o strumenti per pulire il sangue (Feitlowitz 1998). Nel documento finale della Commissione nazionale cilena sulla tortura, si afferma che: «I momenti di tortura erano 
spesso alternati con momenti di rilassamento, nei quali gli agenti si comportavano perfino in modo amicale» (Retting Report 1993, 488).

Gli atti umani del torturatore non sono in conflitto con il suo bisogno di costruire un distacco emotivo dalla vittima; al contrario, ne sono una paradossale conferma, perché i gesti umani e amichevoli nei confronti dei torturati non sono affatto spontanei, sono pianificati e razionali, sono gesti burocratici e hanno come obiettivo lo sfinimento della vittima attraverso l'alternarsi schizofrenico dei suoi stati d'animo. Dal punto di vista del torturato, infatti, gli studi hanno dimostrato che tale ambiguità produce effetti devastanti; facendo leva sull'estremo bisogno di salvezza del torturato, questa finisce per procurargli un grave e duraturo trauma psicologico: i torturati tendono, infatti, con il passare del tempo, a qualificare il proprio comportamento come connivente con il proprio carnefice (Stanley 2004; Feitlowitz 1998).

Affinché la tortura si realizzi è necessario che il torturato non solo sia privato di ogni contatto con l'esterno, ma anche che sia spogliato del sé. Egli deve essere introdotto in un ambiente talmente ostile da cancellargli ogni desiderio, salvo uno: quello di morire.

Ero sdraiata nuda, sempre nuda. Potevano arrivare una, due o tre volte al giorno. Non appena sentivo il rumore dei loro stivali in corridoio, iniziavo a tremare. Dopo, il tempo diventava infinito. I minuti mi sembravano ore e le ore giorni. La parte più difficile è tenere duro nei primi giorni, per abituarsi al dolore. In seguito, ci si stacca mentalmente, un po' come se il corpo galleggiasse. [...]

Durante quei tre mesi avevo un solo obiettivo: suicidarmi, e la più grande sofferenza era volermi uccidere a tutti i costi e non trovare i mezzi per farlo. ${ }^{17}$

Anche Marguerite Feitlowitz riporta nel suo libro, A Lexicon of Terror: Argentina and the Legacies of Torture, le testimonianze di molti torturati che confermano la sopravvivenza di un unico desiderio nella stanza delle torture:

Egli conosceva i limiti della resistenza umana. Una volta, dopo che mi aveva picchiata, riuscii a rubargli un rasoio dal tavolo. Tutto ciò che volevo era uccidermi. Era l'unico modo per fuggire dall'orrore. Texas [pseudonimo del torturatore] lo confiscò è mi disse: 'Tu non riuscirai a morire, ragazzina, non finché noi non lo vogliamo. Qui noi siamo Dio'. (Feitlowitz 1998, 12)

17 Sono le parole di Louisette Ighilahriz (detta Lila) nell'intervista rilasciata a Le Monde per raccontare le torture subite dall'esercito francese in Algeria (Florence Beaugé, «Torturée par l'armée française en Algérie, 'Lila' recherche l'homme qui l'a sauvée», Le Monde, 20 de juin de 2000). 
La costruzione di un contesto adeguato alla pratica della tortura esige, dunque, la compresenza di tre elementi fondamentali: (1) il potere del torturatore di compiere gli atti di tortura; (2) la routinizzazione della pratica di tortura e (3) la disumanizzazione delle vittime (Crelinsten 1993). Sono tutti elementi che possono trovare facilmente spazio nelle istituzioni totali. Queste, afferma Goffman, si contraddistinguono per la presenza di due distinti gruppi di persone al proprio interno: un grande gruppo di internati e un piccolo gruppo di persone che compongono lo staff. Il secondo gruppo ha il potere di esercitare un controllo sul primo. Il requisito indispensabile per la costruzione di questo potere è l'isolamento degli internati, l'eliminazione dei loro contatti con il mondo esterno: «Gli internati vivono generalmente nell'istituzione con limitati contatti con il mondo da cui sono separati, mentre lo staff presta un servizio giornaliero di otto ore ed è socialmente integrato nel mondo esterno» (Goffman 2003, 37).

In un siffatto contesto, le relazioni sociali si fondano su un rigido principio gerarchico e una chiara divisione dei ruoli tra staff e internati; tali relazioni sono caratterizzate dalla sopraffazione e dalla violenza «fra potere e non potere» ed è la ragione per la quale sono state definite «istituzioni della violenza» (Basaglia 2014, s.p.). Gli internati all'interno di queste istituzioni subiscono un forte attacco alla propria identità, sin da quando vi entrano: «la recluta è sottoposta ad una serie di umiliazioni, degradazioni e profanazioni del sé [...]. I processi attraverso i quali il sé di una persona viene mortificato sono alquanto standardizzati nelle istituzioni totali» (Goffman 2003, 44).

In questa prospettiva, le istituzioni totali soddisfano molte delle esigenze materiali della tortura, e il fatto che la tortura si pratichi in luoghi gerarchicamente organizzati dimostra che non è una violenza come le altre; è una violenza generata dall'obbedienza all'autorità (Crelinsten 1993). Il lavoro nella tortura è lavoro dentro una gerarchia: c'è una linea di autorità e, quindi, una linea di obbedienza. Gran parte del lavoro nella tortura, per diventare efficiente, tende a routinizzarsi, ad assumere un carattere semi-ripetitivo. Combinando insieme i due fatti - natura gerarchica della struttura e routinizzazione - appare evidente che il lavoro nella tortura implica disciplina e totale obbedienza all'autorità. Di conseguenza, si può affermare che a ogni tortura corrisponde un ordine emesso dall'alto, oppure un implicito incoraggiamento. Nella maggior parte dei casi - come la storia ha dimostrato - sono però sufficienti le politiche generali dell'autorità per costruire una situazione che consente di tradurle in atti di tortura, senza il bisogno di emettere ordini espliciti e diretti. L'atto di tortura, in altre parole, dà corpo alle politiche istituzionali. 


\subsection{Il segreto del torturatore}

Che cosa fa il torturatore quando finisce il proprio turno di lavoro? Come si relaziona con la società? Come riesce a essere un/a efficace torturatore/torturatrice e, allo stesso tempo, anche un/a buon/a marito/moglie, padre/madre, figlio/figlia o fratello/sorella? Qual è il suo segreto? La sociologia è in grado di fornire risposte a questi interrogativi, senza ricorrere a considerazioni astratte. I legami sociali tra i lavoratori della tortura sono centrali in questa specifica riflessione.

La tortura è caratterizzata da una molteplice negatività etica ed è comunemente considerata la più abominevole tra le violenze, l'unica capace di annientare in modo definitivo la fiducia della vittima nel mondo (Amery 1993, 82). In questo senso, essa conduce un attacco agli stessi fondamenti della vita sociale, danneggiando i legami e pregiudicando «il senso di comunità» (Erickson 1994, 233). Ragione per la quale la tortura richiede sempre un luogo isolato (o riparato dall'altrui vista) per essere realizzata e, allo stesso tempo, l'anonimato dei torturatori (almeno nella maggior parte dei casi). In letteratura è stato sottolineato, infatti, come perfino nei regimi dittatoriali la tortura manifesti l'esigenza di svolgersi in luoghi appartati (Haritos-Fatouros 1988). Ensalaco, ad esempio, segnala come nel Cile di Pinochet i prigionieri fossero regolarmente condotti nei «numerosi centri di detenzione segreti, per essere tenuti in isolamento e interrogati sotto tortura» (Ensalaco 2000, 90).

L'attività di tortura esige, in altre parole, un certo grado di segretezza (Rejali 2009), ovvero una «difesa per così dire aggressiva contro terzi che viene definita appunto [...] segreto» (Simmel 1992, 48). Sarà proprio questo aspetto, il segreto, a guidare la presente riflessione sulle relazioni sociali tra i lavoratori della tortura. Un importante riferimento teorico in questo campo è Georg Simmel, il quale definisce il segreto come «espressione sociologica della cattiveria etica» $(1992,50)$. Per il sociologo e filosofo tedesco, il segreto è una determinazione sociologica che contribuisce a formare il rapporto degli elementi di un gruppo, ma «col sorgere di 'società segrete', può estendersi [...] come totalità» $(1992,72)$ :

Sinché l'essere, il fare e l'avere di un singolo esistono come segreti, il loro significato sociologico generale è l'isolamento, la contrapposizione, l'individuazione egoistica. Qui il significato sociologico del segreto è esteriore, come rapporto tra colui che possiede il segreto e colui che non lo possiede. Non appena però è un gruppo in quanto tale a prendere il segreto come sua forma esistenziale, il suo significato sociologico diventa interiore, perché determina le interazioni di coloro che hanno in comune il segreto. $(1992,72)$ 
Quando Simmel parla di società segrete ha in mente principalmente le bande criminali o i gruppi politici che si oppongono al potere dello Stato:

In modo del tutto generale la società segreta compare ovunque come correlato del dispotismo e della limitazione poliziesca, e come protezione, sia difensiva che offensiva, contro il peso schiacciante dei poteri centrali e quindi assolutamente non solo politici, ma anche all'interno della Chiesa, delle classi scolastiche e delle famiglie. $(1992,76)$

Ciononostante, la riflessione di Simmel è applicabile anche ai gruppi che esercitano la tortura per conto e dentro le istituzioni dello Stato, poiché questi agiscono comunque in contrasto con gli imperativi etici e morali della società aperta (Mackert 2015) e, come Simmel sottolinea, l'elemento che maggiormente contraddistingue le società segrete è proprio la rottura radicale con tali imperativi. Inoltre, le caratteristiche delle due tipologie di società segrete individuate da Simmel si combinano tra di loro, in modo sorprendente, quando si tratta di società segrete create all'interno dello Stato: in tali casi, infatti, non si può conoscere né l'esistenza della società segreta (cioè il suo obiettivo specifico) e neanche l'identità dei suoi membri effettivi. Ciò vale anche con riferimento a quei contesti sociali e politici nei quali la tortura è una sorta di segreto aperto. Si può venire a sapere, infatti, che i torturatori esistono e che provengono da determinati ambienti (esercito, polizia, servizi segreti o altro), ma non è possibile conoscere le identità dei singoli torturatori, né i luoghi o i tempi di realizzazione della tortura.

Seguendo il ragionamento di Simmel, si può affermare come la segretezza non solo determini le relazioni sociali all'interno della società segreta, ma, nel caso delle società segrete di torturatori, essa possa persino spingere i suoi membri a diventare torturatori, attraverso il modellamento dei loro comportamenti e legami. Considerato il disvalore derivante dalla violazione delle norme sociali e dagli effetti distruttivi della tortura sulle vittime, la sopravvivenza della società dei torturatori si regge interamente sulla conservazione del segreto. Il che rappresenta una difficile sfida, poiché in questo caso la conservazione del segreto esige un elevato grado di fiducia reciproca tra i suoi membri: «Il legame particolarmente stretto esistente all'interno della società segreta [...] possiede la sua categoria psicologica nella 'fiducia' specifica» (Simmel 1992, 82). Non si tratta dunque di 'semplice' coesione sociale, che da Durkheim in poi sappiamo essere una proprietà del gruppo in grado di influenzare i comportamenti dei suoi membri, in particolare i loro comportamenti di ruolo (Merton 2000); nelle società segrete si esige un grado superiore di coesione, la quale deve fondarsi su una maggiore intimità e intensità rispetto a quanto richiesto nella società aperta: 
La prima relazione intima, essenziale per la società segreta, è la reciproca fiducia dei suoi elementi. E ce n’è particolare bisogno perché lo scopo per cui si mantiene il segreto è soprattutto la protezione. Di tutte le regole di protezione, la più radicale è certo quella di rendersi invisibili. (Simmel 1992, 73)

La costruzione della fiducia nelle società segrete, afferma Simmel, si basa essenzialmente su due elementi: la gerarchia e il rituale.

All'interno delle società segrete, la formazione del rituale sottostà alle stesse condizioni di evoluzione della gerarchia [...] Forse non c'è alcun tratto esteriore che caratterizza la società segreta distinguendola in modo tanto deciso e tipico dalla società aperta, quanto la valorizzazione degli usi, delle formule, dei riti e del loro tipico rapporto di preponderanza e di contrapposizione ai contenuti di scopo. $(1992,93-4)$

Con riferimento alle società segrete di torturatori appare indispensabile aggiungere un ulteriore elemento: la violenza. Questa ha un carattere strutturale, in quanto è sia un obiettivo specifico che un paradigma operativo della società segreta. Tuttavia, occorre tenere in considerazione il fatto che, nella realtà concreta, tutti gli elementi atti a garantire la stabilità e la protezione delle società segrete dei torturatori tendono a manifestarsi in modo combinato, producendo una situazione sociale dalla quale è molto difficile dissociarsi. Crelinsten (1993) ha messo bene in evidenza questo aspetto analizzando le dichiarazioni di alcuni ex torturatori. In ciascuna delle testimonianze raccolte si può scorgere l'indissolubile intreccio tra gerarchia, ritualità e violenza nella costruzione dei legami sociali interni: «Il giorno che te ne andrai, Jose, ti taglieremo la testa» (Crelinsten 1993, 59). Anche nelle testimonianze riportate da Thomas Plate e Andrea Darvi si ottengono le medesime conferme:

Mi fu poi affidato il compito di cacciare le persone, interrogarle, torturarle e ucciderle. A causa [...] della situazione che stavo vivendo e di quello che ero tenuto a fare, reagii e cercai ripetutamente di andarmene, ma ciò era impossibile, perché una volta entrati non si può uscire. (Plate, Darvi 1983, 59)

La tortura, quindi, non ha soltanto il compito di soffocare le ribellioni delle vittime, ma anche quelle dei torturatori: l'umiliazione estrema del torturato, «attraverso la rivelazione della propria indecenza, [...] ha il compito di sottrarre, a lui come ai suoi carnefici e a tutti gli altri, qualsiasi diritto alla ribellione» (de Certeau 2006, 201).

Le società segrete dei torturatori non si riducono, ovviamente, ai soli esecutori materiali della tortura, che - occorre ribadire - nella pratica 
contemporanea (postmoderna) sono diventati numerosi, a seguito della progressiva tecnologizzazione, parcellizzazione e razionalizzazione del lavoro nella tortura. In esse vanno inclusi anche soggetti collocati ai vertici delle istituzioni dello Stato, i quali però, avendo maggiore potere rispetto agli altri membri semplici, riescono a dissimulare più facilmente la partecipazione alle suddette società (Cohen 2005; Greenberg, Dratel 2005). Le parole di Lynndie England, così come quelle di altri ex torturatori già riportate in questo lavoro, ne danno una chiara conferma: «Ma quando mostri alle persone della CIA, dell'FBI e del MI le foto e loro dicono: 'Hey, ottimo lavoro. Continuate cosi', uno pensa che sia giusto. Erano tutti lì e non hanno detto una parola» (England 2008).

La segretezza rappresenta il confine che separa la società segreta dei torturatori dal resto della società ed è anche ciò che le dà una forma chiusa. Tale forma produce alcuni particolari effetti che consentono una maggiore comprensione delle relazioni all'interno di queste realtà. Tra gli effetti più importanti sono stati individuati: (a) l'autorappresentazione dei membri della società segreta come élite; (b) la necessità di avere sostenitori (semi-)esterni; (c) la particolare spietatezza dei comportamenti (Mackert 2015, 113).

L'autorappresentazione dei torturatori come élite, ovvero come appartenenti a un gruppo o una 'razza' superiore, funge anche da potente collante sociale; può considerarsi uno degli elementi che maggiormente incidono nei legami sociali tra i membri della società:

Inculcare l'idea che l'ESA fosse il più importante sostegno del regime, che questo dipendeva dalla polizia militare per la sicurezza e per la conservazione era di primaria importanza. Le selezioni delle reclute venivano fatte in modo da far credere loro che l'azione di un agente dell'ESA non poteva mai essere messa in discussione; a questi veniva detto: 'Puoi fustigare anche un maggiore'. (Haritos-Fatouros 1988, 1115)

Anche Simmel $(1992,51)$ ha sottolineato come l'appartenenza a una società segreta attribuisca uno «status di eccezione» alla personalità dei suoi membri, anche in considerazione del fatto che «tramite il segreto si ottiene un infinito ampliamento della vita» (48):

Il segreto conferisce alla personalità uno status di eccezione, agisce come un'attrattiva definita in modo puramente sociale, per principio indipendente dal contenuto che protegge, ma naturalmente crescente nella misura in cui il segreto posseduto in modo esclusivo è importante ed esteso. $(1992,51)$

Nella costruzione dell'autorappresentazione come élite, l'ideologia razzista occupa uno spazio rilevante, specie se si considera la storia sociale della stragrande maggioranza dei torturati. È evidente 
che torturare (soprattutto) i membri delle classi sociali più povere e, tra questi, i soggetti più deboli per nazionalità, genere o età, non solo colloca la tortura nel cuore del razzismo, ma costruisce un contesto sociale caratterizzato dal bisogno del torturatore di definire la propria identità in radicale opposizione a quella del torturato: essere élite, per il torturatore, significa innanzitutto essere superiori ai torturati. Il che genera processi di degrado e disumanizzazione, che Asad (1996) ritiene essere alla base di ciò che scatena i sentimenti di onnipotenza dei torturatori, trasformandoli in mostri sociali: «Tu non riuscirai a morire, ragazzina, non finché noi non lo vogliamo. Qui noi siamo Dio» (Feitlowitz 1998, 12). Non è difficile comprendere che il razzismo sperimentato nella vita quotidiana rappresenti una lunga ed efficace palestra di addestramento per ciascuno dei membri della società segreta; il razzismo - come ha efficacemente spiegato Sartre - è sempre razzismo-operazione e, per tale ragione, costituisce un concreto percorso di socializzazione alla violenza, e, allo stesso tempo, anche un elemento di continuità tra il mondo esterno e il mondo interno della società segreta; è una costante che attenua o rende invisibile il conflitto tra il sistema valoriale interno e quello esterno. Non è stato un caso, infatti, che le centinaia di interpreti di lingua araba utilizzati dall'esercito statunitense e dalle imprese militari in Iraq - parte dei quali torturarono decine di prigionieri iracheni (senza aver avuto alcun addestramento specifico) - fossero tutti di religione cristiana oppure provenienti dalla popolazione sciita, storicamente maltrattata dallo Stato iracheno (McCoy 2006). Il loro odio razzista nei confronti della popolazione sunnita è stato 'sfruttato' per la costruzione di un efficace setting di tortura e anche come elemento utile per la stabilità delle società segrete di torturatori. Gli studi realizzati in diverse parti del mondo confermano la tendenza degli Stati a reclutare come torturatori soggetti dichiaratamente razzisti o potenzialmente tali. Il razzismo svolge, dunque, una triplice funzione nella tortura: (a) facilità la disumanizzazione della vittima; (b) funge da collante nelle relazioni sociali dentro le società segrete; (c) attenua o elimina la percezione del conflitto valoriale tra la società segreta e la società aperta. Questo è un aspetto importante nella riflessione complessiva sulla tortura, perché consente di comprendere come l'addestramento dei torturatori professionisti, oppure i processi della loro socializzazione alla violenza nelle caserme, non spieghino tutte le dinamiche e i processi sui quali si costruisce la tortura come fenomeno sociale.

L'organizzazione della tortura e la stabilità delle società segrete di torturatori si reggono anche sul supporto dei fiancheggiatori, i quali solitamente appartengono a determinati gruppi della gerarchia militare o della polizia (anche segreta), a certi settori del personale amministrativo, ai membri dei governi e, più di recente, occorre aggiungere anche elementi appartenenti ad altre categorie (sistema sa- 
nitario, mediatico). Questi soggetti conoscono soltanto parzialmente i segreti della società dei torturatori, perché il loro ruolo non esige che siano a conoscenza di ogni dettaglio. Secondo Simmel (1992), la cerchia sociale dei sostenitori costituisce una zona cuscinetto, che va a collocarsi tra l'interno e l'esterno della società segreta, svolgendo in tal modo un'importante funzione protettiva. Il ruolo dei fiancheggiatori, infatti, è quello di contribuire a conservare l'esistenza e la stabilità delle società segrete. La distanza sociale tra queste ultime e i fiancheggiatori agevola l'adempimento di tale compito. Nel caso di Abu Ghraib, ad esempio, che com'è noto ha segnato una rottura del patto di fiducia tra i membri della società segreta dei torturatori, il ruolo delle istituzioni militari e dell'amministrazione statunitense fu quello di rendere opaco l'intero operato delle società segrete di tortura, inizialmente negandone l'esistenza e, in seguito, dando inizio a un dibattito pubblico orwelliano circa la moralità, l'utilità e l'eticità della tortura (McCoy 2006).

All'interno di un contesto sociale e culturale che non prevede vie di uscita, i torturatori perseguono il loro scopo con estrema crudeltà (Crelinsten 1993). In questo senso, si può comprendere Simmel quando afferma che essere membro di un'associazione segreta implica una libertà dagli imperativi morali che governano la vita sociale all'esterno di essa:

Nulla simboleggia o promuove l'indipendenza delle società segrete dal loro ambiente sociale in modo tanto deciso quanto la caduta di quella finta o effettiva condiscendenza che inserisce continuamente la società aperta nella teleologia della collettività circostante. (Simmel 1992, 109)

Si può inoltre accettare il ragionamento di Collins, laddove afferma che «la chiave della crudeltà si può trovare nella connessione tra la morale e i confini che delineano l'inclusione e l'esclusione in un gruppo» (Collins 1974, 418). In altri termini, la linea di separazione della società segreta dal mondo esterno, marcata dal segreto, rende possibile lo sviluppo di un autonomo sistema valoriale, il che, nel caso in esame, agevola la crudeltà dei membri-torturatori, poiché «le regole razionali, la gerarchia e le procedure dell'organizzazione interna [...] devono dettare il suo comportamento professionale» (Huggins, Haritos-Fatouros, Zimbardo 2002, 106). Se l'obiettivo della società segreta è quello di torturare, allora il sistema valoriale interno non può che essere teso a promuovere tale obiettivo. Di conseguenza, ogni crudeltà esercitata dai torturatori è un'azione accettata, condivisa e promossa; la crudeltà si regge sull'autorizzazione del sistema gerarchico interno, sui rituali che servono a questo per riprodursi e sulla paura scatenata dalla violenza (materiale e ideologica) che lo permea a ogni livello. 
Il segreto, inteso come «mezzo attraverso il quale si mettono in atto le dinamiche di esclusione e quelle di inclusione» e, allo stesso tempo, come elemento che «agisce in senso isolante e individualizzante» (Calabrò 1997, 64), svolge una funzione che metaforicamente si avvicina a quella dello specchio magico di Alice, una soglia invisibile che, consentendo il passaggio da un mondo all'altro, da un ruolo sociale all'altro, elimina le contraddizioni esistenti. Se la società aperta avanza nei confronti dell'individuo richieste che generano conflitti e contraddizioni (i quali vanno risolti in qualche modo), l'isolamento che caratterizza le società segrete tende a limitare o eliminare tali problemi. Gli scopi e i programmi delle società segrete pretendono che gli interessi e i valori della società (aperta) siano lasciati fuori dalla loro porta. Tale condizione è in grado di spiegare le ragioni che consentono ai torturatori di essere, contemporaneamente, sia dei 'mostri sociali' sia dei bravi/e cittadini/e, padri/madri, fratelli/sorelle, figli/figlie. Il loro segreto è tutto qui.

\subsection{Note conclusive}

Elaine Scarry, nel suo The Body of Pain. The Making and Unmaking of the World (1985), afferma come la tortura abbia il potere di ammutolire i torturati, di sopprimere la loro voce. L'esperienza della violenza è tale da rendere le parole inadeguate a descrivere il dolore, mai all'altezza del trauma. Le storie di tortura sono «abitate dall'impossibilità di raccontare» (Laub 1992, 79). L'unica possibilità che ha il linguaggio di spiegare la tortura è soltanto quando si esprime «dentro una collettività» (De Saussure 1974, 14). Il fallimento nella comunicazione, infatti, non si ha nella mancanza di voce del torturato, ma nell'incapacità di comprensione di chi ascolta. Comprendere, in questo caso, significa riconoscere i torturati nella loro interezza, senza ridurli a dei corpi qualsiasi, senza storia, senza identità e appartenenze, cioè in corpi senza voce. Così facendo si può trovare una risposta alla domanda con la quale si è aperto questo capitolo: «Perché spingono delle persone a torturare delle altre?». Le ragioni della spinta a torturare sono strutturalmente inscritte nei sistemi sociali ed economici fondati su gerarchie e sfruttamento. I torturatori sono generati dalle necessità oggettive di siffatti sistemi, e non per volontà di un generico sadismo.

Le cicatrici che la tortura (post)moderna lascia sui torturati di oggi non sono altro che il prosieguo, o l'anticipo delle cicatrici che il mercato, dove sono costretti a vendere la loro forza lavoro, ha già lasciato e continuerà a lasciare. Con la differenza che quelle lasciate dalla tortura si manifestano in una versione più intensa, più cruenta. I torturatori sono la versione horror di quegli 'acconciatori' della 'pelle’ dei lavoratori, di cui parla Karl Marx $(1989,209)$ quando illustra 
la sua biopolitica, perché i torturati appartengono, nella stragrande maggioranza dei casi, alle fila di coloro che sono costretti a vendere la loro 'pelle'. La «banalità del male» (Arendt 2001), o meglio, la banale verità della tortura è tutta qui; è già presente - con forme e dosi variabili a seconda dei casi - nelle dinamiche dell'attuale rapporto sociale di produzione. Attraversati e corrosi dal campo di forze magnetiche che la gerarchia sociale e l'odio razzista, suo figlio primogenito, creano, i torturatori non necessitano di grandi addestramenti o talenti per diventare tali. È la gerarchizzazione molecolare dei rapporti, che si manifesta su ogni piano dell'esistenza, a socializzarli alla violenza, prima ancora che arrivino i suoi professionisti e burocrati, definiti da Sartre «orripilanti lavoratori» (2019b, 94). Se così non fosse, non si spiegherebbero le fila sempre dense degli eserciti di torturatori, passati e presenti. La tortura è, prima di tutto, l'odio dei torturatori verso i torturati:

Dietro questi chirurghi sconvolti e insulsi, si sente un'inflessibilità che li supera e supera i loro stessi capi. [...] In questa attività gli individui non contano: una specie di odio errante, anonimo, un odio radicale dell'uomo, tiene insieme torturatori e vittime, degradandoli insieme e gli uni attraverso gli altri. (Sartre 2019b, 94-5)

Ma anche questo silenzio, questa paura, questi pericoli sempre invisibili e sempre presenti non possono spiegare in modo completo la tenacia dei torturatori, la loro volontà di ridurre all'abiezione le loro vittime e, infine, questo odio dell'uomo che si è impossessato di loro senza il loro consenso, modellandoli. $(94-5,99)$

La tortura non resta quel mistero indicibile che ci fa interrogare sull'umanità dei torturatori se la si percepisce come prodotto di un particolare modellamento sociale derivato dalle relazioni/interazioni fondate sul principio gerarchico e sulla violenza. In questo senso, bisogna evidenziare che la tortura non è un fatto anti-sociale, ma un fatto determinato dai rapporti sociali. La tortura - vietata, criminalizzata e condannata ovunque - si nutre dunque di forze e spinte che nascono nelle viscere del sistema di produzione e delle relazioni sociali che lo accompagnano; le leggi, la morale, l'etica e la politica non sono che semplici barriere da aggirare o, quando necessario, abbattere. Se non si eliminano le condizioni strutturali che rendono la tortura invincibile, parlare della sua abolizione sarà sempre una menzogna. 


\section{Bibliografia}

Adelman, Rebecca A. (2012). «Tangled Complicities: Extracting Knowledge from Images of Abu Ghraib». Cohen, Esther; Toker, Leona; Consonni, Manuela; Dror, Otniel (eds), Knowledge and Pain. Amsterdam-New York: Rodopi, 353-79.

Agamben, Giorgio (2003). Lo stato di eccezione. Torino: Bollati Boringhieri.

Agamben, Giorgio (2009). "Note liminaire sur le concept de démocracie». Agamben, Giorgio, Démocratie dans quel état? Paris: La fabrique, 9-14.

Aleramo, Sibilla (1956). «È il lavoro oggi l'aurora». Aleramo, Sibilla, Luci della mia sera. Poesie (1942-1956). Roma: Ed. Riuniti, 33-4.

Alleg, Henri (1958). La question. Paris: Éditions de Minuit.

Allhoff, Fritz (2012). Terrorism, Ticking-Bombs, and Torture. London: The University of Chicago Press.

Amato, Pierandrea (2014). In posa. Abu Ghraib 10 anni dopo. Napoli: Cronopio. Amery, Jean (1993). Intellettuale a Auschwitz. Torino: Bollati Boringhieri.

Amnesty International (1993). Venezuela: The Eclipse of Human Rights. London: Amnesty International.

Amnesty International (2000). Turkey. The Alleged Torture of Cevat Soysal at National Intelligence Agency Head-Quarters, Ankara. London: Amnesty International.

Amnesty International (2019). Torture: A Global Crisis. URL https://www.amnesty.org/en/get-involved/stop-torture (2019-10-25).

Angel, Maria (2009). «Seeing Things: Image and Affect». Cultural Studies Review, 15(2), 133-46.

Antelme, Robert (1998). L'espèce humaine. Paris: Gallimard Flammarion.

Antunes, Ricardo (2006). Il lavoro in trappola. La classe che vive di lavoro. Milano: Jaca Book.

Apel, Dora (2005). «Torture Culture: Lynching Photographs and the Images of Abu Ghraib». Art Journal, 64(2), 88-100.

Arendt, Hannah (2001). La banalità del male. Eichmann a Gerusalemme. Milano: Feltrinelli.

Armes, Roy (1968). The Cinema of Alain Resnais. London: Zwemmer, Barnes.

Asad, Talal (1996). «On Torture, or Cruel Inhuman, and Degrading Treatment». Social Research, 63, 1081-109. 
Auerhahn, Kathieen; Dermody, Leonard Elizabeth (2000). «Docile Bodies: Chemical Restraints and the Female Inmate». Journal of Criminal Law and Criminology, 90(2), 599-635.

Avant, Deborah (2005). The Market for Force. Cambridge: Cambridge University Press.

Ballardini, Bruno (2013). Isis. Il marketing dell'Apocalisse. Milano: Baldini \& Castoldi.

Barnao, Charlie (2018). «Il soldato (im)perfetto. Addestramento militare, polizia, tortura». Ordines, 2, 58-122.

Barnao, Charlie; Saitta, Pietro (2012). "Autoritarismo e costruzione di personalità fasciste nelle forze armate italiane: un'autoetnografia». Quaderni del CIRSDIG. Working Paper No. 50. URL https://ssrn.com/abstract=1994397 (2019-12-03).

Basaglia, Franco (2014). «Le istituzioni della violenza». Basaglia, Franco (a cura di), L'istituzione negata [ebook]. Milano: Baldini \& Castoldi, s.p.

Basso, Lelio (1953). La tortura oggi in Italia. Novara: Civiltà.

Basso, Pietro (2000). Razze schiave e razze signore. Vecchi e nuovi razzismi. Milano: Franco Angeli.

Basso, Pietro (a cura di) (2010). Razzismo di stato. Stati Uniti, Europa, Italia. Milano: Franco Angeli.

Baudrillard, Jean (1981). Simulacres et simulations. Paris: Galilée.

Bazin, André (1999). Che cosa è il cinema? Il film come opera d'arte e come mito nella riflessione di un maestro della critica. Milano: Garzanti.

Begg, Moazzam; Brittain, Victoria (2006). Enemy Combatant: A British Muslim's Journey to Guantánamo and Back. New York: Free Press.

Benjamin, Walter (2002). I 'passages' di Parigi, vol. 1. Torino: Einaudi.

Bersani, Leo; Dutoit, Ulisse (1993). Arts of Impoverishment: Beckett, Rothko, Resnais. Cambridge (MA): Harvard University Press.

Bidet, Jacques (2012). «ll corpo biopolitico nel Capitale di Karl Marx». Consecutio Rerum. Rivista critica della Postmodernità, 2, 49-70. URL http://www. consecutio.org/2012/02/il-corpo-biopolitico-nel-capitaledi-k-marx (2019-11-30).

Blauwkamp, Joan M.; Rowling, Charles M. (2018). «Are Americans Really Okay with Torture? The Effects of Message Framing on Public Opinion». Media, War \& Conflict, 11(4), 446-75.

Bonini, Carlo (2004). Guantanamo. Usa, il viaggio nella prigione del terrore. Torino: Einaudi.

Bourdieu, Pierre (2013). Sullo Stato. Corso al Collège de France. Vol. I (1989-1990). Milano: Feltrinelli.

Branche, Raphaëlle (2001). La torture et l'armée pendant la guerre d'Algérie (1954-1962). Paris: Gallimard.

Bush, George W. (2010). Decision Points. New York: Broadway Paperbacks.

Calabrò, Anna Rita (1997). L'ambivalenza come risorsa. La prospettiva sociologica. Roma-Bari: Laterza.

Caruth, Cathy (1996). Trauma: Explorations in Memory. Baltimore: Johns Hopkins University Press.

Cassese, Antonio (1994). Umano-disumano. Commissariati e prigioni nell'Europa di oggi. Roma-Bari: Laterza.

Célérier, Patriacia-Pia (2014). «An Interview with Henri Alleg». African Studies Review, 57(2), 149-62. 
Chandler, David (1999). Voices from S-21: Terror and History in Pol Pot's Secret Prison. Berkeley; Los Angeles; London: University of California Press.

Chomsky, Noam; Herman, Edward (1979). The Washington Connection and Third World Fascism [ebook]. Montreal: Black Rose.

Christie, Nils (2000). Crime Control as Industry: Towards Gulags, Western Style. New York: Routledge.

Churchill, Ward (1997). A Little Matter of Genocide: Holocaust and Denial in the Americas 1492 to the Present. San Francisco (CA): City Lights Books.

Clastres, Pierre (1977). La società contro lo Stato. Milano: Feltrinelli.

Cohen, Stanley (2001). States of Denial: Knowing About Atrocities and Suffering. Cambridge (UK): Polity.

Cohen, Stanley (2005). «Post-Moral Torture: From Guantanamo To Abu Ghraib». Index on Censorship, 1, 24-30.

Cohen, Irwin; Corrado, Raymond (2005). «State Torture in the Contemporary World». International Journal of Comparative Sociology, 46, 103-31.

Collins, Randall (1974). «Three Faces of Cruelty: Towards A Comparative Sociology of Violence». Theory and Society, 1(4), 415-40.

Conroy, John (2001). Unspeakable Acts, Ordinary People. London: Vision.

Crelisten, Ronald (2003). «The World of Torture: A Constructed Reality». Theoretical Criminology, 7(3), 293-318.

Crelinsten, Ronald (1993). «The Social Context of Torture: Policy Process and Authority Structure». Crelinsten, Ronald; Schmid, Alex P. (eds), The Politics of Pain: Torturers and Their Masters. Leiden: University of Leiden Press, 21-38.

Crouch, Colin (2003). Postdemocrazia. Roma-Bari: Laterza.

Daney, Serge (1998). Ciné Journal, Volume I/ 1983-1986. Paris: Petite bibliothèque des Cahiers du Cinéma.

Danner, Mark (2004). Torture and Truth: America, Abu Ghraib and the War on Terror. New York: New York Review of Books.

Danzig, David (2012). «Countering the Jack Bauer Effect. An Examination of How to Limit the Influence of Tv's Most Popular and Most Brutal Hero». Salek, Fabiola; Flynn, Michael (eds), Screening Torture: media Representations of State Terror and Political Domination. New York: Columbia University, 21-33.

de Beauvoir, Simone (1966). La forza delle cose. Torino: Einaudi.

de Certeau, Michel (2006). «L'istituzione dell'immondo: Luder». de Certeau, Michel, Storia e psicoanalisi: tra scienza e finzione. Torino: Bollati Boringhieri, 192-207.

De Martino, Ernesto (2002). La fine del mondo. Contributo all'analisi delle apocalissi culturali. Torino: Einaudi.

De Saussure, Ferdinand (1992). Corso di linguistica generale. Roma-Bari: Laterza.

Di Cesare, Donatella (2016). Tortura [ebook]. Torino: Bollati Boringhieri.

Dickinson, Laura (2011). Outsourcing War \& Peace. Preserving Public Values in a World of Privatized Foreign Affairs. New Haven; London: Yale University Press.

Didi-Huberman, Georges (2003). Images malgré tout. Paris: Minuit.

di Luzio, Giulio (2019). Hooligans di Stato. La violazione dei diritti umani [ebook]. Roma: Bibliotheka.

Di Vittorio, Pierangelo; Manna, Alessandro; Mastropierro, Enrico; Russo, Andrea (a cura di) (2009). L'uniforme e l'anima. Indagine sul vecchio e nuovo fascismo. Bari: Action 30.

Dorfman, Ariel (2004). «The Tyranny of Terror: Is Torture Inevitable in Our Century and Beyond?». Levinson, Sanford (ed.), Torture: A Collection. Oxford: Oxford University Press, 3-18. 
Dümling, Albrecht (1998). «Eisler's Music for Resnais' 'Night and Fog' (1955): A Musical Counterpoint to the Cinematic Portrayal of Terror». Historical Journal of Film, Radio and Television, 18(4), 575-84.

Dunigan, Molly; Peterson, Ulrich (2015). The Market for Force. Privatization of Security across World Regions. Philadelphia: University of Pennsylvania Press.

Einolf, Christopher (2007). «The Fall and Rise of Torture: A Comparative and Historical Analysis». Sociological Theory, 25, 101-21.

Ellis, John (2000). Seeing Things: Television in the Age of Uncertainity. London: I.B. Tauris.

Elkins, James (2003). Visual Studies. A Sceptical Introduction. New York: Routledge.

England, Lynndie (2008). «Rumsfeld knew». Stern, 17 March. URL https:// www.stern.de/politik/ausland/lynndie-england--rumsfeldknew--3086946.html (2019-09-07).

Ensalaco, Mark (2000). Chile under Pinochet: Recovering the Truth. Philadelphia: University of Pennsylvania Press.

Erickson, Jeff (2013). «Torture: Henri Alleg and the Algerian War». lowa Historical Review, 4(1), 25-41.

Erickson, Kai (1994). A New Species of Trouble: The Human Experience of Modern Disasters. New York: Norton.

Faldini, Franca; Fofi, Goffredo (a cura di) (1981). L'avventurosa storia del cinema italiano raccontato dai suoi protagonisti 1960-1969. Milano: Feltrinelli.

Fanon, Frantz (2007). I dannati della terra. Torino: Einaudi.

Farci, Manolo; Pezzano, Simona (2009). Blue Lit Stage. Realtà e rappresentazione mediatica della tortura. Milano: Mimesis.

Feitlowitz, Marguerite (1998). A Lexicon of Terror: Argentina and the Legacies of Torture. Oxford: Oxford University Press.

Felman, Shoshana; Laub, Dori (1992). Testimony: Crises of Witnessing in Literature, Psychoanalysis, and History. New York: Routledge.

Finelli, Roberto; Toto, Francesco (2012). «Per un nuovo materialismo». Consecutio Rerum. Rivista critica della Postmodernità, 2, 4-18. URL http://www. consecutio.org/2012/02/editoriale-"per-un-nuovo-materiaz lismo"/ (2018-05-30).

Finke, Ronald A.; Ward, Thomas B.; Smith, Steven M. (1992). Creative Cognition: Theory, Research, and Applications. Cambridge: MIT Press.

Fiorelli, Piero (1953). La tortura giudiziaria nel diritto comune, vol. 1. Milano: Giuffrè.

Floris, Antioco (2010). «Fra cronaca e storia. La sceneggiatura di La battaglia di Algeri (1966)». Cardono, Lucia (a cura di), Franco Solinas: il cinema, la letteratura, la memoria. Pisa: Edizioni ETS, 19-34.

Foucault, Michel (1976). Sorvegliare e punire. Nascita della prigione. Torino: Einaudi.

Foucault, Michel (2005). Nascita della biopolitica. Corso al Collège de France (1978-1979). Milano: Feltrinelli.

Freud, Sigmund (1997). L'interpretazione dei sogni. Torino: Bollati Boringhieri. Frezza, Gino (2015). «Post-umanità di viventi e zombie». Frezza, Gino (a cura di), Endoapocalisse. The Walking Dead, l'immaginario digitale, il post-umano. Cava dei Tirreni: Areablu Edizioni, 265-81.

Geremek, Bronislaw (1986). La pietà e la forca. Storia della miseria e della carità in Europa. Roma-Bari: Laterza.

Giglioli, Daniele (2007). «Postfazione». Jameson, Fredric, Postmodernismo, ovvero la logica culturale del tardo capitalismo. Roma: Fazi Editore, 419-34. 
Giglioli, Daniele (2015). Stato di minorità [ebook]. Roma-Bari: Laterza.

Gin Bar, Yuval (1998). Routine Torture: Interrogation Methods of the General Security Service. Jerusalem: B' Tselem, Israeli Information Center for Human Rights in the Occupied Territories.

Ginzburg, Carlo (1973). I benandanti. Stregoneria e culti agrari tra Cinquecento e Seicento. Torino: Einaudi.

Gjergji, Iside (2016). Sulla governance delle migrazioni. Sociologia dell'underworld del comando globale. Milano: Franco Angeli.

Gjergji, Iside (2019). 'Uccidete Sartre!'. Anticolonialismo e antirazzismo di un revenant. Verona: ombre corte.

Goffman, Erving (2003). Asylums. Le istituzioni totali: i meccanismi dell'esclusione e della violenza. Torino: Einaudi.

Gonnella, Patrizio (2013). La tortura in Italia. Parole, luoghi e pratiche della violenza pubblica. Roma: DeriveApprodi.

Greenberg, Karen; Dratel, Joshua L. (2005). The Torture Papers. The Road to Abu Ghraib. Cambridge: Cambridge University Press.

Gronke, Paul; Rejali, Darius; Drenguis, Dustin; Hicks, James; Miller, Peter; Nakayama, Bryan (2010). «US Public Opinion on Torture, 2011-2009». PS: Political Science and Politics, 43, 437-44.

Hajjar, Lisa (2013). Torture: A Sociology of Violence and Human Rights [ebook]. New York; London: Routledge.

Harel, Alon (2011). «Outsourcing Violence?». Law and Ethics of Human Rights, 5(2), 396-413.

Haritos-Fatouros, Mika (1988). «The Official Torturer: A Learning Model for Obedience to the Authority of Violence». Journal of Applied Social Psychology, 18(13), 1107-20.

Haritos-Fatouros, Mika (2003). The Psychological Origins of Institutionalized Torture. London: Routledge.

Harvey, David (1993). La crisi della modernità. Alle origini dei mutamenti culturali. Milano: il Saggiatore.

Harvey, David (2007). Breve storia del neoliberismo [ebook]. Milano: il Saggiatore.

Hernandez, Julie G. (2007). «The Tortured Body, the Photograph, and the U.S. 'War on Terror'». CLCWeb: Comparative Literature and Culture, 9, 1-11.

Hooks, Gregory; Mosher, Clayton (2005). «Outrages against Personal Dignity: Rationalizing Abuse and Torture in the War on Terror». Social Forces, 83, 1627-45.

Horwitz, Allan V. (1990). The Logic of Social Control. New York: Plenum Press.

Huggins, Martha K. (2000). "Legacies of Authoritarianism: Brasilian Torturers' and Murderers' Reformulation of Memory». Latin American Perspectives, 7(2), 57-78.

Huggins, Martha; Haritos-Fatouros, Mika; Zimbardo, Philip (2002). Violence Workers: Police Torturers and Murderers Reconstruct Brasilian Atrocities. Berkeley; Los Angeles: University of California Press.

Human Rights First (2007). Primetime Torture: Ticking Bombs, Torture and TV. URL http://www. human-rightsfirst.org/us law/etn/primetime (201908-23).

Hutchings, Peter J. (2013). «Entertaining Torture. Embodying Law». Cultural Studies, 27(1), 49-71.

Ignatieff, Michael (1985). «Torture’s Dead Simplicity». New Statesman, 110(2843), 24-6. 
Inhetveen, Karin (2011). «Towards a Body Sociology of Torture». von Trotha, Trutz; Rösel, Jakob (eds), On Cruelty. Cologne: Rüdiger Köppe Verlag, 377-87. Jaffe, Hosea (2010). Era necessario il capitalismo? [ebook]. Milano: Jaca Book Jaffer, Jameel; Singh, Amrit (2007). Administration of Torture: A Documentary Record from Washington to Abu Ghraib and Beyond. New York: Columbia University Press.

Jameson, Fredric (1977). «Imaginary and Symbolic in Lacan: Marxism, Psychoanalitic Criticism, and the Problem of the Subject». Yale French Studies, 55/56, 338-95.

Jameson, Fredric (1998). «Transformations of the Image in Postmodernity». Jameson, Fredric, The Cultural Turn: Selected Writings on the Postmodern, 1983-1998. London: Verso, 93-135.

Jameson, Fredric (2002). «The Dialectics of Disaster». The South Atlantic Quarterly, 101(2), 297-304.

Jameson, Fredric (2007). Postmodernismo, ovvero la logica culturale del tardo capitalismo. Roma: Fazi Editore.

Kelman, Herbert (1993). «The Social Context of Torture: Policy Process and Authority Structure». Crelinsten, Ronald D.; Schmid, Alex P. (eds), The Politics of Pain: Torturers and Their Masters. Boulder (CO): Westview Press, 19-34.

Kerner, Aaron M. (2015). Torture Porn in the Wake of 9/11. Horror, Exploitation and the Cinema of Sensation. New Brunswick; New Jersey; London: Rutger University Press.

Koch, Egmont (2008). Die CIA-Lüge: Foltern im Namen der Demokratie. Berlin: Aufbau Verlag.

Kress, Gunther (2003). Literacy in the New Media Age. New York: Routledge.

Kull, Steven; Ramsey, Clay; Weber, Steven; Lewis, Evan; Brower, Melinda; Ciolek, Melanie; Medoff, Abe (eds) (2008). World Public Opinion on Torture. Washington DC: World Public Opinion. Program in International Policy Attitudes. URL http://www.worldpublicopinion.org/pipa/pdf/jun@8/ WPO_Torture_Jun08_packet.pdf (2019-09-02).

Lagouranis, Tony; Mikaelian, Allen (2007). Fear Up Harsh. An Army Interrogator's Dark Journey Through Iraq. New York: Nal Caliber; New American Library.

Lanzmann, Claude (1991). "Seminar on Shoah». Yale French Studies, 79, 82-99.

Lasby, Clarence (1975). Project Paperclip. New York: Antheneum.

La Torre, Massimo; Lalatta Costerbosa, Marina (2013). Legalizzare la tortura? Ascesa e declino dello Stato di diritto [ebook]. Bologna: il Mulino.

Laub, Dori (1992). «An Event Without a Witness: Truth, Testimony and Survival». Felman, Shoshana; Laub, Dori (eds), Testimony: Crisis of Witnessing in Literature, Psychoanalisis, and History. London: Routledge, 74-92.

Leccardi, Carmen (2015). Sociologie del tempo. Soggetti e tempo nella società dell'accelerazione. Roma-Bari: Laterza.

Levack, Brian P. (2008). La caccia alle streghe in Europa agli inizi dell'età moderna. Roma-Bari: Laterza.

Lewis, Paul H. (2002). Guerrillas and Generals: The 'Dirty War' in Argentina. Westport (CT): Praeger.

Linklater, Andrew (2007). «Torture and Civilisation». International Relations, 21, 111-18.

Lindeperg, Sylvie (2000). Clio de 5 à 7. Les Actualités filmées de la Libération: Archives du futur. Paris: CNRS Éditions. 
Lobe, Jim (2011). «US Poll Tracks Shifts in Public Attitudes since 9/11». Inter Press Service. URL http://www.ipsnews.net/2011/09/us-polltracks-shifts-in-public-attitudes-since-9-11/ (2019-09-30).

Luban, David J. (2005). «Liberalism, Torture, and the Ticking Bomb». Virginia Law Review, 91(1), 425-61.

Lyotard, Jean-François (1991). Leçons sur l'Analytique du Sublime. Paris: Galilée.

Mackert, Jürgen (2015). «The Secret Society of Torturers: The Social Shaping of Extremely Violent Behaviour». International Journal of Conflict and Violence, 9(1), 106-20.

MacMaster, Neil (2004). «Torture: From Algiers to Abu Ghraib». Race and Class, 46, 1-21.

Mann, Bonnie (2014). Sovereign Masculinity. Gender Lessons from the War on Terror. Oxford: Oxford University Press.

Manovich, Lev (2004). Il linguaggio dei nuovi media. Milano: Olivares.

Marra, Claudio (2006). L'immagine infedele. La falsa rivoluzione della fotografia digitale. Milano: Bruno Mondadori.

Marx, Karl (1976). Lineamenti fondamentali della critica dell'economia politica, I. Torino: Einaudi.

Marx, Karl (1989). Il capitale. Critica dell'economia politica. Libro I. Roma: Editori Riuniti.

Mayer, Jane (2008). The Dark Side. New York: Anchor.

Mazzocco, Davide (2019). Cronofagia. Come il capitalismo depreda il nostro tempo. Roma: D Editore.

McCoy, Alfred W. (2006). A Question of Torture: CIA Interrogation, from the Cold to the War on Terror. New York: Metropolitan Books; Henry Halt and Co.

McKelvey, Tara (2006). «The Unaccountables». The American Prospect, 17(9), 44-8.

Merton, Robert K. (2000). Teoria e struttura sociale. II. Studi sulla struttura sociale e culturale. Bologna: il Mulino.

Mitchell, William John Thomas (1994). Picture Theory: Essays on Verbal and Visual Representation. Chicago: University of Chicago Press.

Mitchell, William John Thomas (2002). «Showing Seeing: A Critique of Visual Culture». Journal of Visual Culture, 1(2), 165-81.

Mitchell, William John Thomas (2011). «The Abu Ghraib Archive». Mitchell, William John Thomas (ed.), Cloning Terror: The War of Images, 9/11 to the Present. Chicago: Chicago University Press, 112-27.

Moulton, Samuel T.; Kosslyn, Stephen M. (2009). «Imagining Predictions: Mental Imagery as Mental Emulation». Philosophical Transactions of the Royal Society of London B: Biological Sciences, 364, 1273-80.

Mounier, Emmanuel (1949). La petite peur du XX siècle. Paris: Seuil.

Neroni, Hilary (2015). The Subject of Torture: Psychoanalysis and Biopolitics in Television and Film. New York: Columbia University Press.

Paivio, Allan (1986). Mental Representations: A Dual Coding Approach. New York: Oxford University Press.

Palmiero, Massimiliano; Piccardi, Laura; Giancola, Marco; Nori, Raffaella; D’Amico, Simonetta; Belardinelli, Marta O. (2019). «The Format of Mental Imagery: from a Critical Review to an Integrated Embodied Representation Approach». Cognitive Processing, 20, 277-89.

Parinetto, Luciano (1997). La traversata delle streghe nei nomi e nei luoghi e altri saggi. Paderno Dugnano (Milano): Colibrì.

Pattison, James (2014). The Morality of Private War: The Challenge of Private Military and Security Companies. Oxford: Oxford University Press. 
Percy, Sarah (2007). Mercenaries. Oxford: Oxford University Press.

Perocco, Fabio (a cura di) (2019). Tortura e migrazioni. Venezia: Edizioni Ca' Foscari. DOI https://doi.org/10.30687/978-88-6969-358-8.

Peters, Edward (1996). Torture. Philadelphia: University of Pennsylvania Press.

Peters, John Durham (2001). «Witnessing». Media, Culture and Society, 23(6), 707-23.

Piccardi, Laura; Bocchi, Alessia; Palmiero, Massimiliano; Verde, Paola; Nori, Raffaella (2017). «Mental Imagery Skills Predict the Ability in Performing Environmental Directional Judgements». Experimental Brain Research, 235, 2225-33.

Plate, Thomas; Darvi, Andrea (1983). Secret Police. The Terrifying Inside Story of an International Network. London: Sphere.

Prochaska, David (2003). «That Was Then, This Is Now. The Battle of Algiers and After». Radical History Review, 85, 133-49.

Rancière, Jacques (2003). Le destin des images. Paris: La Fabrique.

Reemtsma, Jan Philipp (1991). «Wir sind alles für dich! An Stelle einer Einleitung: Skizze eines Forschungsprogramms». Reemtsma, Jan Philipp (Hrsg.), Folter: Zur Analyse eines Herrschaftsmittels. Hamburg: Junius, 7-23.

Reemtsma, Jan Philipp (2012). Trust and Violence: An Essay on a Modern Relationship. Princeton: Princeton University Press.

Rejali, Darius (2003). «Modern Torture as a Civic Marker: Solving a Global Anxiety with a New Political Technology». Journal of Human Rights, 2(2), 153-71.

Rejali, Darius (2009). Torture and Democracy. Princeton and Oxford: Princeton University Press.

Rentschler, Carrie A. (2004). «Witnessing: US Citizenship and the Vicarious Experience of Suffering». Media, Culture \& Society, 26, 296-304.

Resnais, Alain (2002). Il metodo, la creazione, lo stile. A cura di Maurizio Regosa. Venezia: Marsilio Editori.

Retting Report (1993). The Report of the Chilean National Commission on Truth and Reconciliation, voll. 1-2. Notre Dame (IN): University of Notre Dame Press.

Risen, James (2014). Pay Any Price. Greed, Power, and the Endless War. New York: Houghton Mifflin Harcourt.

Ross, Edward A. (1901). Social Control: A Survey of Foundations of Order. New York: MacMillan.

Russo, Chandra (2016). «Witness Against Torture. Guantanamo and Solidarity as Resistance». Race\&Class, 58(2), 4-22.

Russo Ruggeri, Carmela (2002). Quaestiones ex libero homine. La tortura degli uomini liberi nella repressione criminale romana dell'età repubblicana e del I secolo dell'Impero. Milano: Giuffrè.

Said, Edward (2006). Orientalismo. L'immagine europea dell'Oriente. Milano: Feltrinelli.

Sallmann, Jean-Michel (1991). «Strega». Duby, Georges; Perrot, Michelle (a cura di), Storia delle donne. Dal Rinascimento all'età moderna. Roma-Bari: Laterza, 455-69.

Sartre, Jean-Paul (1960). Critique de la raison dialectique. Tome I. Théories des ensembles pratique. Paris: Gallimard.

Sartre, Jean-Paul (1964). «'Portrait du colonisé', précédé du 'Portrait du colonisateur'». Sartre, Jean-Paul, Situation V. Paris: Gallimard, 49-56.

Sartre, Jean-Paul (1976). «Sur l'Idiot de la famille». Sartre, Jean-Paul, Situations X. Politique et autobiographie. Paris: Gallimard, 91-115. 
Sartre, Jean-Paul (2004). L'immaginazione. Idee per una teoria delle emozioni. Milano: Bompiani.

Sartre, Jean-Paul (2007). Immaginario. Psicologia fenomenologica dell'immaginazione. Torino: Einaudi.

Sartre, Jean-Paul (2015). Il muro. Torino: Einaudi.

Sartre, Jean-Paul (2019a). «ll colonialismo è un sistema». Gjergji 2019, 59-79.

Sartre, Jean-Paul (2019b). «Una vittoria». Gjergji 2019, 89-103.

Scahill, Jeremy (2007). Blackwater: The Rise of the Most Powerful Mercenary Army. London: Profile Books.

Scarry, Elaine (1985). The Body of Pain. The Making and Unmaking of the World. New York: Oxford University Press.

Scheppele, Kim (2005). «Hypothetical Torture in the 'War on Terrorism'». Journal of National Security Policy and Law, 1, 285-40.

Schwartz, Moshe; Swain, Joyprada (2011). Department of Defense Contractors in Iraq and Afghanistan: Background and Analysis. Washington, DC: Congressional Research Service.

Serralvo, Jose (2012). «Privatized Military Firms' Impunity in Cases of Torture: A Crime of Humanity?». International Community Law Review, 14, 117-35. DOI https://doi.org/10.1163/187197312X633469.

Settembre, Roberto (2014). Gridavano e piangevano. La tortura in Italia: ciò che ci insegna Bolzaneto [ebook]. Torino: Einaudi.

Shirer, William L. (1962). Storia del Terzo Reich, vol. 2. Torino: Einaudi.

Simkin, J (1997). Slave Branding. URL https://spartacus-educational. com/USASbranding.htm (2019-10-20).

Simmel, Georg (1989). Sociologia. Milano: Comunità.

Simmel, Georg (1992). Il segreto e la società segreta. Varese: SugarCo.

Simon, Jonathan (1998). «Discipline and Punish: The Birth of a Post-Modern Middle-Range». Clawson, Dan (ed.), Required Reading: Sociology's Most Influential Texts. Boston: University of Massachussetts Press, 47-54.

Simpson, David (2006). 9/11: The Culture of Commemoration. Chicago: The University of Chicago Press.

Singer, Peter W. (2003). Corporate Warriors: The Rise of the Privatized Military Industry. Ithaca (NY): Cornell University Press.

Sironi, Françoise; Branche, Raffaëlle (2002). «Torture and the Borders of Humanity». International Social Science Journal, 54(174), 539-48.

Skoll, Geoffrey R. (2010). Social Theory of Fear. Terror, Torture, and Death in a Post-Capitalist World. New York: Palgrave.

Sofsky, Wolfgang (1997). The Order of Terror: The Concentration Camp. Princeton: Princeton University Press.

Sofsky, Wolfgang (2005). Traktat über die Gewalt. Frankfurt am Main: Foscher Verlag.

Sontag, Susan (2003). Regarding the Pain of Others. London: Penguin.

Stanley, Elisabeth (2004). «Torture, Silence, and Recognition». Current Issues in Criminal Justice, 16, 5-25.

Stannard, David E. (2001). Olocausto americano. Torino: Bollati Boringhieri.

Stockholm International Peace Research Institute (1978). Anti-Personnel Weapons. London: Taylor \& Francis.

Stora, Benjamin (1991). La gangrene et l'oubli. Paris: La Découverte.

Sturken, Marita; Cartwright, Lisa (2001). Practices of Looking: An Introduction to Visual Culture. Oxford: Oxford University Press. 
Tasker, Yvone (2012). «Television Crime Drama and Homeland Security: From Law and Order to 'Terror TV'». Cinema Journal, 51(4), 44-65.

Tindale, Christopher (1996). «The Logic of Torture. A Critical Examination». Social Theory and Practice, 22(3), 349-74.

Todorov, Tzvetan (2007). «Torture in the Algerian War». South Central Review, 24(1), 18-26.

Todorov, Tzvetan (2009). Torture and the War on Terror. London; New York; Calcutta: Seagull.

Todorov, Tzvetan (2011). Di fronte all'estremo. Milano: Garzanti.

Todorov, Tzvetan (2014). La conquista dell'America. Torino: Einaudi.

Tryon, Chuck (2013). On-Demand Culture. Digital Delivery and the Future of Movies. New Brunswick; New Jersey; London: Rutgers University Press.

Vidal-Naquet, Pierre (1963). Lo stato di tortura. La guerra d'Algeria e la crisi della democrazia francese. Bari: Laterza.

Vinale, Adriano (2015). «Endo-apocalisse zombi. Elementi per un'analisi teologico-politica di The Walking Dead». Frezza, Gino (a cura di), Endoapocalisse. The Walking Dead, l'immaginario digitale, il post-umano. Cava dei Tirreni: Areablu Edizioni, 179-98.

Vivan, Itala (1972). Caccia alle streghe nell'America puritana. Milano: Rizzoli. von Trotha, Trutz (2011). «Dispositionen der Grausamkeit: Über die anthropologischen Grunlagen grausamen Handelns». von Trotha, Trutz; Rösel Jakob (eds), On Cruelty. Cologne: Rüdiger Köppe Verlag, 122-46.

Wacquant, Loïc (2009a). Punishing the Poor. The Neoliberal Government of Social Insecurity. Durham: Duke University Press.

Wacquant, Loïc (2009b). Prisons of Poverty. Minneapolis: University of Minnesota Press.

Wallace, Geoffrey P. (2013). «International Law and Public Attitudes Toward. Torture: An Experimental Study». International Organization, 67(11), 105-40.

Wallerstein, Immanuel (1985). Il capitalismo storico. Economia, politica e cultura di un sistema mondo [ebook]. Torino: Einaudi.

Watson, Peter (1978). War on the Mind: The Military Uses and Abuses of Psychology. New York: Basic Books.

Weber, Max (1998). Scritti politici. Roma: Donzelli.

Welch, Michael (2008). «Ordering Iraq: Reflections on Power, Discourse \& Neocolonialism». Critical Criminology: An International Journal, 16(4), 257-69.

Welch, Michael (2016). «Clinical Torture: Drifting in the Atrocity Triangle». Oñati Socio-Legal Series, 6(4), 957-74.

Williams, Raymond (2000). Televisione. Tecnologia e forma culturale: e altri scritti sulla tv. Roma: Ed. Riuniti.

Wright, Steve (1996). «The New Trade in Technologies of Restraint and Electroshock». Forrest, Duncan (eds), A Glimpse of Hell. London: Amnesty International, 137-52.

Wright Mills, Charles (2018). L'immaginazione sociologica. Milano: il Saggiatore. 

Questo lavoro affronta il tema della tortura con l'ambizione di contribuire a consolidare un suo inquadramento propriamente sociologico portando in primo piano la storia sociale dei torturati anche attraverso l'apporto fondamentale dell'economia politica. Tale categoria non è impiegata in maniera astratta; entra in scena attraverso i corpi dei torturati che non sono considerati semplici corpi biologici soggiogati dal 'potere'; sono, invece, corpi che hanno voce e che sono in grado di rivelare a quali classi sociali appartengono. Porre al centro dell'analisi i corpi-classe consente di cogliere a pieno la sostanza sociologica della tortura, di comprendere le ragioni di fondo della sua storica persistenza e costante diffusione.

Iside Gjergji è sociologa e giurista. Si occupa di migrazioni, lavoro, razzismo e teoria sociale. Già Lecturer presso la Stanford University, è Senior Researcher presso il Centro de Estudos Sociais dell'Universidade de Coimbra. Di recente ha pubblicato:

"Uccidete Sartre!". Anticolonialismo e antirazzismo di un revenant (ombre corte, 2018); Sulla governance delle migrazioni. Sociologia dell'underworld del comando globale (Franco Angeli, 2016). Ha tradotto saggi di Robert K. Merton, Abdelmalek Sayad, Jean-Paul Sartre. Con F. Denunzio ha curato: La sociologia francese contemporanea e La divisione del lavoro sociale di Durkheim, di Robert K. Merton (Kurumuny, 2019).

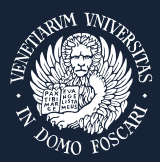

Università

Ca'Foscari

Venezia 